\title{
Microfabricated Systems and Assays for Studying the Cytoskeletal Organization, Micromechanics, and Motility Patterns of Cancerous Cells
}

\author{
Sabil Huda ${ }^{\mathrm{a}}$, Didzis Pilans ${ }^{\mathrm{a}}$, Monika Makurath ${ }^{\mathrm{a}}$, Thomas Hermans ${ }^{\mathrm{a}}$, Kristiana Kandere- \\ Grzybowska $^{\mathrm{a}}$, and Bartosz A. Grzybowski ${ }^{\mathrm{a}, \mathrm{b}}$ \\ aDepartment of Chemical and Biological Engineering, Northwestern University, 2145 Sheridan \\ Road, Evanston, IL, USA \\ ${ }^{b}$ Department of Chemistry, Northwestern University, 2145 Sheridan Road, Evanston, IL, USA
}

\begin{abstract}
Cell motions are driven by coordinated actions of the intracellular cytoskeleton - actin, microtubules (MTs) and substrate/focal adhesions (FAs). This coordination is altered in metastatic cancer cells resulting in deregulated and increased cellular motility. Microfabrication tools, including photolithography, micromolding, microcontact printing, wet stamping and microfluidic devices have emerged as a powerful set of experimental tools with which to probe and define the differences in cytoskeleton organization/dynamics and cell motility patterns in non-metastatic and metastatic cancer cells. In this review, we discuss four categories of microfabricated systems: (i) micropatterned substrates for studying of cell motility sub-processes (for example, MT targeting of FAs or cell polarization); (ii) systems for studying cell mechanical properties, (iii) systems for probing overall cell motility patterns within challenging geometric confines relevant to metastasis (for example, linear and ratchet geometries), and (iv) microfluidic devices that incorporate cocultures of multiple cells types and chemical gradients to mimic in vivo intravasation/extravasation steps of metastasis. Together, these systems allow for creating controlled microenvironments that not only mimic complex soft tissues, but are also compatible with live cell high-resolution imaging and quantitative analysis of single cell behavior.
\end{abstract}

\section{Introduction: Cell motility and metastasis}

Cancer can form in any number of organs and, during its later stages, can disseminate throughout the body in a process called metastasis. ${ }^{[1,2]}$ Once cancer metastasizes, it outcompetes the body's organs for nutrition causing organ malfunction and death. ${ }^{[3]}$ Sadly, despite decades of research, discovery of antimetastatic drugs has one of the lowest success records for drug development, ${ }^{[4]}$ which is at least in part because of the lack of methods/ devices that can diagnose and predict disease progression. ${ }^{[5-7]}$ As present, effective and reliable cancer treatments remain limited to early stage cancers, ${ }^{[8,9]}$ and while metastasized tumors account for over $90 \%$ of cancer-related deaths, ${ }^{[1]}$ treatment of late-stage cancers is mostlypalliative. 
One of the hallmarks of cancer metastasis is increased cell motility and invasion. ${ }^{[10]}$ Cell motility is driven by three major components of the so-called cytoskeleton: ${ }^{[11]}$ actin, ${ }^{[12]}$ microtubules, ${ }^{[13]}$ and focal adhesions. ${ }^{[14,15]}$ It is through the careful coordination of these three cytoskeletal components that a metastasizing cell can propel itself, "tunnel" through the underlying matrix and into the bloodstream (intravasation), ${ }^{[16]}$ before reversing the process (extravasation) ${ }^{[17]}$ in order to seed a new tumor site (Figure 1). The control and inhibition of the cancer cell motility is challenging because of the ubiquitous expression of the proteins which control the cytoskeleton and the fact that many of the body's essential processes rely on motile cells for proper functioning. For example, cell motility is essential in embryonic development, ${ }^{[18]}$ immune response, ${ }^{[19]}$ wound healing, ${ }^{[20]}$ and neurogenesis. ${ }^{[21]}$ Since the genetic pathways which control cell motility across these different processes and cell types are similar, the specific inhibition of the motility of cancerous cells requires precise intervention at the molecular level. ${ }^{[22]}$ What is therefore required is a detailed understanding of the subtle differences in the cytoskeletal regulation in cancerous/metastatic vs. benign cells. Fortunately, there are some promising leads. For instance, metastatic cells are known to be more motile - both in the presence ${ }^{[23]}$ and in the absence ${ }^{[24]}$ of a chemical gradients -than their non-metastatic counterparts. These differences arise from the differential regulation of their cytoskeletons. ${ }^{[11,25,26]}$ Therefore, quantifying the differences between the cytoskeletal regulation of metastatic and nonmetastatic cells can help identify future cancer drug targets.

The purpose of this Review is to summarize recent progress in the development of miniaturized in vitro substrates, devices and systems capable of quantifying various components/processes underlying motility of metastatic tumor cells. ${ }^{[28,29]}$ A salient point in writing such a piece is that it has to address and interest two communities that are, at least historically, quite disjoint - the biologists working on cancer metastasis, and the engineers/ materials scientists working in the area of microfabrication. While there are some groups working at the intersection of these disciplines ${ }^{[30-33]}$ the majority of biologists are probably not conversant with microfabrication and surface functionalization approaches, and few materials scientists or engineers are experts in cancer biology and cell motility. Therefore, our Review aims to be at least informative (but certainly not exhaustive) on both of these aspects with the hope of illustrating the synergies for future interdisciplinary research. Accordingly, we begin by describing the role of the cytoskeleton in cell motility in order to outline which biological processes are amenable to quantitative microanalysis. Only then, we venture into specific fabrication protocols and devices. We end with some forwardlooking suggestions for the future research at this interesting and useful junction between materials science and cancer biology.

\section{Key cytoskeletal events and components involved in cell motility}

\subsection{Cell polarization}

The first step in their migration is for cells to break symmetry and extend actin-based polarized protrusion along the direction of motion. ${ }^{[34]}$ Cells can break symmetry both in the presence and in the absence of topological (haptotaxis) or chemical (chemotaxis) cues. ${ }^{[35,36]}$ Motility can be stimulated in response to changes in the cell's chemical (chemokines, 
cytokines etc.) or physical (extracellular matrix, ECM, binding) microenvironment (Figure 2). While chemical signals from the environment are primarily transduced through G-protein Coupled Receptors (GPCR) ${ }^{[37]}$ and Receptor Tyrosine Kinases (RTK), ${ }^{[38]}$ the physical signals are transmitted through integrins via the so-called substrate/focal adhesion (FA) structures. ${ }^{[15]}$ Ultimately, these extracellular signals cause changes in the dynamics of actin cytoskeleton and in cell's internal organization which ultimately determines the direction of migrating cell (for further details see excellent Reviews ${ }^{[39-43]}$ ). A number of studies have used micropatterned substrates with symmetric and asymmetric discontinuous 2D micropatterns to study cell polarization (see Section 6.1) ${ }^{[44-46]}$.

\subsection{Actin filaments}

Actin monomers assemble in head-to-tail manner to form $8 \mathrm{~nm}$ thick actin filaments (a.k.a. F-actin) composed of two strands of tightly bound actin monomers wound around each other to form a double helix. ${ }^{[47]}$ The monomers in F-actin double stranded helix are all oriented in the same direction and, therefore, the filaments have two distinctly different ends -- the plus or "barbed" end at which monomers are constantly added is close to the leading edge, while the minus or "pointed" end is directed towards cell interior. In cells, actin filaments form networks and secondary structures; the dynamics of actin structures is regulated by a number of regulatory proteins (for further details see Reviews ${ }^{[39-43]}$ ). The details of this regulation are at least partly explained by the dendritic nucleation/array tread milling model (thoroughly reviewed in ${ }^{[42,48,49]}$ ) (Figure 3 ) and with the roles of actin regulatory proteins involved described in ${ }^{[40,41,43]}$ ). In this model, branched actin network turns over or treadmills as new subunits are added near the leading edge membrane and are removed in cell interior/farther away from the membrane, effectively pushing the cell membrane forward. Actin organization in single cells have been studied by using simple micropatterned substrates that impose defined geometric shapes upon cells (see Section 6.1 of this Review).

\subsection{Microtubules}

Microtubules (MTs) are $25 \mathrm{~nm}$ thick macromolecular polymers composed of dimers of a and $\beta$ tubulins (for Review of MT dynamics in vitro see ${ }^{[50]}$ ). Unlike F-actin, which is branched, bundled, cross-linked and organized into secondary structures, by its regulatory proteins, MTs are typically observed as single filaments, sometimes bundled, but never branched. In most cells, majority of MTs emanate from the centrosome near cell center towards the cell periphery forming a radial array (for Reviews on MT dynamics and organization in cells see ${ }^{[51-53]}$ ). One end of the MTs -the so-called minus end - is capped and embedded into the microtubule organizing center (MTOC) at the centrosome, while the other, "plus" end is dynamic. The plus end growth persistently through cell interior, ${ }^{[54]}$ but in cell periphery constantly transitions between phases of growing and shrinking - a phenomenon called "dynamic instability"[55]_ and thus probing and exploring the structures at cell periphery. ${ }^{[51,54]}$ MT dynamics is characterized by following five measures: (i) the speed of MT growth, (ii) the speed of MT shrinkage, (iii) the frequency of catastrophes (i.e. the frequency of MTs transitioning from growth to shrinkage), (iv) the frequency of rescues (transitions from shrinkage to growth), and (v) the time spent in MT pauses ${ }^{[52-53]}$ (Figure 4). MT-binding proteins, such MT plus end tracking protein CLIP-170 and others (see Reviews ${ }^{[52,56,57]}$, control MT dynamics by direct binding to the plus end and by mediating 
MT plus end interactions with cell membrane and organelles, signaling factors, and other cytoskeletal structures. These filaments are used by the cell as tracks for organelle, vesicle and protein trafficking and help the moving cell to maintain polarized morphology during sustained migration. ${ }^{[51-53]}$ In the context of cell motility, recent studies have shown that MTs not only play a role in the formation of lamellipodial protrusions at the front of a moving cell, ${ }^{[58]}$ but are also important in the disassembly of focal adhesions (FAs) at the cell's rear. ${ }^{[51,59,60]}$

Essential for cell motility is the differential regulation of MT dynamics at cell front vs. rear. In most cells, MTs extending to cell front are stabilized whereas MTs extending towards the rear are less stable. In contrast, the rear of the cell is characterized by frequent MT catastrophes, induced by excess of active catastrophe-inducing factors, such as stathmin ${ }^{[61]}$ and also by contact with focal adhesions. ${ }^{[62]}$ MTs located there in are guided towards, ${ }^{[60]}$ target focal adhesions ${ }^{[63]}$ (with which cell attaches to the substrate, see Figure 5 and discussion in the next paragraph) and help to disassemble these multimolecular complexes ${ }^{[51]}$ allowing the cell to retract its tail and ultimately move forward. For excellent discussion of asymmetric microtubule dynamics in migrating cells, the Reader is directed to review ${ }^{[74]}$. In Section 6.1 of this review, we describe an approach used to quantify MT guidance towards FAs by tracking MT trajectories in micropatterned triangular cells ${ }^{[60]}$ in Section 6.1. Other interesting systems, designed to study how MTs interact with cell boundary, include microfabricated chambers in which in vitro polymerized MTs interact with and exert forces against functionalized barriers that mimic cell boundary. ${ }^{664,65]}$

\subsection{Focal Adhesions}

The mechanical forces transmitted to the cytoskeleton from the surroundings via substrate/ focal adhesions (FAs) have a profound effect on cell motility. ${ }^{[66,67]}$ In vivo, the cell is surrounded by a dense 3D polymer matrix composed of proteoglycans, non-proteoglycan polysaccharides, glycoproteins and fibers. ${ }^{[66]}$ This extracellular matrix (ECM) provides support for the cell, which binds to it using multi-molecular adhesion complexes called focal adhesions (FAs). ${ }^{[68]}$ These macro-molecular complexes are initiated by integrin binding and are composed of more than 50 proteins. ${ }^{[69]}$ By controlling the assembly and disassembly of FAs, the cell can spatially control its attachment to the surroundings, thus controlling the directionality and velocity of motion. ${ }^{[70]}$ For further details see Reviews on FAs. ${ }^{[69-70]}$

FAs are initiated by the ligation of integrin transmembrane receptors with matrix proteins (such as laminin, fibronectin and collagen) and grow in proportion to the force applied on them by the moving cell. ${ }^{[71,72]}$ Once the cell attaches to the ECM, the integrins begin to cluster in an autocatalytic process ${ }^{[73-76]}$ and recruit different adaptor/scaffold proteins. The proteins recruited to FAs have diverse functions - some bind to the actin and microtubule cytoskeletons while others serve as signaling molecules. This complex, multi-functional architecture enables FAs to act as signaling hubs within the cell. For example, the two key kinases within the FA complex, FAK and Src, ${ }^{[77-79]}$ phosphorylate other signaling molecules and act as switches which can turn on/off a variety of intracellular signaling cascades. 
The spatially asymmetric dynamics of FA formation and disassembly (at the cell front and rear, respectively, Figure 5) helps the cell choose a direction of movement and maintain its polarization while moving persistently. ${ }^{[80]}$ In the front, Rac dependent FA assembly is directly correlated with the so-called lamellipodial protrusions and direction of cell polarization $^{[81]}$ (see Section 6.1 of this Review). This effect was vividly illustrated by Mahmud et. al. who micropatterned asymmetric microstructures (see Section 6.2) to control FAs localization and bias the directionality of cell motion. ${ }^{\left[{ }^{82]}\right.}$ Lamellipodial FAs are not very large, contain fewer proteins and are referred to as 'nascent adhesions'. ${ }^{[83]}$ These structures, however, are thought to be instrumental in directionality because they pin down the protruding lamellipodia and once they are formed, the cell preferentially protrudes from these sites. ${ }^{[81,83]}$ At the rear, there is no FA assembly but only, maturation, disassembly (see discussion of MTs above) and turnover. ${ }^{[0]}$ A number of other studies we describe in Sections 6.1 and 6.3 focus on FAs and their role in force generation and cell migration.

\section{Cytoskeletal structures in cell motility}

One of the major problems in quantifying the functions of individual components of the cytoskeleton is because actin, MTs and FAs act cooperatively to form a variety of structures that all play distinct roles in cell motility (Figure 6). In fact, it is very rare to be able to attribute a process involved in cell motility to any single cytoskeletal component. For example, for a while, MTs were thought to be excluded from the actin-rich lamellipodial protrusions at the cell's front, but with the advent of advanced microscopic techniques, it was ultimately established that so-called pioneering MTs also play a significant role in forming these protrusions. ${ }^{[58,84]}$

Despite this overlap, however, certain areas of the cell are enriched in specific cytoskeletal components translating into spatial segregation of the cellular/morphological structures underlying cell motility-for instance, lamellipodia, lamella, ruffles, filopodia and invadopodia ${ }^{[85-88]}$ at the cell front, and the tail at the cell rear. ${ }^{[89,90]}$ We discuss the key structures in turn.

\subsection{Actin-based structures at the leading edge: lamellipodia and lamella}

The lamellipodium (close to cell boundary) and lamellum (which starts 1-3 $\mu \mathrm{m}$ from the cell boundary) are protrusive structures found at the front of the moving cell. ${ }^{[42,86]}$ These structures primarily contain actin, which is polymerized by the cell to push against the cell membrane (cf. Figure 3). Lamellipodium and lamellum differ in the protein composition: the former are rich in Arp2/3, ADF/Cofilin, and cortactin ${ }^{[91]}$ and the later are enriched in Myosin II and tropomyosin. ${ }^{[86]}$ This compositional difference translates into differences in the structure of the F-actin that is found in the two regions (the lamellipodium consists of parallel and branched actin filaments, the lamellum contains orthogonally arranged Factin $^{[92]}$ ), as well as different rates of retrograde flow of actin, filament assembly/ disassembly rate, and strengths of substrate adhesion. In an elegant paper, Ponti et. al. showed that the lamellum and lamellipodium are only weakly coupled to each other and that extension of the cell boundary and effective translocation of the cell was better predicted by the stability of the lamella. ${ }^{[86]}$ The authors also proposed that cells could move without lamellipodium, and that the lamellipodium served a more sensory function - one which is 
aided by the presence of other actin-based structures, such as invadopodia, ${ }^{[87]}$ filopodia ${ }^{[93,94]}$ and ruffles. ${ }^{[85]}$ While it is not clear which characteristics of the lamellipodium, lamellum or ruffles studied on 2D surfaces correlate with metastatic potential and invasiveness of cancer cells, actin-based protrusions are important in cancer cell motility. Among them, lamellipodia has been one of the cellular structures most commonly studied cellular structures by using micropatterns (see Section 6.1 and 6.2 and Figure 13). Invadopodia or protrusive structures are used by cancer cells to degrade the basement membrane are clearly important in metastasis, ${ }^{[87,95,96]}$ but are not discussed in detail in this Review because so far (to the best of our knowledge) they have not been studied using microfabrication tools.

\subsection{The leading edge: Filopodia}

Filopodia are thin $(0.1$ to $0.3 \mu \mathrm{m}),{ }^{[109]}$ linear, actin-rich protrusive structures ${ }^{[110]}$ which function as directional sensors and have been shown to be prominent in highly metastatic cells. ${ }^{[11]}$ Although filopodia can emerge from the lamellipodial actin network, these fingerlike protrusions are thought to be initiated by the actin nucleating for mins rather than Arp $2 / 3 .{ }^{[109]}$ This is due to the ability of for mins to nucleate unbranched, linear F-actin and inability of $\operatorname{Arp} 2 / 3$ to do the same. These linear filaments are bundled together by the actinbundling proteins, including Fascin, which arranges the filaments parallel to one another and with uniform polarity, a signature architecture of filopodia. ${ }^{[12]}$ In addition, filopodia do not contain any microtubules and are attached to the substrate through weak focal adhesions only. Their sensory functionality seems to be crucial to cancer cell motility since Fascin overexpression commonly correlates with metastatic potential. ${ }^{[111]}$ This is demonstrated by the observation that a reduction of Fascin levels decreases cell motility and invasion. ${ }^{[13-116]}$ Cells are known to use filopodia to sense and probe, via transient adhesions, nanometer-size topographical features of the microenvironment, both during initial stages of cell attachment to the substrate and while moving across substrates. ${ }^{\text {[105-106] }}$ To date, substrates displaying micro- and nano-topographical features have been used to study filopodia structures formed by fibroblasts, ${ }^{[105,107]}$ neurons, ${ }^{[106]}$ microglia, ${ }^{[108]}$ and leading endothelial cells during angiogenic sprouting of vessels, ${ }^{[109]}$ and for capturing lowabundance cells from the bloodstream. ${ }^{[110]}$ Some key examples are discussed in Section 6.3.2.

\subsection{The cell rear}

The rear of the cell consists of large FAs which anchor thick myosin-II cross-linked actin stress fibers and, as narrated earlier, are deconstructed/disassembled by MTs. ${ }^{[59,89,90,111]}$ The FAs at the rear are often referred to as "mature" FAs because they are large, and contain more proteins that the FAs at the front. ${ }^{[14]}$ These FAs are attached to cross-linked actin stress fibers which exert force on them as the cell moves forward. There are a number of proposed mechanisms for the release of the cell rear, one of them involving MTs. One proposed mechanism stipulates that MTs coordinate dynamin-dependent endocytosis of FA components. ${ }^{[12]}$ Thus without MTs, FAs cannot be internalized and disassembled. Another alternative mechanism proposes that the mechanical stress applied by actin fibers cleaves off the ECM-FA contacts. ${ }^{[113,114]}$ Since the release of the cell rear is crucial for cell motility, the quantification of events leading to the disassembly at the cell's rear FAs could help 
identify new anti-cancer drugs. ${ }^{[115]}$ Furthermore, Poincloux et al. showed that it is the rear (and not Arp2/3-dependent lammelipodia) that drives invasion of MDA-MB-231 breast cancer cell invasion in 3D matrix through exerting strong traction forces ${ }^{[116]}$ (See Section 6.3.1. of this Review).

\section{The many modes of cancer cell motility}

The functional structures that are formed by the coordinated actions of actin, MTs and FAs enable cancer cells to move in a variety of different modes. ${ }^{[117-119]}$ Cancer cells can interchangeably move either as single cells or collectively. ${ }^{[118]}$ Single cell motility can further be subdivided into (i) mesenchymal and (ii) amoeboid modes which also can be used by cancer cells interchangeably.

Mesenchymal motility ${ }^{[118]}$ (Figure 7) is characterized by Arp2/3-dependent actin protrusions at cell's front followed by a retraction of a tail in a microtubule-dependent manner, and is dependent on adhesion to the substrate via integrin receptors ${ }^{[73]}$. In 3D matrices, these cells rely on matrix metalloproteases (MMPs) to degrade the ECM and burrow their path away from the primary tumor. Upon inhibition of MMPs, however, cancer cells can switch to amoeboid mode of motion (cf. below). The switch between the two modes is controlled by changing the expression levels of different proteins which control the cytoskeletal dynamics ${ }^{[40]}$.

Amoeboid cell motility is an integrin independent process which strongly resembles the motion of Dictyostelium. ${ }^{[118,120,121]}$ Although initially observed in lymphoctyes and neutrophils, many other cell types such as mammary carcinomas and lymphomas have been observed to translocate using this motility mode. Amoeboid motility is independent of MMP based matrix remodeling and instead relies on cortical force generation to squeeze through pores within the matrix (Figure 7). ${ }^{[117,118]}$ Unlike mesenchymal motion, amoeboid motility also relies heavily upon the formation of blebs which are rich in acto-myosin structures. ${ }^{[122]}$

Cancer cells also have the ability to move collectively as long chains or as balls of clustered cells (Figure 7). ${ }^{[118,123]}$ During chain migration, cells form cell-cell junctions at their "tips", which helps these cells in the communication of polarity and chemotactic signals while also aiding in matrix degradation. ${ }^{[118]}$ Groups of cells have also been seen to move together as functional units/clusters that typically consist of cells with different functionality. For example, as reported by Friedl et. al., ${ }^{[124]}$ "path-generating" cells within the migrating cluster are primarily responsible for matrix degradation, while cells at the trailing edge maintain cell-cell junctions and are simply being dragged by the force generated by the leading cells.

Due to the heterogeneity of cell motion, it is difficult to know which motility mode is most important to study in the context of metastasis. In general, once tumor cells undergo an epithelial-mesenchymal transition (EMT) - i.e., a process during which epithelial cells loose polarity and cell-cell junctions, and acquire spindle-shaped mesenchymal morphology and ability to migrate via mesenchymal motility mode ${ }^{[25]}$ - their rate of dissemination tends to increase. Since mesenchymal motility is heavily reliant upon MMPs, there has been a strong push in the pharmaceutical industry to develop protease inhibitors. ${ }^{[125]}$ However, these 
studies have yielded mixed results with likely explanation being the plasticity of tumor cells to switch between motility modes. It was found that in certain cases, upon inhibition of protease activity cancer cells underwent mesenchymal-amoeboid transition in which cells moving via mesenchymal mode switched to ameboid motility mode. ${ }^{[117]}$ This transition resulted in the development of an even more metastatic phenotype. Perhaps the most confusing observation was that of amoeboid and mesenchymal cells transforming back into the collective cell migration via the so-called collective-amoeboid transition or back to normal non-motile phenotype via the mesenchymal-epithelial transition. ${ }^{[118]}$

Microfabricated substrates and devices have been developed to aid the study of both single cell (see Section 6) and collective migration (see ${ }^{[119]}$ for excellent Review on the use of microfabrication to study collective cell migration).

\section{Connection to current microtechnology}

Many recent studies have shown that there is a strong link between the microenvironment of the cell and its motility characteristics. ${ }^{[127,128]}$ These findings combined with the rapidlyexpanding toolbox of microfabrication techniques have prompted development of microsystems that go beyond traditional cell motility assays - such as the Boyden chamber assay ${ }^{[129]}$-and allow high resolution imaging of the internal cytoskeletal dynamics of the migrating cell under precisely controlled topological, chemical, or haptic conditions. These methods allow researchers to de-convolute the effects of the numerous physical and chemical factors which influence cell motility thus allowing its study under different contexts and in greater molecular detail than previously possible. The assayed endpoints of these studies can be broadly grouped into four categories:(i) the study of individual subprocesses which are a part of cell motility ${ }^{[130]}$ (e.g., actin organization and dynamics, MT guidance to FAs, etc. described in Section 6.1 of this Review); (ii) assays for the mechanical properties of stationary and motile cells ${ }^{[131]}$ (described in Section 6.3) ; (iii) systems probing the overall cell motility within various geometric confines ${ }^{[132,133]}$ (described in Section 6.2 and 6.3.3); and (iv) systems where cell motility is studied under conditions that in part mimic in vivo microenvironment ${ }^{[30,31]}$ (described in Section 6.4 and 6.5).

Before we delve into specific systems and devices, we briefly summarize the underlying microfabrication protocols - since many excellent and in-depth reviews on microfabrication have been written, ${ }^{[134-136]}$ we only outline the key features and aspects that will later allow us to understand how specific assays we discuss were fabricated.

\subsection{Micropatterning}

Techniques such as microcontact printing $(\mu \mathrm{CP}),{ }^{[134]}$ microfluidic patterning, ${ }^{[137]}$ or wet stamping $(W E T s)^{[138]}$ can be used to create geometrically well-defined adhesive patches, ${ }^{[45,82,134]}$ simultaneously deposit multiple biomolecules, ${ }^{[137]}$ or create patterns for constraining cells ${ }^{[45,46,82,138]}$ (see Sections 6.1, 6.2, 6.3.2). On the other hand, micromolding and soft lithography can be used to fabricate micropatterned elastomeric substrates $^{[131,140,141]}$ (Section 6.3.1) or microfluidic devices ${ }^{[31,32,134]}$ (Sections 6.4 and 6.5). Although the fabrication steps necessary for creating these different types of substrates differ, they all rely on a popular photolithography (for detailed description of steps, see 
excellent review papers ${ }^{[134,136]}$ ) which is used to replicate a pattern from a photo mask onto a light-sensitive polymer (photoresist) (Figure 8).

While photolithographically patterned masters themselves have many industrial uses, especially in electronics, ${ }^{[142-144]}$ biological studies benefit most from a class of techniques called soft lithography - originally developed by the Whitesides' group - whereby the masters serve as templates for the replication of patterns into soft materials. ${ }^{[134]}$ Typically, after performing photolithography, poly (dimethylsiloxane) (PDMS) elastomer is cast and cured against the photolithographic master (Figure 8).

When cured and peeled-off the master, the elastomer constitutes a "stamp" with a micropattern embossed on its surface. Multiple such stamps can be made serially off one master and can subsequently be used to mold other polymers or to create micro- and nanometer scale chemical patterns on a variety of surfaces. Common soft lithographic techniques such as micromolding and microcontact printing offer low-cost, high-yield and easy-to-use methods that allow the design of bio-inspired substrates for studying cell motility and other processes.

Micromolding was originally used as a process for manufacturing products such as $\mathrm{CDs}$, ${ }^{145]}$ DVDs, ${ }^{[145]}$ holograms, ${ }^{[146]}$ and lenses. ${ }^{[147]}$ This decades-old method has been modified and adapted for bench-top use primarily in the Whitesides' group (http:// gmwgroup.harvard.edu/) since the mid-90's. ${ }^{[134]}$ Although there are several varieties of micromolding procedures, they all begin with the use of a reusable patterned PDMS "master" (Figure 8b, c). If PDMS or some other liquid polymer (e.g., epoxy) is poured onto a flat substrate, the stamp pressed against this layer will imprint/mold a micropattern on this substrate. In the so-called microtransfer molding ( $\mu \mathrm{TM})$ the PDMS is coated with a polymer and then stamped onto a surface such as a glass coverslip (Figure 9a). Once stamped, the polymer is then cured so that it sets onto the surface and the PDMS mold is peeled away leaving behind only the pattern. In micromolding in capillaries (MIMIC), the PDMS mold is first placed onto the surface and then a polymer is deposited on one end of the PDMS (Figure 9b). Capillary forces draw the polymer into the mold and, once inside, it is cured and the mold is removed. PDMS masters with micropatterns in bas relief can also be used to create surface patterns using solvent assisted micromolding (SAMIM). In this process, the surface to be patterned is first coated with a polymer and the PDMS mold is stamped onto the surface. The solvent evaporates from the places where the PDMS contacts the surface and thus an imprinted pattern is created (Figure 9c).

The patterned polymers fabricated by the methods described above have been used to prepare substrates to study cell mechanics ${ }^{[131,148]}$ cell motility ${ }^{[149,150]}$ and cell cultures ${ }^{[151]}$-these specific applications will be discussed in more detail later in the text (cf. Sections 6.2 and 6.3). In the meantime, we outline one more micropatterning approach that is, arguably, most relevant to biological studies. This method is called microcontact printing ${ }^{[152]}(\mu \mathrm{CP})$ and allows for the printing of a wide range of organic ${ }^{[153]}$ and inorganic ${ }^{[154,155]}$ molecular and macromolecular "inks," onto surfaces (Figure 10). In "classical" $\mu \mathrm{CP}$, the surface of a micropatterned PDMS is wetted with a desired ink. Upon application of the stamp onto a surface, the ink transfers only at the places of stamp/surface 
contact thus printing the micropattern. $\mu \mathrm{CP}$ has typically been used to pattern gold surfaces with self-assembled monolayers (SAMs) ${ }^{[156]}$ of alkanethiols, including those that are terminated with functionalities promoting protein adsorption (e.g., GRGD peptides ${ }^{[157,158]}$ ) as well as those preventing it (e.g., oligo (ethylene glycols), $\mathrm{EGs}^{[158]}$; for details and further information on monolayer chemistries, see www.prochimia.com). In cell biological studies, $\mu \mathrm{CP}$ has been used to pattern cell-adhesive islands surrounded by regions of EG SAMs preventing cell adhesion. ${ }^{[159]}$ Using this method, it has been possible to endow cells various shapes (from circular to polygonal ${ }^{[134,160,162]}$ ) and study cell proliferation, apoptosis, ${ }^{[160]}$ division, ${ }^{[161]}$ and motility. ${ }^{[162]}$

It is important to note that while $\mu \mathrm{CP}$ of SAMs on gold is a very robust method, with optimized protocols $\mu \mathrm{CP}$ can be used to stamp patterns of various other "inks" -- small molecules, DNA and importantly proteins -- unto a variety of surfaces (other metals, glass, PDMS or even polystyrene). [134, 152, 163-166]

One of the few disadvantages of micropatterning methods that use gold-coated coverslips as substrates is that the thin metal film onto which the inks are printed is a continuous one. This complicates microscopic imaging from the flat/backside of the substrate (e.g., in wide-field or confocal imaging with inverted microscopes), since the metal attenuates fluorescence. One application in which such a capability is important is imaging of live cells adherent and spread onto the micropatterns-ideally, one would like these patterns to define cells shape but remain transparent to allow cell imaging. To this end, a subtractive patterning technique called Wet Stamping (Figure 11), WETS, ${ }^{[46,60,82,130,138,167,168]}$ has been developed in which the stamps are made of a gel (e.g., agarose) capable of holding metal etchant solution. When this etchant is delivered onto the metal surface, it does not print but rather etches away the metal at the pattering sites (Figure 11). Once microetching is complete, the remaining portions of the metal layer can be functionalized with "inks" that render these regions, for example, resistant to cell adhesion. ${ }^{[130,138]}$ When cells are applied onto such a surface, they attach only to the etched "microislands" and assume their shape (for details, see $\left.^{[138]}\right)$. These islands serve as microscopic "windows into cells" during cell imaging studies and, as we describe later, have been used to study various aspects of cell motility, ${ }^{[82,130]}$ including microtubule dynamics ${ }^{60]}$ and cell polarization ${ }^{[46]}$ (See Sections 6.1 and 6.2 of this Review). In principle, other $\mu \mathrm{CP}$ methods developed more recently that use glass as substrate (such as method described by Fink et al. ${ }^{[164]}$ to microcontact print proteins directly unto various surfaces) could be useful for high resolution imaging of cytoskeleton dynamics inside live cells as well.

\subsection{Microfluidics}

There is perhaps little need to narrate fabrication of microfluidic systems in a journal of Advanced Materials family. Suffice to say that with the advent of soft-lithographic techniques, most microfluidic devices are based on PDMS with channels defined by photolithography followed by molding. Input and output channels are pierced through PDMS, appropriate tubing is connected to a micropump system, and the device is sealed against a plasma-oxidized glass slide or PDMS (for details, see reviews ${ }^{[32,169,170]}$ ). 
Microfluidic chips are often used to create gradients of proteins, ${ }^{[173]}$ growth factors, ${ }^{[174]}$ drugs ${ }^{[175]}$ or a combination of these and other substances. ${ }^{[176,177]}$ These systems often operate in the laminar regime, in which mixing occurs only through diffusion. By manipulating the flow rates of the input channels, a gradient (diffusion profile) can be formed with variable intensities. ${ }^{[178]}$ In addition, changing the direction of the gradient or creating an oscillating gradient can be accomplished by simply altering the flow rates and switching the input flows to the device. Aside from enabling researchers to rapidly change the fluidic environment around a cell in a precise manner, microfluidics can also be used to pattern substrates. Since the shape and concentration profile of the fluid flow can be controlled by passing a gradient of a biomolecule (such as a protein, ligand, etc.) through the microfluidic device, one can functionalize the surface in a similar pattern. This is very useful for biological studies that mimic in vivo conditions to study cell motility ${ }^{[31,32,188]}$ and also to pattern cell cultures inside of chips ${ }^{[180]}$ as discussed in several examples below.

\section{Probing cytoskeletal structures, cell mechanics and cell motility by microfabricated substrates and systems}

We are now in position to discuss the interdisciplinary junction of cell motility studies and microfabrication approaches. As we have seen in the previous sections, cell motility is a carefully coordinated process that depends on the differential regulation of the cytoskeleton at the cell's front and the rear. ${ }^{[181]}$ It is this coordination of the protrusive front, the retraction of the rear ${ }^{[59]}$ and the action of the polarity-maintaining molecules ${ }^{[182]}$ that allows the cell to translocateits center of mass. Therefore, in order to characterize the motile cell, it is necessary to quantify the individual processes and also their spatio-temporal "synchronization". In the following, we survey various types of microassays that capitalize on different microfabrication modalities to achieve these goals.

\subsection{Controlling the organization of cytoskeletal components by micropatterned substrates}

Arguably the simplest microsystems that have been used to test the response of the cytoskeleton to surface patterns are substrates which confine single cells to micro-contactprinted discontinuous, cell-adhesive islands surrounded by the "background" resistant to cell adhesion (Figure 13). The islands commensurate with cell size allow for controlling cell shape (typically, most cells assume the shapes of the adhesive islands) while smaller, sub$\mu \mathrm{m}$-size islands allow to control the positioning of FAs and lamellipodia. In their pioneering studies, Whitesides, Ingber and Chen (Figure 13a) showed that cell shape determines cell's choice of life (specifically, growth/proliferation) vs. death (apoptosis) paths. ${ }^{[159,160]} \mathrm{By}$ using islands of various sizes, it was shown that the extent of cell spreading and not the amount of matrix/cell contacts, or FAs, scaled with cell growth rates. In other words, the cell shape and confinement determined cell fate decisions. These initial works inspired subsequent studies in which control of cell shape allowed for deconstructing the cell motility machinery. Specifically, a number of works ${ }^{[45,46,60,162,183,184]}$ showed that the confinement of single cells on micro contact printed cell adhesive islands commensurate with cell size can control spatial distribution of cytoskeletal components (Figure 13b). Cells immobilized onto circular microislands form FAs and extend actin-rich lamellipodial protrusions symmetrically along the entire cell perimeter ${ }^{[130,183]}$. In contrast, on polygonal 
islands, FAs and lamellipodial protrusions localize to the vertices where the curvature is the highest, actin stress fibers run along the island's edges and emanate out of FAs at the vertices into cell interior (Figure 13b), and the MTs emanate from centrally located centrosome towards cell periphery. ${ }^{[138,162,183]}$ Novak et al. ${ }^{[185]}$ has suggested that FA localization at the high-curvature points could be explained by reaction-diffusion model that incorporates positive feedback between FA and stress fiber formation. Actin stress fibers associated with adhesions in the central region grow in different directions thus compensating for the forces they generate and resulting in a small net tensile force and small adhesions. In contrast, actin stress fibers associated with adhesions at the vertices are mostly directed into cell interior or along cell perimeter, thus adhesions at the vertices experience larger net forces. Since larger adhesions are needed to stabilize the actin network against these forces, adhesions tend to assemble more rapidly at the cell vertices rather than at other cellular regions.

From a biological point of view, the excellent studies described in the preceding paragraph are limited by the fact that micro-contact-printed islands on continuous gold films preclude fluorescent imaging in live cells. Consequently, it is necessary to fix (i.e., "kill" the cells) before imaging of the cytoskeletal structures can be performed. This limitation is avoided using WETS(see Section 5.1) whereby the islands etched into the gold films are transparent. As we describe next, this property allows for simultaneously manipulating cell shape and performing high-resolution dynamic live cell imaging.

As we have seen in Section 2.3, in moving cells, dynamic MTs target and disassemble FA sites allowing for the cell to detach from the substrate and move forward. The spatial overlap of MTs, FAs and actin bundles within unconstrained cells has precluded the analysis of putative long-range mechanism whereby MTs growing through the cell body reach FAs at cell periphery. Building on WETS (see Section 5.1) ${ }^{[46,82,138,168]}$ an experimental platform has been developed in which constraining live cells to micropatterned, optically transparent triangular islands (Figure 13c) is used to remove the spatial overlap of cellular structures and localize FAs exclusively at triangle's vertices ${ }^{[138]}$. This system allows for unambiguous observation and quantitative analysis of MT guidance to FAs ${ }^{[60]}$ (Figure 13c). Specifically, using high-resolution live cell imaging of the tips of the growing MTs (by tracking fluorescently encoded MT plus end proteins YFP-CLIP-170 or GFP-EB3), it was shown that initial MT nucleation occurs at the centrosome without any directional preference ${ }^{[60]}$. However, with increasing distance from the centrosome, the trajectories of MTs progressively align with FAs at the vertices, suggesting that MT growth is a non-random, guided process. MT growth was guided along actin stress-fibers and dependent on the FA localization at the vertices. Removal of stress fibers by depletion of Myosin IIA or IIB with RNA interference, or removal of FAs by culturing cells on alternative substrates (specifically, Concanavalin A) reverted MTs to un-guided, random growth (Figure 13c). These results suggest a long-range mechanism (in addition to short range MT-FA interactions) operating throughout the entire cell guides MTs to FA sites. The ability to quantify MT guidance as demonstrated in this study not only lead to a novel insight into how MT component of cell motility machinery may operate in moving cells, but may also serve as a test system for identifying new molecules that connect MTs with FAs, and/or for 
assessing the effectiveness of anti-cancer drugs to target MT-dependent processes. In the context of the present review, it is important to stress the key role of novel microtechnology in answering a long-standing biological question that could not be addressed with traditional molecular biology approaches.

One drawback of the studies with cells with circular and polygonal shapes, however, is that these symmetric shapes exemplify stationary cells, whereas motile cells often display more complex, asymmetric tear-drop shapes with wider end characterized as the "leading edge" and the sharp end being "tail" or "rear". In an attempt to mimic moving cells, investigators have fabricated substrates with arrays of asymmetric micropatterns, such as tear-drop (Figure 13d) ${ }^{[44,46]}$ or cross-bow patterns ${ }^{[45]}$ (Figure 13e, ii). Cells constrained to the asymmetric micropatterns reorganize their internal cytoskeleton resulting in asymmetric distribution of cortical and internal polarity marking molecules and structures/organelles (e.g., F-actin, vinculin marking FAs, cortactin marking lamellipodia protrusions at the leading edge, and centrosome localization between nucleus and the leading edge) characteristic of motile cells. ${ }^{[44-46]}$ Moreover, such polarization enforced by asymmetric micropatterns is functional. This was demonstrated by desorbing the self-assembled monolayers and releasing "polarized" cells from the constraints - as expected, cells moved in the direction of the wider-end of the micropattern (Figure 13d, i) ${ }^{[44]}$ In a different approach to control the directions of cellular motions, Xia et al. used substrates with micro contact printed small circular focal-adhesion size islands $(D=1 \mu \mathrm{m})$ coated with fibronectin (Fn) and separated by non-adhesive barriers of various lengths ${ }^{[81]}$ (Figure 13d, ii). On such substrates, cells preferentially assembled FAs over Fn-coated islands and Rac1, the GTPAse that initiates lamellipodia protrusions, was activated at cell periphery over Fn-coated islands. As a result, it became possible to guide the cell movements along the direction characterized by the smaller inter-island spacing ( $x$ direction for 1C-1.5,3 pattern in Figure 13d, ii) whereas cells on a pattern with equal spacing in both directions $(1 \mathrm{C}-3,3)$ moved randomly, without any directional preference.

Notably, while the key findings - localization of FAs at high curvature points, MT guidance and cell polarization by asymmetric micropatterns-are common to both non-cancerous cells (NIH 3 T3 cells, human endothelial cells, COS-7 cells used in ${ }^{[44]}$ Jiang et al., and human retinal pigment epithelial cells used by Thery et al. ${ }^{[45]}$ ) and some cancerous cells (highly motile B16-F1 mouse melanoma cells used by Kandere-Grzybowska et al. ${ }^{[130,138]}$ ), differences between the normal and cancerous cells also have been documented. First, highly motile B16F1 mouse melanoma cells spontaneously polarize-i.e., display polarized distribution of F-actin and focal adhesion - even on circular islands ${ }^{[46]}$ (Figure 13e, i) whereas normal cells extend lamellipodia around entire perimeter (Figure 13b). This example also highlights one important practical benefit of generating arrays of cells with identical shapes and, consequently, uniform organization of the cytoskeleton - namely, this approach enables to obtain the averages of the cytoskeleton distributions over cell populations which, in turn, allows for statistically significant and truly quantitative approach to cell biology (see also $\left.{ }^{[45}, 46,60,184\right]$ and Figure 13e, i). In example in Figure 13e, $(i)$ reorganization of FAs and F-actin is followed over time - quantification allows for distinguishing different "degrees" of polarized state - to show that initially polarized cells 
on circular islands gradually "depolarize" to ultimately reach uniform distribution. In contrast, it is impossible to describe average distribution of cytoskeleton fibers for a population of unconstrained cells with heterogeneous/different shapes. Lastly, while the reorganization of F-actin/FAs was easily tractable in some highly motile metastatic cancer cells (here, B16-F1), it is important to note that other highly motile cells may present additional challenges. For instance, we found that metastatic MDA-MB-231 breast cancer cells move/"jiggle" within the micropatterned islands by continuously changing the direction/position of their leading edge (unpublished data) and thus never fully occupy the micropatterned islands. This lead us to adopt a different strategy for studying highly motile metastatic cancer cells -that of confining the motions of cells to linear microtracks, such as described in Section 6.2 of this Review.

\subsection{Quantifying and directing cell motions on 1D Linear and Ratchet Microtracks}

Traditionally, the motions of cells were studied on planar/2D substrates and were then taken as representative of cellular motions in vivo. Recent advances in microscopy (especially multiphoton microscopy modalities like second and third harmonic generation ${ }^{[186,187]}$ ), however, suggest that this extrapolation is unwarranted. In particular, it has been found that (i) 2D motility patterns of cells like fibroblasts do not exhibit fast unidirectional migrations observed in tissue-mimicking 3D matrices and along linear, $1 \mathrm{D}$ domains $[149,188,189,190]$ and (ii) metastasizing tumor cells in vivo attach preferentially to and move along linear fibers (e.g. from collagen ${ }^{[197]}$ ) which also form tube-like microchannels or slits. ${ }^{[191]}$ These findings suggest that substrates patterned with linear/1D microtracks (e.g., fabricated using $\mu \mathrm{CP}^{[189]}$ or WETS $^{[82,130]}$; see also ${ }^{[149,188,190]}$ ) are more biologically relevant than planar surfaces (see also Section 6.3.3 on microfabricated microchannels). The use for such substrates also allows some unprecedented opportunities for the quantification of motility patterns- in particular, of the characteristic ability of cancerous cells to move persistently in one direction ("directional persistence") rather than constantly change their direction of motion. This is so because on linear microtracks, the persistence lengths of cell motions correspond unambiguously to the turning points - that is, to the distances between consecutive points where the moving cells change direction of motion from "left to right" to "right to left", or vice versa (Figure 14a, $20 \mu \mathrm{m}$ wide lines). This is in sharp contrast to 2D or 3D substrates where the cell trajectories are curvilinear and it is difficult to assign straight "step" a cell is making in any given direction. Then, by observing cells over long periods of time (and/or multiple cells on different lines), it is possible to collect probability distribution functions characterizing motility patterns of different cell types (Figure 14a, bottom). While the mathematical analyses of such motions are rather difficult, they provide significantly more information about cell motility than simple "average speeds", average persistence times, or diffusion coefficients that are typically extracted from 2D/3D trajectories. In a somewhat amusing extension, the linear microtracks for cell motility have recently been used in the first ever World Cell Race for different cancerous and non-cancerous cell lines from different laboratories. ${ }^{[189]}$ This work described motions of all cell types on lines (here, $4 \mu \mathrm{m}$ and $12 \mu \mathrm{m}$-wide lines coated with fibronectin) as 1D correlated random walks and showed that cell mean speeds correlated with mean persistence paths. In other words, fast moving cells also were also moving persistently in a direction (for details see ${ }^{[189]}$ ). Still another remarkable study tracked the motions of cells that are difficult to obtain and culture 
(human-patient-derived primary glioma and adenocarcinoma of lung and colon metastatic to brain) on substrates with microscale linear guidance structures ( $5 \mu \mathrm{m}$ wide, $5 \mu \mathrm{m}$ tall linear ridges separated by $45 \mu \mathrm{m}$ groves) generated by soft-lithographic micromolding. All cancer cells in this study moved uniaxially along the direction of linear patterns. ${ }^{[149]}$ These studies also suggest that microfabricated substrates presenting linear tracks for cellular locomotion could ultimately prove useful in probing and targeting the mechanisms underlying the motility phenotype of metastatic cancer cells - though, so far, such mechanistic approach has been applied only to non-cancerous fibroblasts. ${ }^{[192]}$

With the adjustments of the shapes of the microtracks, it is possible to bias the direction of cell motion via the so-called ratcheting mechanism originating from and widely studied in physics (Figure 14b). ${ }^{[193-195]}$ In one illustrative example, Mahmud et al. have shown that by constraining cells to asymmetric microtracks (e.g., WETs-patterned tracks of connected triangles in Figure 14b), the motions of cells are no longer "left-right" random but rather rectified/biased in one direction. ${ }^{[82]}$ At every triangular unit of the microtrack, the moving cell experiences spatially asymmetric geometrical cues that affect the distribution of cytoskeletal components, including alignment of actin stress fibers and distribution of FAs. This imposed asymmetry then translates into preferential cell motions in the "funneling" direction of the channel (in Figure 14b, from right to left). The ratcheting phenomenon can be extended to systems involving cells of different types. The example in (Figure 14b, right) shows a microtrack having slanted, inward-pointing spikes which interact differently with cancerous (B16F1 mouse melanoma or MDA-MB-231 breast cancer) and non-cancerous (Rat2 fibroblasts) cells. Remarkably, when a mixture of such cells is placed on the ratchet, cells of different types migrate in opposite directions allowing for partial separation of cell populations. Again, these motility differences reflect different organization of the cytoskeleton and different ability of cancerous vs. non-cancerous cells to form different types of protrusions - cancer cells formed large, wide lamellipodia whereas normal cells (here, Rat2) used their long protrusions to "grab" the in-channel spikes and move in opposite direction (Figure 14b, for details, see ${ }^{[82]}$ ).

The concept of micropattern asymmetry to guide cell motions has subsequently been used by others. Kumar et al. used patterns consisting of four tear-drop shapes separated by small gaps $(\sim 3 \mu \mathrm{m})$ and arranged at $90^{\circ}$ angles to form square-shaped tracks that guided cell motions unidirectionally (Figure 14c, i). ${ }^{[196,197]}$ Two variations of this pattern with different alignment of the blunt and sharp ends of the tear-drop shapes were shown to guide NIH 3T3 fibroblast cell motions in opposite directions. The direction of the movement depended on the presence of an adjacent island along the axis of the elongated cell body. ${ }^{[196]}$ Cells did not always move in the direction of the blunt end as would be expected from cell polarization on isolated tear-drop shape islands (as shown in Figure 13d) where wider end promotes lamellipodial protrusion, while sharp end promotes formation of the tail. The same group has designed micropatterns consisting of 15tear-drop shapes joined head-to-tail to form a circular track (Figure 14c, ii). ${ }^{[198]}$ On these tracks, NIH 3T3 cells move in the direction of blunt end of tear-drop shape as expected from morphological polarization of the cells on such islands. In an attempt to guide cell motions across large distances, the tear-drop shapes were arranged to form linear tracks but the bias was not impressive. However, bias 
was improved by arranging the tear-drops at an angle so as to construct zig-zag microchannels (Figure 14c, iii). ${ }^{[199]}$ Interestingly, another group showed that MCF-10A epithelial cells on identical micropatterns - four tear-drop rectangular track - are guided to move with $82 \%$ bias in the opposite direction (i.e., from sharp end of one tear-drop to blunt end of another island) than NIH 3T3 cells. ${ }^{[197]}$ The bias could be further improved by combining stripe/linear segments with tear-drop shapes into spear-shaped patterns (Figure $14 \mathrm{c}$, iv) to remarkable $98 \% .{ }^{[199-201]}$ The key advantage of using micropatterned tracks is that cell motions could be directed over large distances (much larger than a span of the gradient) in manner free of either haptotatic or chemotactic gradient.

\subsection{Microfabricated tools for studying cell mechanics}

Classical methods, such as atomic force microscopy (AFM), micropipette aspiration, optical stretching and magnetic twisting cytometry have been used to measure the mechanical properties of single cancer cells (for an excellent review of this work the Reader is directed to $\left.{ }^{[201]}\right)$. More recently, biomechanical/biophysical characteristics of cells, such as traction forces (TFs) exerted upon substrate, (reviewed in ${ }^{[131]}$ and ${ }^{[202]}$ ), 3D cell shape, ${ }^{[168]}$ and cell responses to challenging/constrained $3 \mathrm{D}$ environments ${ }^{[132,133,203]}$ and varying substrate stiffness ${ }^{[131,204]}$ have been studied as potential biomarkers for metastatic potential. Various microfabricated substrates and tools reviewed below have been developed to enable quantitative characterization of mechanical properties of cancerous and non-cancerous the cells.

\subsubsection{Microfabricated substrates for measuring cellular traction forces-The}

intracellular tension generated by actomyosin contractile network and actin polymerization of motile cells is transmitted via substrate/focal adhesions onto the underlying substrate by the so-called cellular traction forces $(\mathrm{TF})^{[205]}$. TFs are the driving force for cell movement ${ }^{[206]}$ and their magnitude and spatial distribution has been shown to be altered during malignant transformation toward metastatic phenotype ${ }^{[202,207]}$ (see also refs cited below). The classical technique for measuring TFs called traction force microscopy $(\mathrm{TFM})^{[202,206]}$ uses elastic polyacrylamide (PA) gels of defined and tunable stiffness with randomly distributed fluorescent markers/beads embedded into them. The displacements of the beads - comparing bead positions in the substrate at deformed state due to the force applied by an adherent cell and in there laxed substrate after removal of the cell/force - are used to obtain substrate deformation maps from which TF distribution maps are then computed. In steadily migrating fibroblasts (non-transformed normal NIH 3T3 cells), the active propulsive forces are generally concentrated in the leading edge lamellipodium and correlate with direction of motion suggesting "frontal towing model" where frontal force in lammelipodium actively pulls the rest of cell body forward ${ }^{[208,209]}$. In contrast, transformed NIH 3T3 cells (which also have increased metastatic potential) migrate over 2D substrates with poor directional stability and exert smaller, transient and dispersed (not concentrated in a single large lamellipodium) TFs indicating that metastatic cells are composed of several poorly coordinated mechanical domains. More recently, some studies report that increased TFs correlate with increasing metastatic potential (endothelial, lung, breast, prostate, sarcoma cancer cells, reviewed in ${ }^{[202]}$ and ${ }^{[210]}$ ), while few other studies have reported an inverse relationship between TFs and metastatic potential (murine breast cancer cell lines 
and bladder epithelial cancer cells). ${ }^{[211,212]}$ Time-dependent TF measurements and their correlation with cell motions such as performed in these studies is an information-rich, but a time consuming process especially when obtaining such measurements for large cell populations. To enable measurements of cellular TFs over large cell populations, Tseng et al. has combined cell micropatterning for the control over cell geometry (see also Section 6.1) with the deformable PA substrates of tunable stiffness ${ }^{[213]}$ (see also ${ }^{[214]}$ for micropatterning PA gels). In this method, PA substrate was exposed to deep UV (180 nm) through an optical quartz mask displaying desired features (here, crossbow pattern), and coated with fibronectin (Figure 15a, Fn) resulting in cell attachment only to the micropatterns. Here, crossbow pattern was used because cell spreading over adhesive/ nonadhesive regions (Figure 15a, Actin) in this pattern stimulated cells to exert stronger (vs. circular pattern), and oriented traction forces (upward toward the wide end of the cell). Due to a controlled organization of actin stress fibers (all emanating out of bottom point of crossbow), cells spreading on PA gels with crossbow patterns deformed the underlying substrate resulting in crossbar shortening; the local shortening of the crossbar was then shown to correlate with total TFs as measured by classical TFM indicating that crossbar shortening could be used as straightforward measure of global contraction levels/TFs in large-scale experiments (Figure 15a, Blebb). ${ }^{[213]}$ Notably, the use of micropatterned PA gels allowed for the generation of population-average TF maps (Figure 15a, TFs) analogous to the population-average maps of cytoskeleton distributions (as in Figure 13e). This method was used to confirm previous results, namely that cancer cells with different genetic or chemically-induced alterations show increased or decreased net TFs. ${ }^{[213]}$ Given these conflicting results, the exact role of TFs generated by metastatic cancer cells in metastatic progression remains unclear and overall net TFs (determined for cells migrating over2D substrates, and see also later note on 3D TFs) do not appear useful as a universal marker of metastatic potential.

As mentioned above, the random distribution of fluorescent markers in the PA gels require that bead position is determined both in the presence of cells and after their removal. In addition, conversion of substrate deformation maps to TFs maps requires assumptions about force distribution patterns and is computationally intensive. To overcome these difficulties, Balaban et al. ${ }^{[215]}$ used soft lithography to fabricate elastomeric PDMS substrates with embedded regular arrays of fluorescent topographical features/markers, the height of which were kept small $(\sim 0.3 \mu \mathrm{m})$ to avoid potential effects of topography on cell adhesion and spreading. Any distortion of the regular array of the markers was then due to the application of the force by adherent cells; thus regular array of markers simplified traction force calculations. By combining high-resolution dual channel fluorescence microscopy to simultaneously visualize TFs (from displacements of the embedded markers) and FAs (marked by GFP-vinculin), it was shown that in stationary cells, the size, total fluorescence intensity, and orientation of individual FAs correlated positively with locally applied TFs. In contrast, by tracking TFs and FAs in fibroblasts migrating on PA-gels (classical TFM method), Beningo et al. ${ }^{[216]}$ showed that small nascent adhesions at the leading edge generated stronger "propulsive" TFs which diminished as nascent adhesions matured into large FAs, while the rear adhesions did not show this inverse relationship. A study that would be interesting to perform in the future would be to simultaneously track and compare 
FA dynamics (size/fluorescence intensity over time) and local TFs in non-metastatic vs. metastatic cells moving on substrates with identical mechanical and chemical properties.

The main drawback of using continuous soft substrates, even with regular arrays of embedded markers discussed in the previous paragraph, is that deformations made by discrete FA sites propagate within these substrates making any accurate analysis of force distributions difficult. To overcome these limitations, substrates with arrays of flexible (typically made of PDMS) closely-spaced micro-posts (also called microfabricated postarray detectors, mPADs, or micropillar substrates) have been fabricated ${ }^{[217,218]}$ (Figure $15 b)$. Cells spread across these substrates and bend the micro-posts. The deflection of each post is independent of the neighboring posts and thus is directly proportional to locally applied TF by an adherent cell. In other words, deflections of the posts unambiguously and quantitatively report location, direction and magnitude of TFs without a need to employ assumptions about force distributions (as with continuous substrates). mPAD substrates have been used to confirm previous observations made with continuous flexible substrates showing positive correlation between TFs and FA size in stationary cells, and have been since used to map forces in migrating single cells ${ }^{[219]}$ (Figure 15b, bottom right), as well as in epithelial cell sheets/monolayers and within groups of cells (reviewed in ${ }^{[131]}$ ). Furthermore, the micropost substrates are versatile since (1) by controlling the geometry of the microposts it is possible to control mPAD substrate mechanics independently of substrate chemistry (for example, varying the height and/or diameter of the posts controls substrate rigidity such that longer posts are more deformable and thus physiologically more relevant than rigid substrates ${ }^{[141,220]}$; on the other hand, substrates with posts of oval crosssections - more rigid in one direction - were used to show that epithelial cells grow and migrate along the direction of highest substrate rigidity ${ }^{[221]}$ ); (2) microcontact printing can be used to deliver matrix proteins onto the tips of the posts either in a uniform manner or in a patterned manner so as to simultaneously control the cell shape (Figure 15b, bottom left ${ }^{[204,222]}$;(3) substrates can be combined with microfluidic gradient generators to study chemotactic cell motility ${ }^{[223]}$; (4) forces can be locally applied to living cells by using magnetic field to deflect magnetic nano-wires or nano-particles embedded inside selected posts ${ }^{[224,225]}$. An interesting variation on the latter example is a recently developed 3D microtissue culture system for quantifying contraction force and stiffness of the entire tissues. In this method, microtissues formed by fibroblasts in 3D collagen gels are suspended between two micropillarsone of which is magnetic and allows for application of external mechanical loading. ${ }^{[226]}$ The application of the micropillar methods/devices to study mechanical properties of cancer cells/tissues is an exciting area of future research.

In this review, we mostly focus on substrates for measuring TFs exerted in $2 \mathrm{D}$ because a number of research groups have used microfabrication tools to improve (and/or provide alternative approach) the classical TFM method. However, it also important to note that recent studies have reported developing a technique for quantifying multidimensional TFs. ${ }^{[227]}$ TFs measurements for cancer cells embedded in 3D collagen matrix - similar to those on 2D surfaces (see discussion above) -- showed that the magnitude of TFs was not crucial for the invasion, instead the anisotropic distribution of 3D TFs observed in highly invasive cancer cells appeared important. ${ }^{[228]}$ Interestingly, Poincloux et al. showed that 
strongest TFs that drive MDA-MB-231 breast cancer cell invasion in 3D matrix are localized to the cell rear. ${ }^{[116]}$ For more discussion on cellular force generation and measurements in 3D the Reader is directed to ${ }^{[202]}$.

6.3.2. Traction forces and nanotopography sensing by filopodia-Moving cells use nano-scale spike-like protrusions called filopodia to sense and probe their microenvironment. To study how filopodia sense substrate topography, Albuschies and Vogel have prepared substrates featuring highly flexible silicon nanowires (NWs) (Length, 5-10 $\mu \mathrm{m}$; Diameter, $40 \mathrm{~nm}$ ) confined to micropatterned islands (Figure 15c). ${ }^{[105]}$

Observation of the very initial stages of cell spreading (before the appearance of ruffles and lamellipodia) indicated that initial cell contact with the substrate is mediated exclusively by a large number of filopodia. Most of these filopodia "peeled off" the substrate and retracted, but the ones that contacted NWs, pulled on them and aligned with them. The alignment of the two fibers leads to adhesions via multiple but small adhesion points that, however, collectively result in strong attachment. The stability of the interaction depends on the contact angle between the interacting filopodium and NW/substrate. Using flexible NWs as force sensors it was determined that filopodia exerted $\mathrm{nN}$ range forces upon NWs. Mitotic cells which typically round up during cell division displayed "topographical preference" moving preferentially from flat 2D surface unto micropatterned islands with NWs where they used filopodia-based mechanism to spread into dendritic shapes. In the same vein, another study suggests that filopodia stabilization by nanotopographical features - in that study linear grooves -- may guide the direction of migrating cells. ${ }^{[106]}$ The "topographical preference" of nanofibrillar substrates (displaying nanopillars, nanowires or nanotexture) may be a possible mechanism accounting for the successful use of such substrates in capturing of low abundance circulating tumor cells (CTC) from cancer patients' blood. ${ }^{[110]}$

\subsubsection{Reconstruction of 3D cell shape for studying cell mechanical properties}

-Mechanical properties of materials can also be quantified by the way these materials deform under their own weight - a classical example here is that the degree of bending of a metal beam fixed at one end provides information about the beam's Young's modulus. This line of thinking has been combined with micropatterning and confocal microscopy to reconstruct 3D shapes of cells plated on Wet Stamped, circular microislands ${ }^{[168]}$ (circles were chosen to impose symmetric "boundary conditions" on the cells). As shown in the series of images in Figure 15d, cells on islands of different diameters assume markedly different equilibrium shapes -however, rigorous physical modeling shows that in all cases, these shapes correspond to surfaces that minimize cell's elastic energy. What is important and perhaps surprising is that the shapes are virtually identical across different cell types, including cancerous vs. non-cancerous cells, indicating that purely mechanical considerations are not sufficient to distinguish between normal and diseased cells. This approach, which we called cell tomography, is also unprecedented for two other reasons. First, it allows for the reconstruction of internal structures within the shape-controlled cells. In this way, we showed, for instance, that the stiff nucleus provides a "rigid" boundary condition for any changes in the overall shape of a much more flexible cell "body". Second, the detailed knowledge of 3D cell shape allows for analyzing its changes upon selective alterations/removal of certain cytoskeletal components. In one significant experiment, we 
showed that when the cell's microtubules are chemically depolymerized using nocodazole, the overall cell shape remains intact- this appears to contradict the popular tensegrity model of cell micromechanics ${ }^{[229,230]}$ according to which microtubules are rigid "struts" supporting the cell shape, and their removal should result in the cell collapse.

\subsubsection{Effects of 3D confinement/challenging substrate topography on cancer}

cell motility-Lines micropatterned on flat substrates can be extended into microchannels flanked by side walls and/or covered with a "roof". The microchannels can be fabricated from more rigid materials such as PDMS ${ }^{[231-233]}$ or molded into softer materials such a polyacrylamide ${ }^{[234]}$ or extracellular matrix protein collagengels, ${ }^{[235]}$ and typically have cross-section comparable to cell size. These microstructures have been instrumental in demonstrating that mechanical properties play a key role in cell migration. Irimia et. al. showed that cells confined to microchannels $(12 \times 15 \times 600 \mu \mathrm{m}$ PDMS channels coated with collagen or fibronectin) in the absence of any soluble chemical gradient displayed surprising directional persistence with some cells moving in the same direction for hours (in contrast, the same cells on 2D substrates would constantly switch direction of motion). Unidirectional migration was observed for metastatic cancer cells whereas non-cancerous NIH3T3 fibroblasts were able to move with similar speeds but switched directions and paused more often than metastatic cancer cells (Figure 16a). ${ }^{[231]}$ To challenge the cells with a more complex task, Scherber et al. microfabricated simple microscopic mazes filled with uniform concentrations of media and growth factors. ${ }^{[236]}$ Epithelial cancer cells navigated these mazes moving directionally and persistently. In the end, they found the exit via the shortest path - in doing so, the cells used a previously unknown self-guidance strategy involving EGF uptake from the media and subsequent generation of local gradients of epithelial growth hormone (EGF) that guided cell's persistent motions.

Interestingly, studies of leukocytes revealed that they can move persistently through confined domains (e.g., 3D fibrin gels) without any integrins and thus without forming any adhesions; ${ }^{[237]}$ this integrin independent motility of leukocytes was not observed on 2-D surfaces. It is not clear whether cancer cell migration in microchannels is also independent of integrins, but initial studies show that the increased motility of cells subject to 3D confinement arises from pressure effects. ${ }^{[238]}$ The plasticity of tumor cells enhances their ability to deform, enter and traverse a microchannel. ${ }^{[232]}$ To test the likelihood of cells entering a confined environment, Mak et. al. designed tapered PDMS microchannels having different widths ${ }^{[232]}$ (Figure 16b) and used time-lapse microscopy to compare behavior of two types of cells -- the highly metastatic MDA-MB-231and non-metastatic MCF-10A cells. The authors observed that the probability of permeation (i.e., the probability that a cell enters the narrow channel) is greater for the metastatic cells than the non-metastatic ones. Moreover, this difference in enhanced when the spatial gradient is shallow and a larger tapering area is used. The ability of metastatic cells to squeeze into narrow channels might rely upon the elasticity of their membrane which, in turn, depends on their ability to dynamically remodel the cytoskeleton. Studies with acute promyelocyticleukemia (APL) cells showed that stiffening the MT cytoskeleton with paclitaxel inhibited cells' ability to squeeze into channels and migrate. In addition, Rolli et.al. demonstrated that the treatment of pancreatic cancer cells with sphingosylphosphorylcholine (SPC), which increased cell 
membrane deformability, enables cancer cells to invade and permeate then arrow channels (7 $\mu \mathrm{m}$ wide) which without SPC treatment they would not traverse (Figure 16c). ${ }^{[233]}$ The studies described above are in agreement with the notion that metastatic cells have a lower Young's modulus (measured using AFM) than non-cancerous cells and that this difference can be a basis for differentiation of metastatic cells from non-metastatic/non-cancerous cells $^{[239]}$ (but see cell-shape micromechanics studies described in Section 6.3.3).

Another approach is to microfabricated micro-channels of defined dimensions within softer and physiologically more realistic 3D collagen gels ${ }^{[235]}$ (Figure 16d). Such microchannels can be fabricated within matrices with a range of collagen densities and were shown to accurately represent micro-tracks formed by proteolytic cancer cells in vivo. ${ }^{[191]}$ Noninvasive epithelial MCF-10A cells, which naturally are not able to move in unpatterned 3D collagen matrix, were able to migrate rapidly and persistently along the collagen microchannels. The migration speed and maximum invasion distance were also increased for metastatic MDA-MB-231 cells moving through the channels as compared to unpatterned 3D matrix. ${ }^{[235]}$ Interestingly, the movement of metastatic cells through the patterned microchannels was independent of matrix metalloprotease (MMP) activity suggesting one reason why MMP inhibitors fail when administered to cancer patients. Taken together, the confinement of metastatic cancer cells to microchannels (see references above and also ${ }^{[234]}$ ) or even to micropatterned lines of extracellular matrix enhances the migration of cancer cells (see Section 6.2).

The structural flexibility not only allows metastatic cells to traverse narrow channels, but also allows them to occupy challenging topographical terrains that cannot be occupied by non-metastatic cells. Along this line of reasoning, Liu et al. microfabricated substrates presenting "landscapes" of isolated cubical highlands elevated by hundreds of microns (= several cell diameters ${ }^{[203]}$ - cells with higher metastatic potential were found to be more likely to "climb" these elevations via vertical ascent paths than non-metastatic cells (Figure 16e). The authors developed a model which suggested that lower occupancy of highlands by non-metastatic cells was due to the so-called contact inhibition which is absent in metastatic cells. It was also suggested that this approach provides a new way to differentiate between invasive and non-invasive cancerous cells.

\subsection{Using microfabrication to study the effects of chemical gradients on cancer cell motility}

The "guided" motions of cells along chemical gradients, the so-called "chemotaxis" for soluble or "haptotaxis" for substrate-adherent chemical gradients, are commonly observed during metastasis (Figure 2). ${ }^{[240]}$ The process is carefully regulated by chemokines (the most common of which is CXCR4 ${ }^{[241]}$, cytokine receptors, growth factors and growth factor receptor proteins (GPCRs) ${ }^{[242]}$ whose aberrant expression is often related to cancer progression and invasion. ${ }^{[242-245]}$ In fact, the means by which the chemoattractant is presented (solid-state or soluble ${ }^{[246]}$ ) and, subsequently, the cell's method of chemosensing $[119,242,247,248]$ both dictate its polarization and whether it will undergo mesenchymal, amoeboid or collective migration. ${ }^{[242]}$ The morphological differences at the cell level are indicative of the activation of specific biochemical pathways with overlapping 
components. In general, chemotaxis begins with the sensing of a chemical signal through integrins or GPCRs. This leads to cell polarization through Rho GTPases ${ }^{[249]}$ and the asymmetric distribution of actin binding proteins, and hence asymmetric distribution of actin polymerization within the cell. ${ }^{[242,250]}$ Through polarized recruitment of GEFs and the protein cofilin-which severs F-actin and controls its directional growth ${ }^{[250]}$-the cell responds to the chemical gradient by polarizing towards it (see Section 2). Once polarized, it relies upon Myosin II to retract its tail and move towards the gradient. ${ }^{[59]}$ For amoeboid cells which lack a tail, the steps seem to be a bit different since, as we have seen, this type of motion depends on actomyosin contractility to squeeze through ECM pores independent of MMP activity. ${ }^{[119]}$ The cell's response to chemoattractant is also dependent on ECM integrity and composition since the ECM itself can either offer resistance or assistance to migration. ${ }^{[251]}$

Studies of cell response to chemical gradients reveal that metastatic cells can respond to even shallow gradients, ${ }^{[252]}$ are more likely to move directionally up the gradient, ${ }^{[253]}$ and that this response correlates to asymmetric receptor stimulation and subsequent asymmetric activation of signaling pathways that control cytoskeletal remodeling and cell motility. ${ }^{[242]}$ There are several types of microdevices-mostly microfluidic - that have been used to study cells' response to chemical gradients. The main advantage of microfluidic devices generating concentration gradients over traditional chemotaxis assays is that by modifying the geometries of mixing channels, gradients of different "shapes" can be generated and can be kept stable over time. More sophisticated devices comprise inlets with variable flow composition and flow rates, thus allowing for dynamic control over the gradient characteristics (Figure 17a). ${ }^{[254]}$ Devices that can simultaneously constrain the cell and/or place physical barriers in its path and expose it to a chemical gradient (Figure 17b, c) have also been fabricated. ${ }^{[255-258]}$ Furthermore, by using microfluidic chemotaxis chambers generating stable and precise chemical gradients, the responses of metastatic MDA-MB-231 cells to linear (with various slopes) and non-linear (polynomial of the form $y=$ const $^{*} x^{4.2}$ ) EGF gradient profiles were studied. It was found that linear gradients did not elicit directional cell movement, while non-linear profile (optimal range being 0-50 ng EGF) elicited marked directional motion towards higher EGF concentration ${ }^{[259]}$.

Interestingly, when the gradients were combined with physical confinement imposed by narrow channels, the behavior of cells depended on their type (Figure 17b, c). In particular, using a chemoattractant to force cells to squeeze into $3 \mu \mathrm{m}$ wide channels demonstrated that cancer cells (from three different lines tested) deformed and increased their surface area by almost nine-fold. ${ }^{[255]}$. In a related work (Figure 18c), Tong et. al. showed that when squeezing into $3 \mu \mathrm{m}$ wide channels in response to a gradient of chemoattractant, cancerous cells adopted a non-mesenchymal shape with characteristic F-actin network and a-tubulin distribution. ${ }^{[254]}$ The authors also showed that metastatic cells were more likely to traverse the entire length of the channels than non-metastatic cells. ${ }^{[257]}$

Lastly, Chung et. al. has developed a versatile microfluidic device which controls chemoattractant gradient and allows for imaging at a single cell level as cells migrate through 3D collagen gel scaffolds up the gradient or towards another cell type (Figure 17d). This device was used to quantify endothelial cell migration towards a gradient of vascular 
endothelial growth factor (VEGF). In stiffer gel matrices migrating cells formed structures resembling tube-like capillaries, while is softer gels cells migrated as sheets. Lastly, cell migration was examined in experiments where endothelial cells were co-cultured with cells of another type - the two cell types were separated by 3D collagen gel layer, but allowed to communicate via paracrine secreted/soluble signals. Using co-culture set-up it was shown that MTLn3 breast cancer cells attracted migrating endothelial cells, while or smooth muscle cells suppressed endothelial cell migration. ${ }^{[258]}$ See also Section 6.5 for a similar device adapted to study tumor cell intravasation and extravasation.

\subsection{Putting it all together: Developing the in vitro tumor niche to study cancer cell transmigration across endothelial layers}

Inside of the human body, metastasizing cancer cells move through topologically complex, three-dimensional (3D) and mechanically "soft" extracellular matrix defining specific tissues. With the advances in soft-lithographic techniques, construction of at least primitive tissue mimics has become a tangible experimental possibility. ${ }^{[31,203,260,261]}$ The most advanced microfluidic in vitro (outside animal) systems are designed to mimic complex 3D in vivo microenvironment while providing precise control over its biochemical and cellular composition (Figure 18). Several such systems which test the ability of cancer cells to transmigrate across to endothelial cell layer (mimicking intravasation and extravasation steps of metastasis) have been developed. ${ }^{[31,262,263]}$ These assays are essentially upgraded Boyden chamber assays ${ }^{[129]}$ which were designed to mimic the environment in which cells traverse the endothelial barrier. Typical Boyden assay monitors how cells migrate in response to a chemical gradient through pores in a filter separating two chambers. The chemical gradient is generated by separating the cells and media without chemoattractant and media with chemoattractant by the porous filter. The filter can be coated with extracellular matrix or uncoated. The total number of cells that have migrated cross the filter/matrix towards chemoattractant after a specified incubation time is quantified and used as a potential indication of invasiveness ${ }^{[129]}$. Importantly, Boyden assay does not allow for high resolution imaging of cells as they migrate across the filter/matrix.

The new microfluidics-based assays allow for more accurate mimicking of 3D microenvironments and are specifically designed to enable high resolution imaging of migrating and interacting cells. Inside the human body, the blood vessels are lined with endothelial cells while their exterior is in contact with the ECM. To mimic tumor-blood vessel interface and intravasation process, the two cell culture channels for cancer and endothelial cells were interconnected by 3D collagen gel. Endothelial cells formed continuous functional endothelial monolayer, while tumor cells invaded collagen gel, adhered to endothelial monolayer, and finally transmigrated (Figure 18a). ${ }^{[263]}$ Yet another device was developed to mimic extravasation. In this device, endothelial cells were introduced and allowed to form a monolayer along the walls of the microchannel, followed by introduction of cancer cells in the same microchannel. Cancer cells could transmigrate across the endothelial layers into 3D collagen gel in an adjacent chamber (Figure 18b). ${ }^{\text {[262] }}$ In both cases, the flow composition and rate were controlled by microfluidic pumps. Since these assays were conducted in transparent 3D gels, they allowed for real-time, highresolution observation and quantification of tumor cells and their interactions with 
endothelial monolayers. In addition, they allowed for accurate control over the biochemical stimuli, establishment of chemoattractant gradients, introduction of other cell types and realtime monitoring of the permeability of endothelial layer. ${ }^{[262,263]}$ These advanced assays are useful since they elucidate details of the invasion process which could not be observed previously. For example, it was found that tumor cell intravasation was inefficient across monolayers with intact barrier function, but significantly increased in the presence of cytokine (tumor necrosis factor $a, T N F-a$ ) secreting macrophages which also increase the permeability of endothelial monolayers. ${ }^{[263]}$ Intravasation and endothelial permeability was also increased when the endothelial monolayers were stimulated by soluble TNF-a (in the absence of macrophages) in the presence of EGF gradient which guides cancer cells towards endothelial monolayer.

Recent advances have also led to the development of cylindrical, endothelial-lined lumens which mimic blood vessels. ${ }^{[264]}$ These systems - principally developed in the Beebe lab have been developed using the familiar soft lithographic techniques. Here, microfabricated PDMS channels are first filled with ECM-hydrogel, then lumens are patterned into ECMhydrogel by passive pumping of media, and finally the ECM-hydrogel lumens are "coated" with endothelial cells to form endothelial cell-lined lumens (Figure 18c). These lumens were used to study endothelial cell motility (so-called sprouting during angiogenesis) under coculture conditions (enabled by having designs featuring two or three interconnected microchannels) and in the presence of spatially precise gradients stable over time. ${ }^{[264]}$

In addition, in order to test the efficacy and toxicity of anti-cancer drugs, several labs have begun work on reconstituting entire organs ${ }^{[265]}$ and organ systems in vitro ${ }^{[266]}$ (Figure 18d). Using microfabrication and microfluidics, the Ingber lab has been able to recreate organ level functions on in vitro chips. ${ }^{[265]}$ For example, their lung-on-a-chip device is capable of both stretching and contraction, thus mimicking alveolar function. The micro-architecture of the device is also designed to resemble the actual lung. ${ }^{[265]}$ Complementing this work, the Shuler lab has built devices which connect several of these organs together to form an organ system. ${ }^{[266]}$ However, studies of cell motility within these systems are yet to be performed. Perhaps in the near future, we will begin to see devices with the architectural sophistication of the in vivo lumens and with the global coherence of organ systems.

\section{Conclusions and outlook}

The main message of this review is that while microfabrication has already led to several interesting systems with which to study cell motility, it is still a work in the making in terms of providing us with biological answers related to cancer and cancer metastasis. The technical aspects of microfabrication and micropatterning techniques are nowadays well developed and allow for creating a large variety of structures with which cells can then be made to interact. Thus, the real challenge for future research does not lie in our microfabrication ability per se-instead, what is essential is to prepare microstructures that become realistic models of the in vivo environments, mimicking their mechanical, topological and chemical properties. Achieving such sophistication will likely require combing multiple techniques and materials: for instance, PDMS to delineate channels, hydrogels to mimic soft tissues, and microfluidics to establish chemical gradients affecting 
cell motility. In Section 6.5 we have seen some of such systems already being developed and defining the frontier of this exciting research. Another and largely unexplored area is to develop micro or even nanostructured systems that can address not only the motility of whole cells but also probe their morphological substructures. As we have seen in Figure 6, these substructures are on scales from hundreds of nanometers to 1-2 microns. Since these length scales are accessible to modern microfabrication, one could envision microsystems which would isolate and stabilize lamellipodia, invadipodia or filopodia to specific regions of a motile cell (as in polygonal islands separating cytoskeletal components; cf. Figure 13) and would then analyze these regions (by either microscopy or spectroscopy analyses) for the presence, expression levels and dynamics of specific proteins whose interaction underlies cell motility. Such junction of microfabrication and high-resolution imaging/ analysis would allow insights into the spatial distribution and dynamics/transport ${ }^{[267]}$ of the proteins controlling cytoskeletal activity and cell motility. Without such analyses at microscopic levels and in quantitative detail, the study of cell motility risks being bogged down at the level of data acquisition and network representations of protein-protein interactions purportedly involved in the process- such PPI networks are becoming so complex that hardly anyone can draw any meaningful conclusions how they orchestrate motility of cells and why this motility is distinctly different in metastatic cells. Microfabricated systems can help us quantify this "big data" ${ }^{[252,268]}$ being acquired and, ultimately, can help identify proteins responsible for the motility phenotype of invasive cancerous cells.

\section{References}

1. Chaffer CL, Weinberg RA. Science. 2011; 331:1559. [PubMed: 21436443]

2. Palmer TD, Ashby WJ, Lewis JD, Zijlstra A. Adv. Drug Del. Rev. 2011; 63:568.

3. Cairns RA, Harris IS, Mak TW. Nat. Rev. Cancer. 2011; 11:85. [PubMed: 21258394]

4. Debeir, O.; Adanja, I.; Kiss, R.; Decaestecker, C. The Motile Actin System in Health and Disease. Lambrechts, A.; Ampe, C., editors. Vol. 2. Kerala, India: Trans. Res. Net.; 2008. p. 123-156.

5. Fedele S. Head \& Neck Oncol. 2009; 1:1.

6. Christensen JD, Patz EF. Radiol. Clin. North. Am. 2012; 50:1001. [PubMed: 22974783]

7. Bohunicky B, Mousa SA. Nanotechnol. Sci. Appl. 2010; 4:1. [PubMed: 24198482]

8. Henson DE, Alboressaavedra J, Corle D. Cancer. 1992; 70:1493. [PubMed: 1516000]

9. Jemal A, Siegel R, Ward E, Hao YP, Xu JQ, Murray T, Thun MJ. CA Cancer J. Clin. 2008; 58:71. [PubMed: 18287387]

10. Hanahan D, Weinberg RA. Cell. 2011; 144:646. [PubMed: 21376230]

11. Kedrin D, van Rheenen J, Hernandez L, Condeelis J, Segall JE. J. Mammary Gland Biol. Neoplasia. 2007; 12:143. [PubMed: 17557195]

12. Yamazaki D, Kurisu S, Takenawa T. Cancer Sci. 2005; 96:379. [PubMed: 16053508]

13. Etienne-Manneville S. Traffic. 2004; 5:470. [PubMed: 15180824]

14. Nagano M, Hoshino D, Koshikawa N, Akizawa T, Seiki M. Int. J. Cell Biol. 2012; 2012:310616. [PubMed: 22319531]

15. McLean GW, Carragher NO, Avizienyte E, Evans J, Brunton VG, Frame MC. Nat. Rev. Cancer. 2005; 5:505. [PubMed: 16069815]

16. Gligorijevic B, Wyckoff J, Yamaguchi H, Wang Y, Roussos ET, Condeelis J. J. Cell Sci. 2012; 125:724. [PubMed: 22389406]

17. Vicente-Manzanares M, Sanchez-Madrid F. Nat. Rev. Immunol. 2004; 4:110. [PubMed: 15040584] 
18. Armstrong PB. Cancer Metast. Rev. 1985; 4:59.

19. Germain RN, Robey EA, Cahalan MD. Science. 2012; 336:1676. [PubMed: 22745423]

20. Gabbiani G. Pathol. Res. Pract. 1994; 190:851. [PubMed: 7899134]

21. Haendel MA, Bollinger KE, Baas PW. J. Neurocytol. 1996; 25:289. [PubMed: 8793733]

22. Jones D. Nat. Rev. Drug. Discov. 2008; 7:874.

23. Miekus K, Lukasiewicz E, Jarocha D, Sekula M, Drabik G, Majka M. Cell Death \& Disease. 2013:4.

24. Varani J, Fligiel SEG, Perone P. Int. J. Cancer. 1985; 35:559. [PubMed: 3988372]

25. Yilmaz M, Christofori G. Cancer. Metast. Rev. 2009; 28:15.

26. Hall A. Cancer. Metast. Rev. 2009; 28:5.

27. Ribatti D, Mangialardi G, Vacca A. Clin. Exp. Med. 2006; 6:145. [PubMed: 17191105]

28. Hulkower KI, Herber RL. Pharmaceutics. 2011; 3:107. [PubMed: 24310428]

29. Eccles SA, Box C, Court W. Biotechnol. Annu. Rev. 2005; 11:391. [PubMed: 16216785]

30. Underhill GH, Galie P, Chen CS, Bhatia SN. Annu. Rev. Cell Dev. Biol. 2012; 28:385. [PubMed: 23057744]

31. Bersini S, Jeon JS, Moretti M, Kamm RD. Drug Discov. Today. 2014; 19:735. [PubMed: 24361339]

32. Sackmann EK, Fulton AL, Beebe DJ. Nature. 2014; 507:181. [PubMed: 24622198]

33. Heath JR, Phelps ME, Hood L. Mol. Imaging Biol. 2003; 5:312. [PubMed: 14630511]

34. Huttenlocher A. Nat. Cell. Biol. 2005; 7:336. [PubMed: 15803131]

35. Pathak A, Kumar S. Plos One. 2011; 6:e18423. [PubMed: 21483802]

36. Wang YC, Ding SJ, Wang W, Jacobs JM, Qian WJ, Moore RJ, Yang F, Camp DG, Smith RD, Klemke RL. Proc. Natl. Acad. Sci. U. S. A. 2007; 104:8328. [PubMed: 17494752]

37. Yan J, Jin T. Bioarchitecture. 2012; 2:15. [PubMed: 22754623]

38. Holly SP, Larson MK, Parise LV. Exp. Cell Res. 2000; 261:69. [PubMed: 11082276]

39. Dos Remedios CG, Chhabra D, Kekic M, Dedova IV, Tsubakihara M, Berry DA, Nosworthy NJ. Physiol. Rev. 2003; 83:433. [PubMed: 12663865]

40. Dos Remedios, CG.; Chhabra, D. Actin Binding Proteins and Disease. New York: Springer; 2006.

41. McGough A. Curr. Opin. Struct. Biol. 1998; 8:166. [PubMed: 9631289]

42. Pollard TD, Borisy GG. Cell. 2003; 112:453. [PubMed: 12600310]

43. Uribe R, Jay D. Mol. Biol. Rep. 2009; 36:121. [PubMed: 17939058]

44. Jiang X, Bruzewicz DA, Wong AP, Piel M, Whitesides GM. Proc. Natl. Acad. Sci. U. S. A. 2005; 102:975. [PubMed: 15653772]

45. Thery M, Racine V, Piel M, Pepin A, Dimitrov A, Chen Y, Sibarita JB, Bornens M. Proc. Natl. Acad. Sci. U. S. A. 2006; 103:19771. [PubMed: 17179050]

46. Kandere-Grzybowska K, Soh S, Mahmud G, Komarova Y, Pilans D, Grzybowski BA. Soft Matter. 2010; 6:3257. [PubMed: 23826026]

47. Littlefield R, Fowler VM. Nat. Cell Biol. 2002; 4:E209. [PubMed: 12205481]

48. Pollard TD. Nature. 2003; 422:741. [PubMed: 12700767]

49. Pollard TD, Blanchoin L, Mullins RD. Annu. Rev. Biophys. Biomol. Struct. 2000; 29:545. [PubMed: 10940259]

50. Desai A, Mitchison TJ. Annu. Rev. Cell Dev. Biol. 1997; 13:83. [PubMed: 9442869]

51. Small JV, Geiger B, Kaverina I, Bershadsky A. Nat. Rev. Mol. Cell Biol. 2002; 3:957. [PubMed: 12461561]

52. van der Vaart B, Akhmanova A, Straube A. Biochem. Soc. Trans. 2009; 37:1007. [PubMed: 19754441]

53. Kaverina I, Straube A. Semin. Cell Dev. Biol. 2011; 22:968. [PubMed: 22001384]

54. Komarova Y, De Groot CO, Grigoriev I, Gouveia SM, Munteanu EL, Schober JM, Honnappa S, Buey RM, Hoogenraad CC, Dogterom M, Borisy GG, Steinmetz MO, Akhmanova A. J Cell Biol. 2009 Mar 9.184(5):691. [PubMed: 19255245]

55. Mitchison T, Kirschner M. Nature. 1984; 312:237. [PubMed: 6504138] 
56. Akhmanova A, Steinmetz MO. J. Cell Sci. 2010; 123:3415. [PubMed: 20930136]

57. Akhmanova A, Steinmetz MO. Nat. Rev. Mol. Cell Biol. 2008; 9:309. [PubMed: 18322465]

58. Waterman-Storer CM, Worthylake RA, Liu BP, Burridge K, Salmon ED. Nat. Cell. Biol. 1999; 1:45. [PubMed: 10559863]

59. Ballestrem C, Wehrle-Haller B, Hinz B, Imhof BA. Mol. Biol. Cell. 2000; 11:2999. [PubMed: 10982396]

60. Huda S, Soh S, Pilans D, Byrska-Bishop M, Kim J, Wilk G, Borisy GG, Kandere-Grzybowska K, Grzybowski BA. J. Cell Sci. 2012; 125:5790. [PubMed: 22992457]

61. Wittmann T, Bokoch GM, Waterman-Storer CM. J. Biol. Chem. 2004; 279:6196. [PubMed: 14645234]

62. Efimov A, Schiefermeier N, Grigoriev I, Ohi R, Brown MC, Turner CE, Small JV, Kaverina I. J. Cell Sci. 2008; 121:196. [PubMed: 18187451]

63. Kaverina I, Rottner K, Small JV. J. Cell Biol. 1998; 142:181. [PubMed: 9660872]

64. Laan L, Dogterom M. Methods Cell Biol. 2010; 95:617. [PubMed: 20466156]

65. Laan L, Pavin N, Husson J, Romet-Lemonne G, van Duijn M, López MP, Vale RD, Jülicher F, Reck-Peterson SL, Dogterom M. Cell. 2012; 148:502. [PubMed: 22304918]

66. Reticker-Flynn NE, Malta DFB, Winslow MM, Lamar JM, Xu MJ, Underhill GH, Hynes RO, Jacks TE, Bhatia SN. Nat. Commun. 2012; 3

67. Lo CM, Wang HB, Dembo M, Wang YL. Biophys. J. 2000; 79:144. [PubMed: 10866943]

68. Zaromytidou A-I. Nat. Cell Biol. 2013; 15:141.

69. Zamir E, Geiger B. J. Cell Sci. 2001; 114:3583. [PubMed: 11707510]

70. Burridge K, Chrzanowska-Wodnicka M. Annu. Rev. Cell Dev. Biol. 1996; 12:463. [PubMed: 8970735]

71. Ciobanasu C, Faivre B, Le Clainche C. Int. J. Cell Biol. 2012; 2012:941292. [PubMed: 22505938]

72. Seo CH, Jeong H, Furukawa KS, Suzuki Y, Ushida T. Biomater. 2013; 34:1764.

73. Huttenlocher A, Horwitz AR. Cold. Spring Harb. Perspect. Biol. 20113

74. Desgrosellier JS, Cheresh DA. Nat. Rev. Cancer. 2010; 10:9. [PubMed: 20029421]

75. Yu T, Wu X, Gupta KB, Kucik DF. Am. J. Physiol. Cell Physiol. 2010; 299:C399. [PubMed: 20445173]

76. Kawakami K, Tatsumi H, Sokabe M. J. Cell Sci. 2001; 114:3125. [PubMed: 11590239]

77. Parsons JT. J. Cell Sci. 2003; 116:1409. [PubMed: 12640026]

78. Mitra SK, Hanson DA, Schlaepfer DD. Nat. Rev. Mol. Cell Biol. 2005; 6:56. [PubMed: 15688067]

79. Brunton VG, Frame MC. Curr. Opin. Pharmacol. 2008; 8:427. [PubMed: 18625340]

80. Mohl C, Kirchgessner N, Schafer C, Hoffmann B, Merkel R. J. Cell Sci. 2012; 125:155. [PubMed: 22250204]

81. Xia N, Thodeti CK, Hunt TP, Xu QB, Ho M, Whitesides GM, Westervelt R, Ingber DE. FASEB J. 2008; 22:1649. [PubMed: 18180334]

82. Mahmud G, Campbell CJ, Bishop KJM, Komarova YA, Chaga O, Soh S, Huda S, Kandere-

Grzybowska K, Grzybowski BA. Nat. Phys. 2009; 5:606.

83. Webb DJ, Parsons JT, Horwitz AF. Nat. Cell Biol. 2002; 4:E97. [PubMed: 11944043]

84. Wadsworth P. Cell Motil. Cytoskel. 1999; 42:48.

85. Chhabra ES, Higgs HN. Nat. Cell Biol. 2007; 9:1110. [PubMed: 17909522]

86. Ponti A, Machacek M, Gupton SL, Waterman-Storer CM, Danuser G. Science. 2004; 305:1782. [PubMed: 15375270]

87. Murphy DA, Courtneidge SA. Nat. Rev. Mol. Cell Biol. 2011; 12:413. [PubMed: 21697900]

88. Small JV, Stradal T, Vignal E, Rottner K. Trends Cell Biol. 2002; 12:112. [PubMed: 11859023]

89. Pellegrin S, Mellor H. J. Cell Sci. 2007; 120:3491. [PubMed: 17928305]

90. Hotulainen P, Lappalainen P. J. Cell Biol. 2006; 173:383. [PubMed: 16651381]

91. Delorme V, Machacek M, Der Mardirossian C, Anderson KL, Wittmann T, Hanein D, WatermanStorer C, Danuser G, Bokoch GM. Dev. Cell. 2007; 13:646. [PubMed: 17981134]

92. Wirtz D, Khatau SB. Nat. Mater. 2010; 9:788. [PubMed: 20864937] 
93. Arjonen A, Kaukonen R, Ivaska J. Cell Adh. Migr. 2011; 5:421. [PubMed: 21975551]

94. Pertz O. Commun. Integr. Biol. 2011; 4:436. [PubMed: 21966564]

95. Yamaguchi H. Eur. J. Cell Biol. 2012; 91:902. [PubMed: 22658792]

96. Yamaguchi H, Pixley F, Condeelis J. Eur. J. Cell Biol. 2006; 85:213. [PubMed: 16546563]

97. Mattila PK, Lappalainen P. Nat. Rev. Mol. Cell Biol. 2008; 9:446. [PubMed: 18464790]

98. Yang CS, Svitkina T. Cell Adh. Migr. 2011; 5:402. [PubMed: 21975549]

99. Machesky LM, Li A. Commun. Integr. Biol. 2010; 3:263. [PubMed: 20714410]

100. Vignjevic D, Kojima S, Svitkina T, Borisy GG. J. Cell Biol. 2006; 174:863. [PubMed: 16966425]

101. Hashimoto Y, Skacel M, Lavery IC, Mukherjee AL, Casey G, Adams JC. BMC Cancer. 2006; 6:11. [PubMed: 16412235]

102. Hashimoto Y, Ito T, Inoue H, Okumura T, Tanaka E, Tsunoda S, Higashiyama M, Watanabe G, Imamura M, Shimada Y. Clin. Cancer Res. 2005; 11:2597. [PubMed: 15814639]

103. Schoumacher M, Goldman RD, Louvard D, Vignjevic DM. J. Cell Biol. 2010; 189:541. [PubMed: 20421424]

104. Zheng JQ, Wan JJ, Poo MM. J. Neurosci. 1996; 16:1140. [PubMed: 8558243]

105. Albuschies J, Vogel V. Sci Rep. 2013; 3:1658. [PubMed: 23584574]

106. Jang KJ, Kim MS, Feltrin D, Jeon NL, Suh KY, Pertz O. PLoS One. 2010; 5:e15966. [PubMed: 21209862]

107. Dalby MJ, Gadegaard N, Riehle MO, Wilkinson CD, Curtis AS. Int J Biochem Cell Biol. 2004; 36:2005. [PubMed: 15203114]

108. Amadio S S, De Ninno A, Montilli C, Businaro L, Gerardino A, Volonté C. BMC Neurosci. 2013; 14:121. [PubMed: 24119251]

109. Nguyen DH, Stapleton SC, Yang MT, Cha SS, Choi CK, Galie PA, Chen CS. Proc Natl Acad Sci U S A. 2013; 110:6712. [PubMed: 23569284]

110. Yoon HJ, Kozminsky M, Nagrath S. ACS Nano. 2014; 8:1995. [PubMed: 24601556] Kim GS, Kim DJ, Hyung JH, Lee MK, Lee SK. Anal Chem. 2014; 86:5330. [PubMed: 24773579]

111. Lauffenburger DA, Horwitz AF. Cell. 1996; 84:359. [PubMed: 8608589]

112. Ezratty EJ, Partridge MA, Gundersen GG. Nat. Cell Biol. 2005; 7:581. [PubMed: 15895076]

113. Hamadi A, Bouali M, Dontenwill M, Stoeckel H, Takeda K, Ronde P. J. Cell Sci. 2005; 118:4415. [PubMed: 16159962]

114. Oakes PW, Beckham Y, Stricker J, Gardel ML. J. Cell Biol. 2012; 196:363. [PubMed: 22291038]

115. Jordan MA, Wilson L. Nat. Rev. Cancer. 2004; 4:253. [PubMed: 15057285]

116. Poincloux R, Collin O, Lizárraga F, Romao M, Debray M, Piel M, Chavrier P. Proc. Natl. Acad. Sci. U. S. A. 2011; 108:1943. [PubMed: 21245302]

117. Wolf K, Mazo I, Leung H, Engelke K, von Andrian UH, Deryugina EI, Strongin AY, Brocker EB, Friedl P. J. Cell Biol. 2003; 160:267. [PubMed: 12527751]

118. Friedl P, Wolf K. Nat. Rev. Cancer. 2003; 3:362. [PubMed: 12724734]

119. Vedula SR, Ravasio A, Anon E, Chen T, Peyret G, Ashraf M, Ladoux B. Methods Cell Biol. 2014; 120:235. [PubMed: 24484669]

120. Yumura S, Mori H, Fukui Y. J. Cell Biol. 1984; 99:894. [PubMed: 6381508]

121. Condeelis J, Jones J, Segall JE. Cancer. Metast. Rev. 1992; 11:55.

122. Yoshida K, Soldati T. J. Cell Sci. 2006; 119:3833. [PubMed: 16926192]

123. Friedl P, Gilmour D. Nat. Rev. Mol. Cell Biol. 2009; 10:445. [PubMed: 19546857]

124. Friedl P, Noble PB, Walton PA, Laird DW, Chauvin PJ, Tabah RJ, Black M, Zanker KS. Cancer Res. 1995; 55:4557. [PubMed: 7553628]

125. Overall CM, Lopez-Otin C. Nat. Rev. Cancer. 2002; 2:657. [PubMed: 12209155]

126. Friedl P, Wolf K. J. Cell Biol. 2010; 188:11. [PubMed: 19951899]

127. Taddei ML, Giannoni E, Comito G, Chiarugi P. Cancer Lett. 2013; 341:80. [PubMed: 23376253]

128. Friedl P, Alexander S. Cell. 2011; 147:992. [PubMed: 22118458]

129. Chen HC. Meth. Mol. Biol. 2005; 294:15. 
130. Kandere-Grzybowska K, Campbell CJ, Mahmud G, Komarova Y, Soh S, Grzybowski BA. Soft Matter. 2007; 3:672.

131. le Digabel J, Ghibaudo M, Trichet L, Richert A, Ladoux B. Med. Biol. Eng. Comput. 2010; 48:965. [PubMed: 20424924]

132. Irimia D. Methods Cell Biol. 2014; 121:141. [PubMed: 24560508]

133. Le Berre M, Zlotek-Zlotkiewicz E, Bonazzi D, Lautenschlaeger F, Piel M. Methods Cell Biol. 2014; 121:213. [PubMed: 24560512]

134. Whitesides GM, Ostuni E, Takayama S, Jiang X, Ingber DE. Annu. Rev. Biomed. Eng. 2001; 3:335. [PubMed: 11447067]

135. Beebe DJ, Mensing GA, Walker GM. Annu. Rev. Biomed. Eng. 2002; 4:261. [PubMed: 12117759]

136. Qin D, Xia Y, Whitesides GM. Nat. Protoc. 2010; 5:491. [PubMed: 20203666]

137. Velve-Casquillas G, Le Berre M, Piel M, Tran PT. Nano Today. 2010; 5:28. [PubMed: 21152269]

138. Kandere-Grzybowska K, Campbell C, Komarova Y, Grzybowski BA, Borisy GG. Nat. Methods. 2005; 2:739. [PubMed: 16179919]

139. Raghavan S, Desai RA, Kwon Y, Mrksich M, Chen CS. Langmuir. 2010; 26:17733. [PubMed: 20886900]

140. Yang MT, Sniadecki NJ, Chen CS. Adv. Mater. 2007; 19:3119.

141. Fu J, Wang YK, Yang MT, Desai RA, Yu X, Liu Z, Chen CS. Nat. Methods. 2010; 7:733. [PubMed: 20676108]

142. Doniavi A, Mileham AR, Newnes LB. Int. J. Prod. Res. 2000; 38:2515.

143. Wallraff GM, Hinsberg WD. Chem. Rev. 1999; 99:1801. [PubMed: 11849011]

144. Madou, M. Fundamentals of Microfabrication:The Science of Miniaturization. CRC Press; 2002.

145. Heckele M, Schomburg WK. J. Micromech. Microeng. 2004; 14:R1.

146. Haines K. Practical Holography. 1996; 2652:45.

147. Ong NS, Koh YH, Fu YQ. Microelectron. Eng. 2002; 60:365.

148. Kim DH, Wong PK, Park J, Levchenko A, Sun Y. Annu. Rev. Biomed. Eng. 2009; 11:203. [PubMed: 19400708]

149. Gallego-Perez D, Higuita-Castro N, Denning L, DeJesus J, Dahl K, Sarkar A, Hansford DJ. Lab Chip. 2012; 12:4424. [PubMed: 22936003]

150. Ventre M, Valle F, Bianchi M, Biscarini F, Netti PA. Langmuir. 2012; 28:714. [PubMed: 22121886]

151. Park TH, Shuler ML. Biotechnol. Prog. 2003; 19:243. [PubMed: 12675556]

152. Ruiz SA, Chen CS. Soft Matter. 2007; 3:168.

153. Wilbur JL, Kumar A, Kim E, Whitesides GM. Adv. Mater. 1994; 6:600.

154. Santhanam V, Andres RP. Nano Lett. 2004; 4:41.

155. Hidber PC, Helbig W, Kim E, Whitesides GM. Langmuir. 1996; 12:1375.

156. Kumar A, Whitesides GM. Appl. Phys. Lett. 1993; 63:2002.

157. Prime KL, Whitesides GM. Science. 1991; 252:1164. [PubMed: 2031186]

158. Roberts C, Chen CS, Mrksich M, Martichonok V, Ingber DE, Whitesides GM. J. Am. Chem. Soc. 1998; 120:6548.

159. Singhvi R, Kumar A, Lopez GP, Stephanopoulos GN, Wang DIC, Whitesides GM, Ingber DE. Science. 1994; 264:696. [PubMed: 8171320]

160. Chen CS, Mrksich M, Huang S, Whitesides GM, Ingber DE. Science. 1997; 276:1425. [PubMed: 9162012]

161. Thery M, Racine V, Pepin A, Piel M, Chen Y, Sibarita JB, Bornens M. Nat. Cell Biol. 2005; 7:947. [PubMed: 16179950]

162. Brock A, Chang E, Ho CC, LeDuc P, Jiang XY, Whitesides GM, Ingber DE. Langmuir. 2003; 19:1611. [PubMed: 14674434]

163. Thery M, Piel M. Cold. Spring Harb. Protoc. 2009; 2009 pdb prot5255. 
164. Fink J, Théry M, Azioune A, Dupont R, Chatelain F, Bornens M, Piel M. Lab Chip. 2007; 7:672. [PubMed: 17538708]

165. Lauer L, Klein C, Offenhäusser A. Biomaterials. 2001; 22:1925. [PubMed: 11396899]

166. Jungblut M, Knoll W, Thielemann C, Pottek M. Biomed Microdevices. 2009; 11:1269. [PubMed: 19757074]

167. Campbell CJ, Smoukov SK, Bishop KJM, Grzybowski BA. Langmuir. 2005; 21:2637. [PubMed: 15779924]

168. Soh S, Kandere-Grzybowska K, Mahmud G, Huda S, Patashinski AZ, Grzybowski BA. Adv. Mater. 2012; 24:5719. [PubMed: 22886834]

169. Whitesides GM. Nature. 2006; 442:368. [PubMed: 16871203]

170. Xia YN, Whitesides GM. Annu. Rev. Mater. Sci. 1998; 28:153.

171. Giridharan V, Yun Y, Hajdu P, Conforti L, Collins B, Jang Y, Sankar J. J. Nanomater. 2012

172. Wang YJ, Lin WY, Liu K, Lin RJ, Selke M, Kolb HC, Zhang NG, Zhao XZ, Phelps ME, Shen CKF, Faull KF, Tseng HR. Lab Chip. 2009; 9:2281. [PubMed: 19636457]

173. Allazetta S, Cosson S, Lutolf MP. Chem. Commun. 2011; 47:191.

174. van der Meer AD, Vermeul K, Poot AA, Feijen J, Vermes I. Am. J. Physiol. Heart Circul. Physiol. 2010; 298:H719.

175. Pihl J, Sinclair J, Sahlin E, Karlsson M, Petterson F, Olofsson J, Orwar O. Anal. Chem. 2005; 77:3897. [PubMed: 15987089]

176. Weibel DB, Whitesides GM. Curr. Opin. Chem. Biol. 2006; 10:584. [PubMed: 17056296]

177. Kim S, Kim HJ, Jeon NL. Integr. Biol. 2010; 2:584.

178. Dertinger SKW, Chiu DT, Jeon NL, Whitesides GM. Anal. Chem. 2001; 73:1240.

179. Huang Y, Agrawal B, Sun DD, Kuo JS, Williams JC. Biomicrofluidics. 2011; 5:13412. [PubMed: 21522502]

180. Rhee SW, Taylor AM, Tu CH, Cribbs DH, Cotman CW, Jeon NL. Lab Chip. 2005; 5:102. [PubMed: 15616747]

181. Ridley AJ, Schwartz MA, Burridge K, Firtel RA, Ginsberg MH, Borisy G, Parsons JT, Horwitz AR. Science. 2003; 302:1704. [PubMed: 14657486]

182. Etienne-Manneville S, Hall A. Nature. 2002; 420:629. [PubMed: 12478284]

183. Parker KK, Brock AL, Brangwynne C, Mannix RJ, Wang N, Ostuni E, Geisse NA, Adams JC, Whitesides GM, Ingber DE. FASEB J. 2002; 16:1195. [PubMed: 12153987]

184. James J GE, Hu H, Liu C, Mrksich M. Cell Motil. Cytoskel. 2008; 65:841.

185. Novak IL, Slepchenko BM, Mogilner A, Loew LM. Phys. Rev. Lett. 2004; 93:268109. [PubMed: 15698031]

186. Condeelis J, Segall JE. Nat. Rev. Cancer. 2003; 3:921. [PubMed: 14737122]

187. Alexander S, Weigelin B, Winkler F, Friedl P. Curr. Opin. Cell Biol. 2013; 25:659. [PubMed: 23896198]

188. Doyle AD, Wang FW, Matsumoto K, Yamada KM. J. Cell Biol. 2009; 184:481. [PubMed: 19221195]

189. Maiuri P, Terriac E, Paul-Gilloteaux P, Vignaud T, McNally K, Onuffer J, Thorn K, Nguyen PA, Georgoulia N, Soong D, Jayo A, Beil N, Beneke J, Lim JC, Sim CP, Chu YS, JimenezDalmaroni A, Joanny JF, Thiery JP, Erfle H, Parsons M, Mitchison TJ, Lim WA, LennonDumenil AM, Piel M, Thery M. W. C. R. participants. Curr. Biol. 2012; 22:R673. [PubMed: 22974990]

190. Pouthas F, Girard P, Lecaudey V, Ly TB, Gilmour D, Boulin C, Pepperkok R, Reynaud EG. J. Cell Sci. 2008; 121:2406. [PubMed: 18577576]

191. Wolf K, Friedl P. Trends Cell Biol. 2011; 21:736. [PubMed: 22036198]

192. Guo WH, Wang YL. Mol. Biol. Cell. 2012; 23:1657. [PubMed: 22398722]

193. Astumian RD, Hanggi P. Phys. Today. 2002; 55:33.

194. Reimann P. Phys. Rep. 2002; 361:57.

195. Feynman RP, Leighton RB, Sands M. The Feynman Lectures on Physics, Vol. I: Mainly Mechanics, Radiation, and Heat. Basic Books. 2011 
196. Kumar G, Ho CC, Co CC. Adv. Mater. 2007; 19:1084.

197. Kushiro K, Chang S, Asthagiri AR. Adv. Mater. 2010; 22:4516. [PubMed: 20818616]

198. Kumar G, Co CC, Ho CC. Langmuir. 2011; 27:3803. [PubMed: 21355564]

199. Ko YG, Co CC, Ho CC. Soft Matter. 2013; 9:2467. [PubMed: 24533031]

200. Kushiro K, Asthagiri AR. Langmuir. 2012; 28:4357. [PubMed: 22313398]

201. Suresh S. Acta Biomater. 2007; 3:413. [PubMed: 17540628]

202. Kraning-Rush CM, Carey SP, Califano JP, Reinhart-King CA. Methods Cell. Biol. 2012; 110:139. [PubMed: 22482948]

203. Liu L, Sun B, Pedersen JN, Aw Yong KM, Getzenberg RH, Stone HA, Austin RH. Proc. Natl. Acad. Sci. U.S.A. 2011; 108:6853. [PubMed: 21474778]

204. Tee SY, Fu J, Chen CS, Janmey PA. Biophys. J. 2011; 100:L25. [PubMed: 21354386]

205. Pelham RJ Jr, Wang Y. Mol. Biol. Cell. 1999; 10:935. [PubMed: 10198048]

206. Dembo M, Wang YL. Biophys. J. 1999; 76:2307. [PubMed: 10096925]

207. Paszek MJ, Zahir N, Johnson KR, Lakins JN, Rozenberg GI, Gefen A, Reinhart-King CA, Margulies SS, Dembo M, Boettiger D, Hammer DA, Weaver VM. Cancer Cell. 2005; 8:241. [PubMed: 16169468]

208. Munevar S, Wang YL, Dembo M. Mol. Biol. Cell. 2001; 12:3947. [PubMed: 11739792]

209. Munevar S, Wang Y, Dembo M. Biophys. J. 2001; 80:1744. [PubMed: 11259288]

210. Kraning-Rush CM, Califano JP, Reinhart-King CA. PLoS One. 2012; 7:e32572. [PubMed: 22389710]

211. Indra I, Undyala V, Kandow C, Thirumurthi U, Dembo M, Beningo KA. Phys. Biol. 2011; 8:015015. [PubMed: 21301068]

212. Peschetola V, Laurent VM, Duperray A, Michel R, Ambrosi D, Preziosi L, Verdier C. Cytoskeleton. 2013; 70:201. [PubMed: 23444002]

213. Tseng Q, Wang I, Duchemin-Pelletier E, Azioune A, Carpi N, Gao J, Filhol O, Piel M, Thery M, Balland M. Lab Chip. 2011; 11:2231. [PubMed: 21523273]

214. Rape AD, Guo WH, Wang YL. Biomater. 2011; 32:2043.

215. Balaban NQ, Schwarz US, Riveline D, Goichberg P, Tzur G, Sabanay I, Mahalu D, Safran S, Bershadsky A, Addadi L, Geiger B. Nat. Cell. Biol. 2001; 3:466. [PubMed: 11331874]

216. Beningo KA, Dembo M, Kaverina I, Small JV, Wang YL. J. Cell Biol. 2001; 153:881. [PubMed: 11352946]

217. Tan JL, Tien J, Pirone DM, Gray DS, Bhadriraju K, Chen CS. Proc. Natl. Acad. Sci. U.S.A. 2003; 100:1484. [PubMed: 12552122]

218. du Roure O, Saez A, Buguin A, Austin RH, Chavrier P, Silberzan P, Ladoux B. Proc. Natl. Acad. Sci. U.S.A. 2005; 102:2390. [PubMed: 15695588]

219. Jorrisch MH, Shih W, Yamada S. Biol. Open. 2013; 2:368. [PubMed: 23616920]

220. Saez A, Buguin A, Silberzan P, Ladoux B. Biophys. J. 2005; 89:L52. [PubMed: 16214867]

221. Saez A, Ghibaudo M, Buguin A, Silberzan P, Ladoux B. Proc. Natl. Acad. Sci. U.S.A. 2007; 104:8281. [PubMed: 17488828]

222. Han SJ, Bielawski KS, Ting LH, Rodriguez ML, Sniadecki NJ. Biophys. J. 2012; 103:640. [PubMed: 22947925]

223. Ricart BG, Yang MT, Hunter CA, Chen CS, Hammer DA. Biophys. J. 2011; 101:2620. [PubMed: 22261049]

224. Sniadecki NJ, Anguelouch A, Yang MT, Lamb CM, Liu Z, Kirschner SB, Liu Y, Reich DH, Chen CS. Proc. Natl. Acad. Sci. U.S.A. 2007; 104:14553. [PubMed: 17804810]

225. le Digabel J, Biais N, Fresnais J, Berret JF, Hersen P, Ladoux B. Lab Chip. 2011; 11:2630. [PubMed: 21674117]

226. Zao R, Boudou T, Wang W, Chen CS, Reich DH. Adv. Mater. 2013; 25:1699. [PubMed: 23355085]

227. Legant WR, Choi CK, Miller JS, Shao L, Gao L, Betzig E, Chen CS. Proc. Natl. Acad. Sci. U.S.A. 2013; 110:881. [PubMed: 23277584] 
228. Koch TM, Münster S, Bonakdar N, Butler JP, Fabry B. PLoS One. 2012; 7:e33476. [PubMed: 22479403]

229. Ingber DE. J. Cell Sci. 1993; 104:613. [PubMed: 8314865]

230. Ingber DE. Annu. Rev. Physiol. 1997; 59:575. [PubMed: 9074778]

231. Irimia D, Toner M. Integr. Biol. 2009; 1:506.

232. Mak M, Reinhart-King CA, Erickson D. PLoS One. 2011; 6:e20825. [PubMed: 21695222]

233. Rolli CG, Seufferlein T, Kemkemer R, Spatz JP. PLoS One. 2010; 5:e8726. [PubMed: 20090950]

234. Pathak A, Kumar S. Proc. Natl. Acad. Sci. U.S.A. 2012; 109:10334. [PubMed: 22689955]

235. Kraning-Rush CM, Carey SP, Lampi MC, Reinhart-King CA. Integr. Biol. 2013; 5:606.

236. Scherber C, Aranyosi AJ, Kulemann B, Thayer SP, Toner M, Iliopoulos O, Irimia D. Integr. Biol. 2012; 4:259.

237. Lammermann T, Bader BL, Monkley SJ, Worbs T, Wedlich-Soldner R, Hirsch K, Keller M, Forster R, Critchley DR, Fassler R, Sixt M. Nature. 2008; 453:51. [PubMed: 18451854]

238. Hawkins RJ, Piel M, Faure-Andre G, Lennon-Dumenil AM, Joanny JF, Prost J, Voituriez R. Phys. Rev. Lett. 2009; 102:058103. [PubMed: 19257561]

239. Cross SE, Jin YS, Rao J, Gimzewski JK. Nat. Nanotechnol. 2007; 2:780. [PubMed: 18654431]

240. Kay RR, Langridge P, Traynor D, Hoeller O. Nat. Rev. Mol. Cell Biol. 2008; 9:455. [PubMed: 18500256]

241. Lazennec G, Richmond A. Trends Mol. Med. 2010; 16:133. [PubMed: 20163989]

242. Roussos ET, Condeelis JS, Patsialou A. Nat. Rev. Cancer. 2011; 11:573. [PubMed: 21779009]

243. Condeelis, XSJ.; Backer, JM.; Wyckoff, J.; Segall, J. Cell Motility : From Molecules to Organisms. Wiley; 2005. (for chapter 11)

244. Yamaguchi H, Wyckoff J, Condeelis J. Curr. Opin. Cell Biol. 2005; 17:559. [PubMed: 16098726]

245. McGee SF, Lanigan F, Gilligan E, Groner B. EMBO Rep. 2006; 7:1084. [PubMed: 17057642]

246. Patel DD, Koopmann W, Imai T, Whichard LP, Yoshie O, Krangel MS. Clin. Immunol. 2001; 99:43. [PubMed: 11286540]

247. Iglesias PA, Devreotes PN. Curr. Opin. Cell Biol. 2008; 20:35. [PubMed: 18207721]

248. Sahai E. Curr. Opin. Genet. Dev. 2005; 15:87. [PubMed: 15661538]

249. Fukata M, Nakagawa M, Kaibuchi K. Curr. Opin. Cell Biol. 2003; 15:590. [PubMed: 14519394]

250. DesMarais V, Ghosh M, Eddy R, Condeelis J. J. Cell. Sci. 2005; 118:19. [PubMed: 15615780]

251. Perumpanani AJ, Simmons DL, Gearing AJH, Miller KM, Ward G, Norbury J, Schneemann M, Sherratt JA. Proc. Roy. Soc. B-Biol. Sci. 1998; 265:2347.

252. Saadi W, Wang SJ, Lin F, Jeon NL. Biomed. Microdev. 2006; 8:109.

253. Soon L, Mouneimne G, Segall J, Wyckoff J, Condeelis J. Cell Motil. Cytoskeleton. 2005; 62:27. [PubMed: 16025469]

254. Cooksey GA, Sip CG, Folch A. Lab Chip. 2009; 9:417. [PubMed: 19156291]

255. Chaw KC, Manimaran M, Tay FE, Swaminathan S. Microvasc. Res. 2006; 72:153. [PubMed: 17081570]

256. Tong Z, Balzer EM, Dallas MR, Hung WC, Stebe KJ, Konstantopoulos K. PLoS One. 2012; 7:e29211. [PubMed: 22279529]

257. Mak M, Reinhart-King CA, Erickson D. Lab Chip. 2013; 13:340. [PubMed: 23212313]

258. Chung S, Sudo R, Mack PJ, Wan CR, Vickerman V, Kamm RD. Lab Chip. 2009; 9:269. [PubMed: 19107284]

259. Wang SJ, Saadi W, Lin F, Minh-Canh Nguyen C, Li Jeon N. Exp. Cell Res. 2004; 300:180. [PubMed: 15383325]

260. Soman P, Kelber JA, Lee JW, Wright TN, Vecchio KS, Klemke RL, Chen S. Biomater. 2012; 33:7064.

261. Sala A, Hanseler P, Ranga A, Lutolf MP, Voros J, Ehrbar M, Weber FE. Integr. Biol. 2011; 3:1102.

262. Jeon JS, Zervantonakis IK, Chung S, Kamm RD, Charest JL. PLoS One. 2013; 8:e56910. [PubMed: 23437268] 
263. Zervantonakis IK, Hughes-Alford SK, Charest JL, Condeelis JS, Gertler FB, Kamm RD. Proc. Natl. Acad. Sci. U.S.A. 2012; 109:13515. [PubMed: 22869695]

264. Bischel LL, Young EW, Mader BR, Beebe DJ. Biomater. 2013; 34:1471.

265. Huh D, Matthews BD, Mammoto A, Montoya-Zavala M, Hsin HY, Ingber DE. Science. 2010; 328:1662. [PubMed: 20576885]

266. Sung JH, Shuler ML. Lab Chip. 2009; 9:1385. [PubMed: 19417905]

267. Soh S, Byrska M, Kandere-Grzybowska K, Grzybowski BA. Angew. Chem. Int. Ed. 2010; 49:4170.

268. Young EWK, Beebe DJ. Chem. Soc. Rev. 2010; 39:1036. [PubMed: 20179823] 


\section{Metastasis}
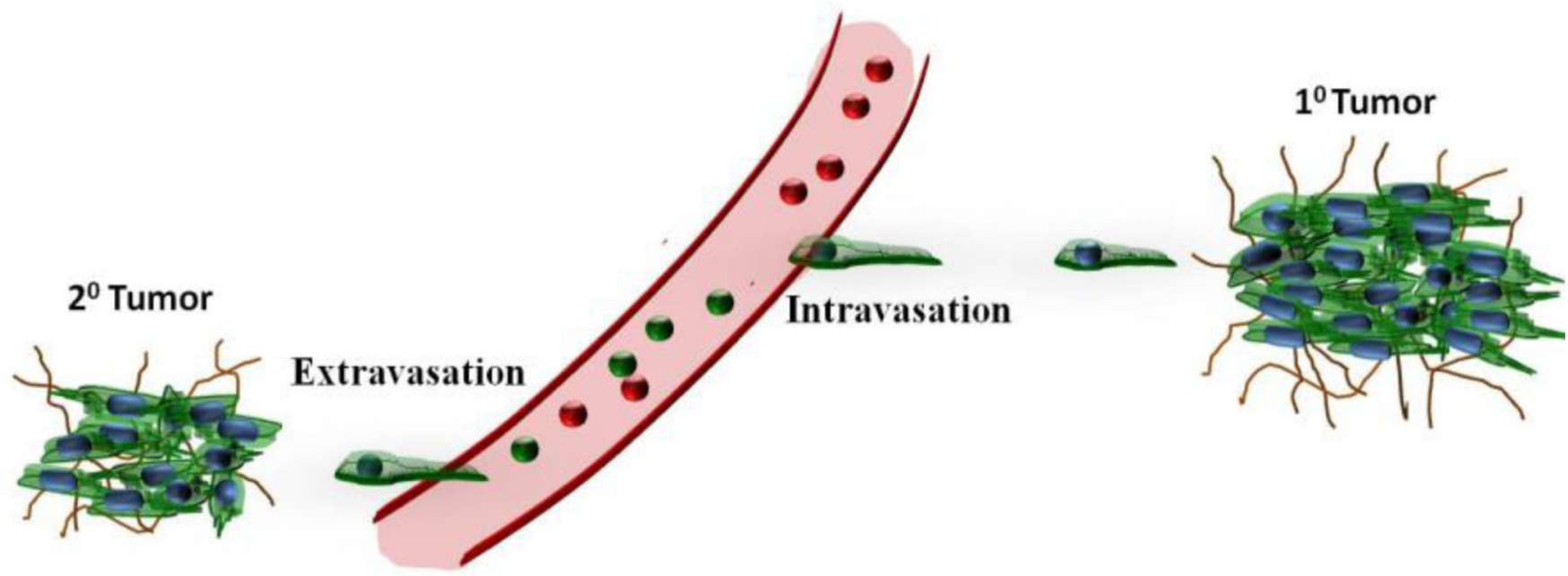

Figure 1.

Cell motility is a hallmark of a multi-step metastasis process. Metastatic cancer cells move away from the primary tumor site, enter the blood stream, then leave it through extravasation and move/migrate inside target tissue before finally seeding secondary tumors. The site selection is likely driven by the presence of appropriate growth conditions as suggested by the "seed and soil" hypothesis. ${ }^{[27]}$ 


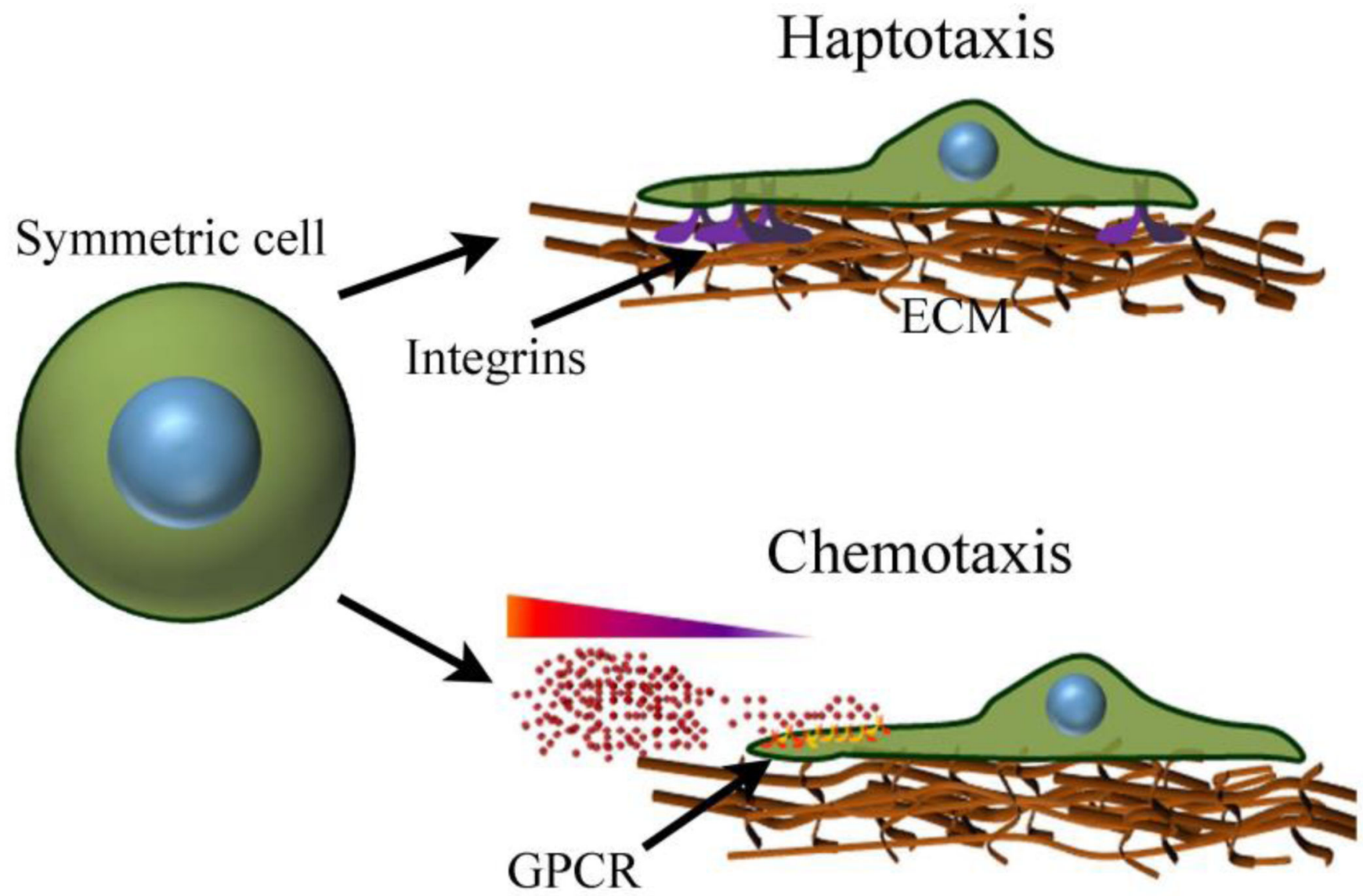

Figure 2.

Cells polarize in response to topological or chemical gradients. Gradients in adhesion sites, topology or surface-bound chemicals cause cells to polarize and undergo haptotaxis. Cells can also be stimulated to break symmetry and move directionally (here, direction of movement is from right to left) in the presence of chemical gradients (chemotaxis). 


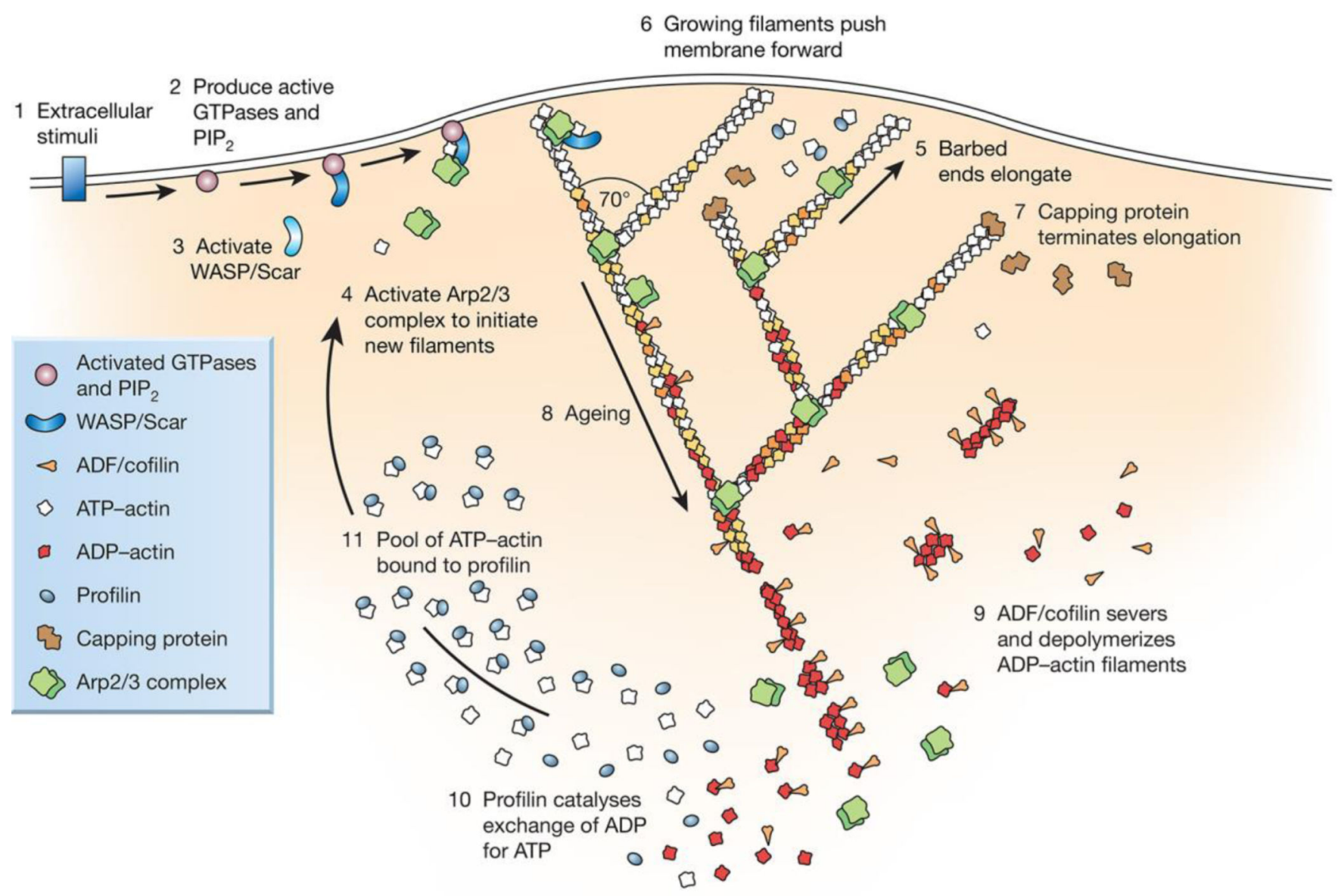

Figure 3.

Dendritic Nucleation / Array Treadmilling model. ${ }^{[42,48,49]}$ Actin filament assembly is controlled by a set of proteins which bind to it. Actin polymerization at the barbed end begins when integrin stimulation leads to the uncapping of this end and initiation of Arp2/3mediated filament elongation. New filaments are polymerized off the existing filaments at $70^{\circ}$ angle leading to a branched network of actin filaments. At the pointed end, F-actin is disassembled by Cofilin and ADP-actin is catalyzed to ATP-actin by Profilin. The net result of these processes is that the polymerizing actin filament network pushes the cell membrane forward. The image is reproduced with permission from Pollard. ${ }^{[48]}$ 
(a) MT polymerization

\section{$(-)$ end}

(+) end

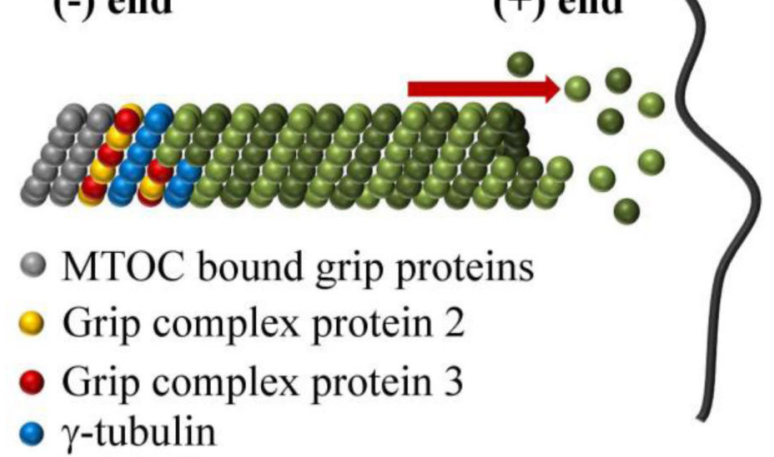

$\alpha$-tubulin

- $\beta$-tubulin

(b)

(c)

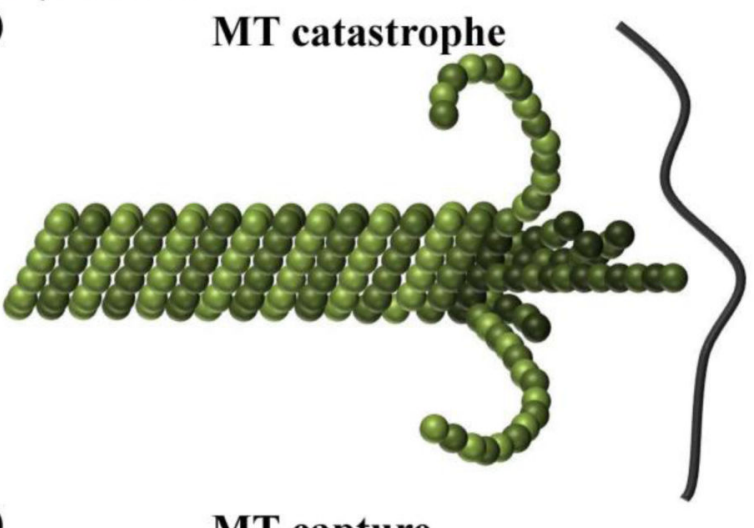

MT capture

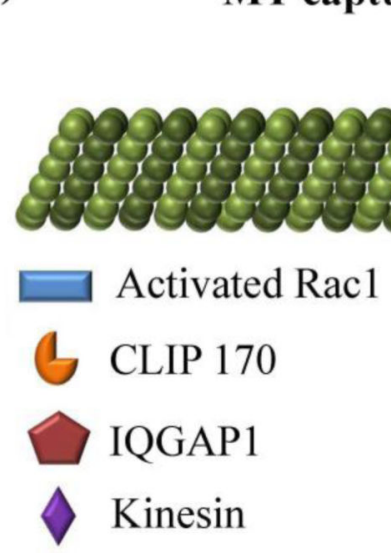

Figure 4.

MT polymerization and dynamic instability. (a) New microtubules (MTs) are nucleated at the microtubule organizing center (MTOC) by the $\gamma$-TuRC complex. (b) MTs can undergo catastrophes- that is, they can transition from a growth to a shrinking phase. (c) Growing MTs can be captured and stabilized at the membrane by the so-called +TIP proteins (for example, CLIP170, IQGAP1, kinesin) and membrane bound proteins. 
(a)

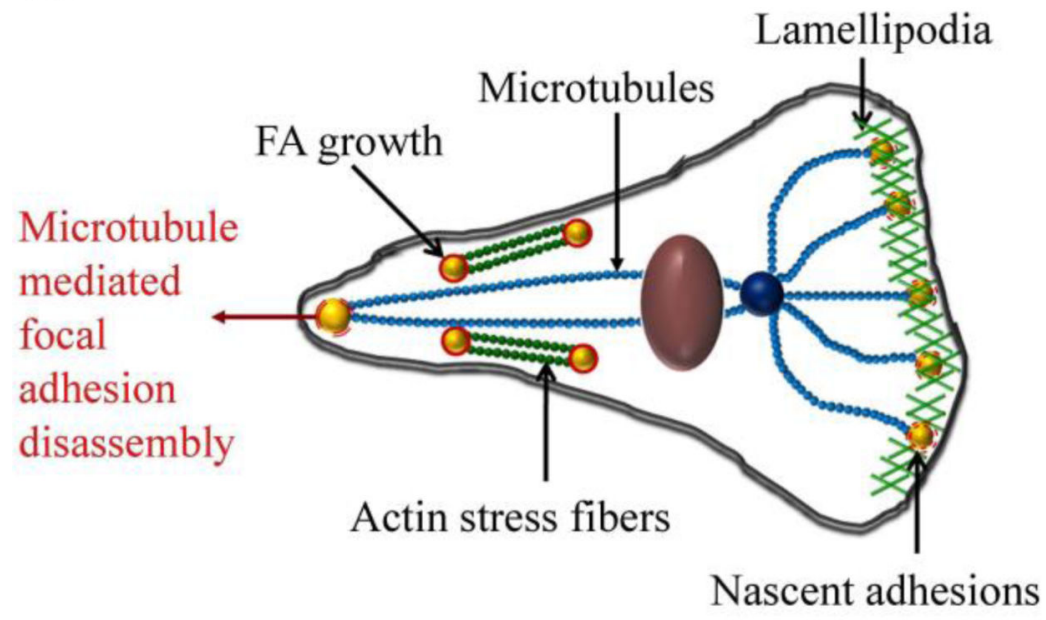

(b)

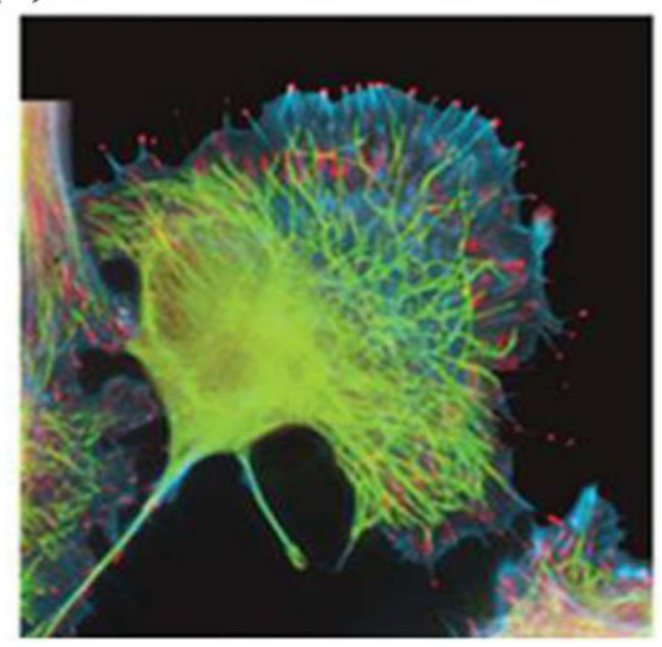

Figure 5.

Focal adhesion (FA) turnover in a moving cell. (a) Nascent FAs are preferentially formed at the cell front. As the cell moves forward, nascent adhesions either turn over or grow/mature under the influence of actin stress fibers. At the rear, FA disassembly is facilitated by MTs and actomyosin stress fibers. (b) Image of a polarized B16F1 mouse melanoma cell showing FAs (phosphotyrosine, red), microtubules (tubulin, green) and actin (actin, cyan) visualized by immunostaining. 
(a)

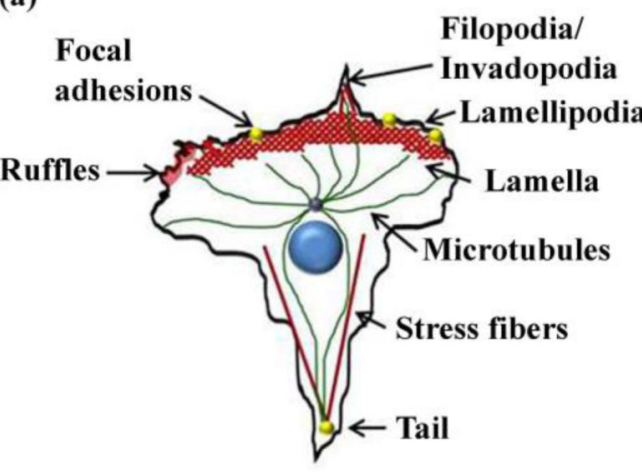

(b)

\begin{tabular}{cccccc}
\hline Structures & Actin & Microtubule & $\begin{array}{c}\text { Focal } \\
\text { Adhesion }\end{array}$ & Mode & Size \\
\hline Lamellipodia & $\sqrt{ }$ & & $\sqrt{ }$ & M, A, C & $\sim \mathbf{1} \mu \mathrm{m}$ \\
Invadopodia & $\sqrt{ }$ & $\sqrt{ }$ & $\sqrt{ }$ & M, C & $\sim \mathbf{0 . 5} \mu \mathbf{m}$ \\
Filopodia & $\sqrt{ }$ & $\sqrt{ }$ & & M, C & $\sim \mathbf{0 . 3 \mu m}$ \\
Lamella & $\sqrt{ }$ & $\sqrt{ }$ & $\sqrt{ }$ & M, A, C & $\sim \mathbf{2} \mu \mathrm{m}$ \\
Ruffles & $\sqrt{ }$ & & & M, C & $\sim \mathbf{1} \mu \mathbf{m}$ \\
Tail & $\sqrt{ }$ & $\sqrt{ }$ & $\sqrt{ }$ & M, C & - \\
\hline
\end{tabular}

*Mesenchymal (M), Amoeboid (A), Collective (C)

Figure 6.

Cytoskeletal structures and motility modes. (a) Components of the cytoskeleton are found in different configurations and are combined to form a variety of different phenotypic structures which help the cell control its mode of motility. (b) The table lists the cytoskeletal components in different motility structures, relates these structures to different motility modes $(\mathrm{M}=$ mesenchymal, $\mathrm{A}=$ amoeboid, $\mathrm{C}=$ collective; see Section 4$)$, and gives their typical dimensions. 


\section{Morphology}
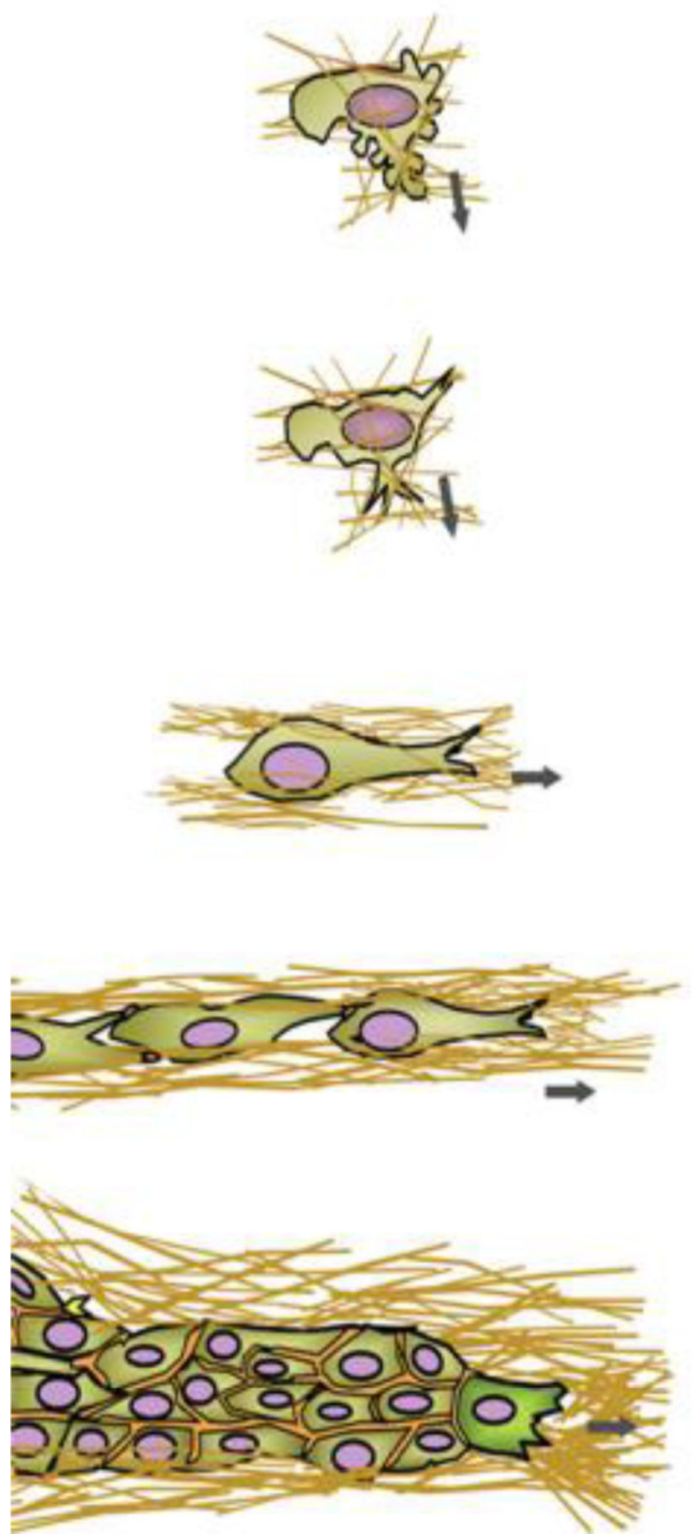

Migration

mode

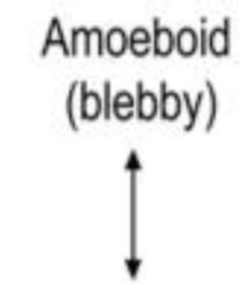

Amoeboid

(pseudopodal,

filopodal)

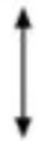

Mesenchymal

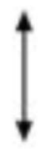

Multicellular

streaming

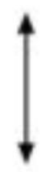

Collective

Figure 7.

The different modes of cell motility. Cells can move collectively or as single cells. While the collective mode of motion features $\beta 1$ integrin dependency and cell-cell junctions, single cell motion is either MMP-dependent (mesenchymal) or MMP-independent but actomyosin dependent (amoeboid). The image is reprinted with permission from Peter Friedl \& Katarina Wolf, 2009. Originally published in Journal of Cell Biology. doi: 10.1083/jcb. $200909003^{[126]}$. 
(a)

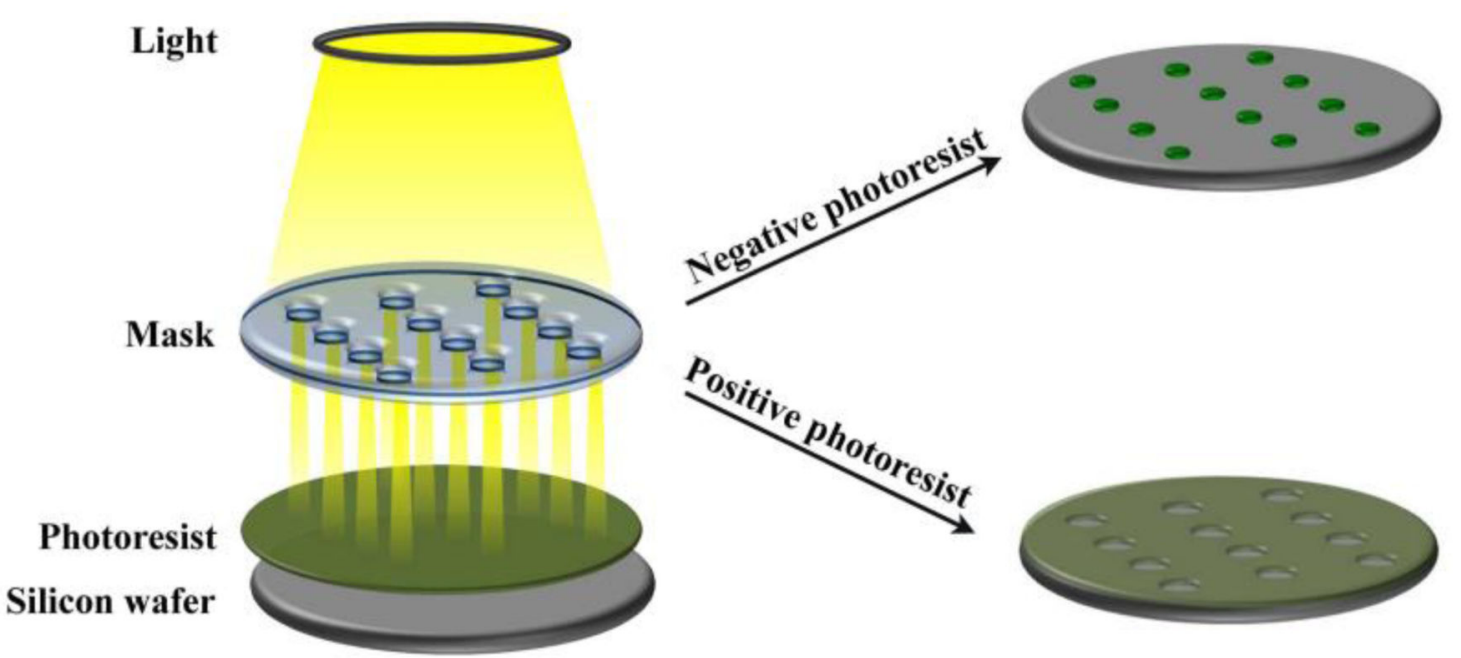

(b)

(-) Photoresist

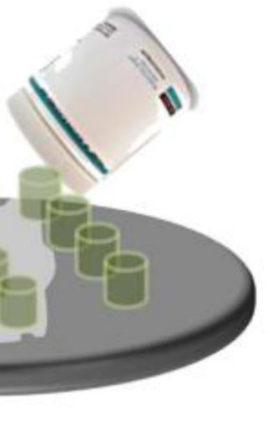

Si wafer

(c)

\section{(+) Photoresist}

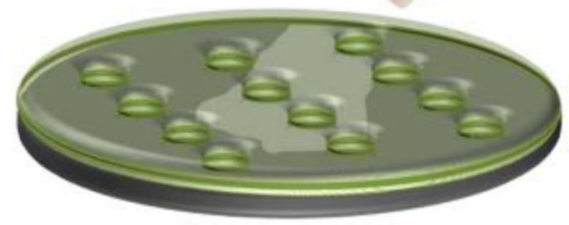

PDMS

\section{Imprinted $\mu$-patterns}

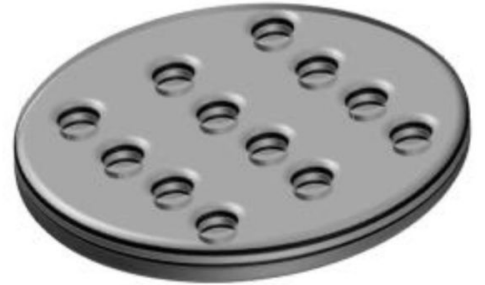

$\mu$-patterns in bas relief

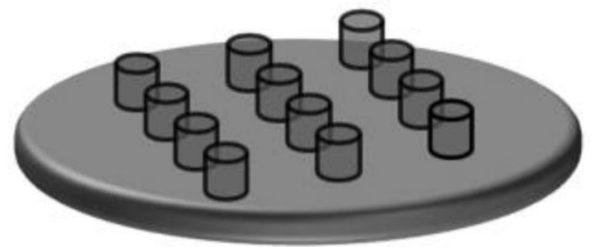

Figure 8.

Photolithography. (a) A silicon wafer is coated with a photoresist and then exposed to UV light projected through a patterned mask. The mask contains the pattern which is to be transferred to the photoresist. If a negative photoresist is used, then the areas which are exposed to light harden and the surrounding areas can be dissolved using a developer solution. Conversely, if a positive photoresist is used, then the exposed area becomes more dissolvable and can be washed away using a developer solution. Replication of patterns into PDMS “master" from (b) a negative and (c) positive photoresist. 
(a) $\mu$-transfer molding

\section{Coat PDMS w/ Polymer Stamp and}

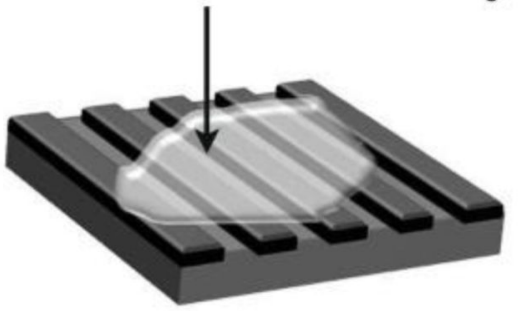

cure

Peel away PDMS

(b)

\section{$\mu$-molding in capillaries}

Place PDMS on support and add polymer (c)

Support

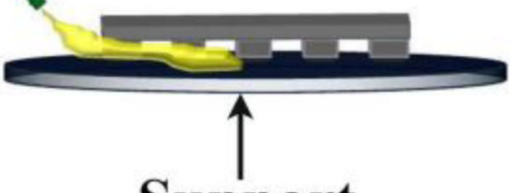

Coat surface with polymer

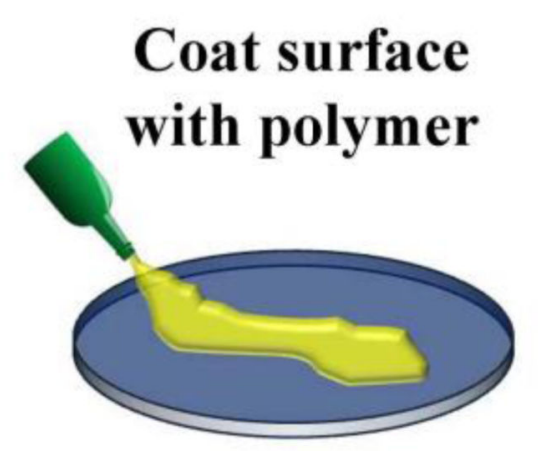

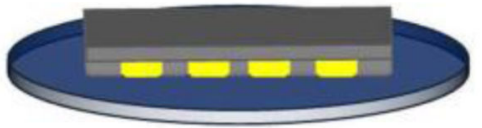

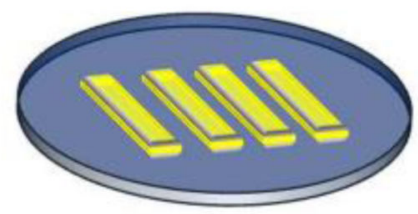

Cure

Remove PDMS

Solvent assisted $\mu$-molding
Place mold on surface

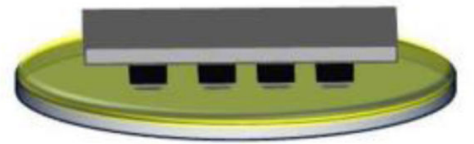

Evaporate solvent remove mold

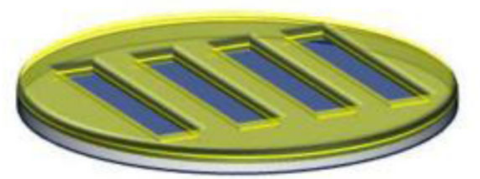

Figure 9.

Methods of micromolding. (a) Microtransfer molding (b) micromolding in capillaries and (c) solvent assisted micromolding. 
(a)

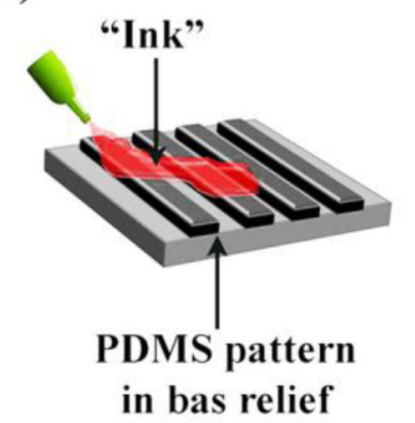

(b)

Stamp

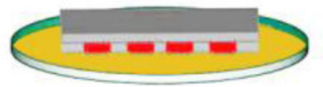

(c)

\section{Patterned surface}

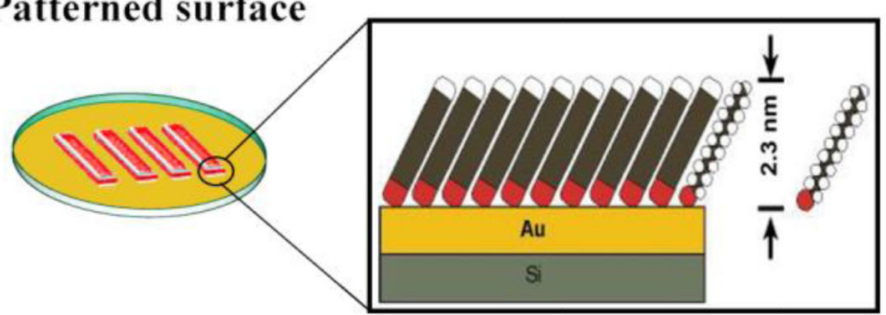

Figure 10. Microcontact printing

(a) A PDMS stamp is covered with and "ink" (small molecules, proteins, or DNA), and then (b) stamped onto the receiving surface (most often gold, Au, on glass or gold on Silicon, $\mathrm{Si}$, wafer, but also directly unto other metals, glass, silicon or even polystyrene ${ }^{[134,162,163]}$ ) leaving behind a (c) patterned surface which can be used to study biological processes. 


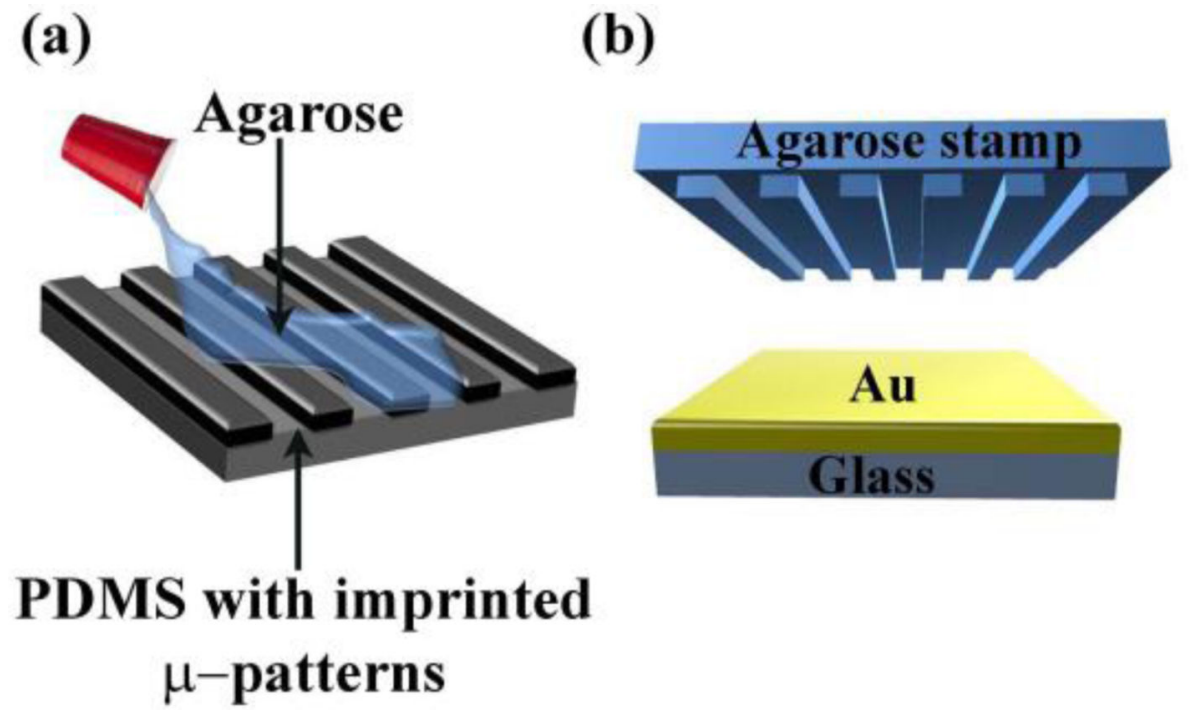

(c)

\section{Micropatterned} substrate

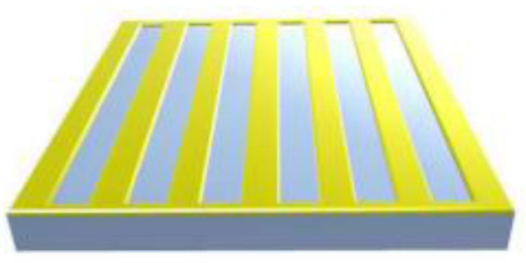

\section{Figure 11.}

WETS can be used to create optically transparent micropatterns (circles as small as $20 \mu \mathrm{m}$ ) in thin $(20 \mathrm{~nm}$ ) metal films. (a) Agarose is poured onto a PDMS master (which is fabricated using conventional photolithography and micromolding, see Figure 8) to create a stamp for patterning. (b) This stamp is then soaked in an etchant solution and then used to etch away (c) the specific pattern from a metal surface such as gold (Au). Subsequently, gold regions are derivatized by $\mathrm{EG}_{6} \mathrm{SAMs}$ to render substrates for geometrically-controlled cell adhesion that are compatible with high-resolution imaging of fluorescently tagged fusion proteins in live cells. ${ }^{[46,60,82,130,138]}$ 
(a)

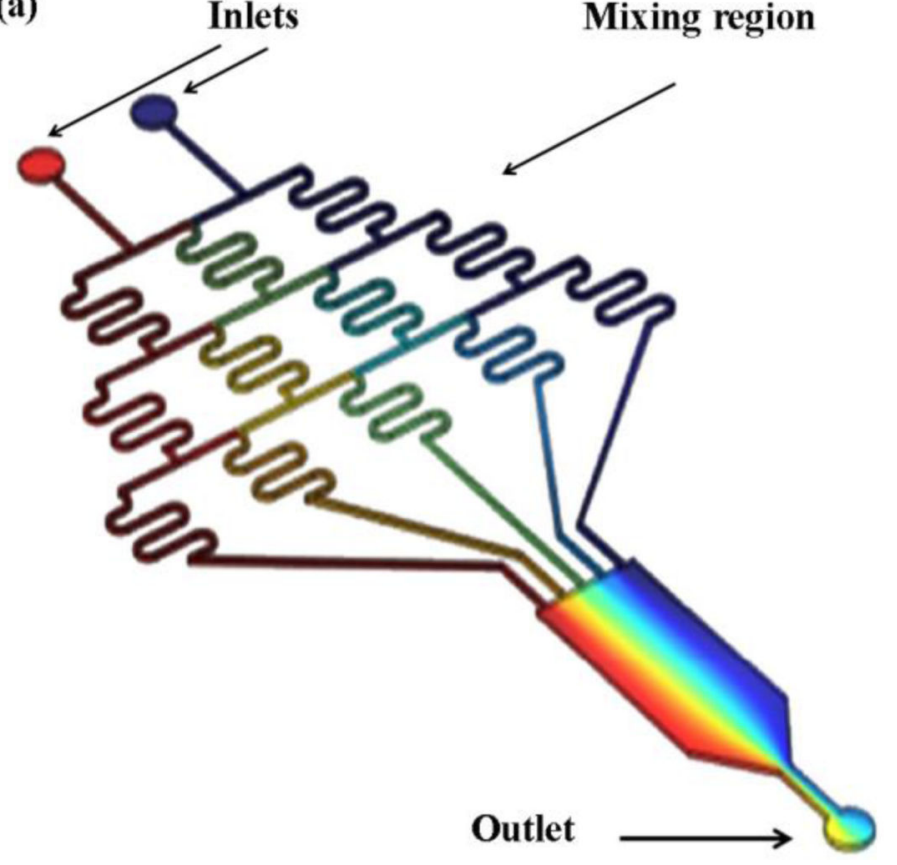

(b)

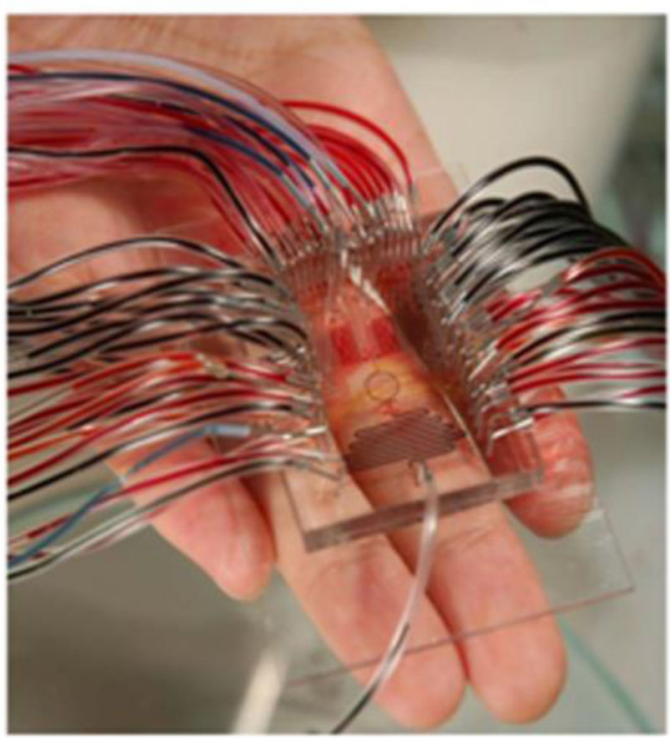

Figure 12.

Microfluidic chips. (a) A schematic of a typical microfluidic chip. In this specific example, there are two inlets and a systems of channels which allows for spatially controlled mixing of the otherwise laminarly flowing liquids. When these flows are recombined, they give rise to a continuous chemical gradient. The image reprinted with permission from Giridharan et al. ${ }^{[171]}$ (b) A photograph of a more complex microfluidic system capable of performing 1024 chemical reactions in parallel (reprinted with permission from reference ${ }^{[172]}$ ). Such devices have been adapted for biological studies as discussed in the text of this Review in Sections 6.4 and 6.5 . 


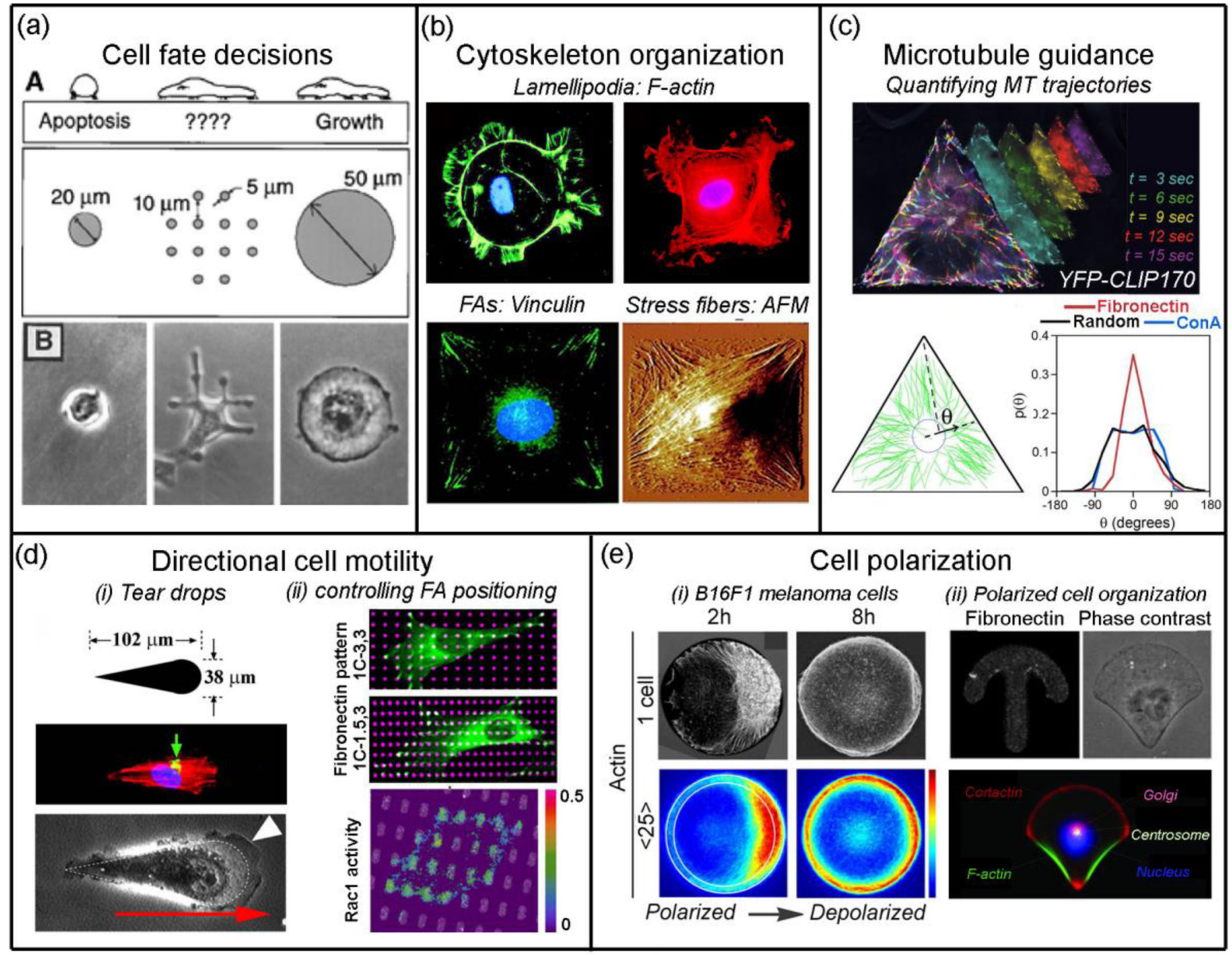

Figure 13. Controlling cell shape and cell motility machinery with surface micropatterns (a) Cell shape rather than amount of cell-ECM contacts governs cell decisions regarding life (proliferation/growth) vs. death (apoptosis). Restricting cell spreading by growing cells on small micro contact printed cell adhesive islands (here, circular islands with $D=20 \mu \mathrm{m}$; lower panel shows phase-contrast image of an apoptotic cell on a small island) promotes cell death/apoptosis whereas increased cell extension on large islands $(D=50 \mu \mathrm{m})$ promotes cell growth. To test a role of cells spreading vs. cell-ECM contacts in cell fate decisions, cells were allowed to spread on substrates displaying closely spaced small adhesive points (middle in B) so that cells would extend over the same area as cells on large islands (right) while keeping cell-ECM contact area the same as for cells on small islands (left). Projected area of cells scaled with cell growth rates and apoptosis was switched off when cells were allowed to extend without increased cell-ECM contact area (middle). Image adapted and reprinted with permission from Chen et al., 1997. ${ }^{[160]}$ (b) Geometric confinement controls spatial organization of the cell motility machinery. (Top) Actin-based lamellipodial protrusions (F-actin shown in green for circular island with Diameter, $D=50 \mu \mathrm{m}$ and in red for square island $40 \mu \mathrm{m} \times 40 \mu \mathrm{m}$; lamellipodia are the flat, fan-shaped F-actin-rich structures 
extending beyond the borders of the islands) extend symmetrically around entire perimeter of circular cells (here, endothelial cells), but are confined to the corners of polygonal cells. (Bottom) Focal adhesions (FAs=Vinculin, green) localize exclusively to the corners of cells (here, fibroblasts) on polygonal islands (here, square), while actin stress fibers (note thick bundles in atomic force microscopy, AFM, image) emanate out of the FAs at vertices into cell interior, and also run along the sides/edges of the polygonal cells (see rectangular cell, top). Nucleus is shown in blue. Images adapted and reprinted with permission from Parker et al., 2002. ${ }^{[183]}$ (c) Immobilization of cells (B16F1 or Rat2 fibroblast) on triangular (Side $=54$ $\mu \mathrm{m}$, Area $=1257 \mu \mathrm{m}^{2}$ ) micro islands removes spatial overlap of cell cytoskeleton, ensures that FAs localize exclusively to the vertices, ${ }^{[138,183]}$ and allows for quantifying microtubule (MT) guidance to FAs at triangle's vertices. (Top) Single color images show subsequent snap-shots (3 min apart) from time-series of MT plus end marker yellow fluorescent protein (YFP) fusion to CLIP-170; multicolor image show MT growth trajectories that are reconstructed from high-resolution microcopy of live cells with colors corresponding to time. Image reprinted with permission from Kandere-Grzybowska et al. ${ }^{[138]}$ (Bottom, left) All trajectories tracked in one triangular cell are shown in green; $\theta$ indicates the angle by which each trajectory at a given time point deviates from its target, the closest vertex. (Bottom, right) Quantification of MT trajectories-probability distributions of $\theta$ for cells on fibronectin-coated islands on which FAs are restricted to vertices (red curve, sharp peak indicates guided MT growth towards the vertices), or Concanavalin A-coated islands on which cells adhere without FAs (blue curve, lack of sharp peak indicated random MT growth), or computationally obtained Random case where trajectories grow in all possible directions (black curve). Images reprinted with permission from Huda et al. ${ }^{[60]}$ (d) Micropatterned substrates allow for controlling cell polarization and the direction of cell movements. (i) Asymmetric micropatterns, such as tear-drops, impose polarization of internal motility machinery and determine the direction of cell migration. (Top) Confinement of cells (here, NIH 3T3) to tear-drop shape islands with width: length aspect ratio of $1: 2.7$ resulted in centrosome (green) localization between nucleus (blue) and leading edge (i.e., wider end of the tear-drop) which indicates cell polarization (microtubules, red). (Bottom) Phase-contrast image of a cell immobilized on a tear-drop island shows that cell extends lamellipodia (white arrowhead) towards the wider end of the island. Subsequent "release" of cells from islands by electrochemical desorption of selfassembled monolayers that support the patterns, resulted in directional cell migration towards the wider end of the pattern (red arrow shows direction of motion). Images adapted and reprinted with permission from Jianget al. ${ }^{[44]}$ (ii) NIH 3T3 cells were cultured on substrates displaying focal adhesion-size islands $(D=1 \mu \mathrm{m})$ coated with fibronectin (Fn, purple) separated by non-adhesive barriers (1C-3,3 separation by $3 \mu \mathrm{m}$ in both $x$ and $y$ directions; 1C-1.5, 3 separated by $1.5 \mu \mathrm{m}$ in $x$ and $3 \mu \mathrm{m}$ in $y$ direction). Cells formed FAs exclusively over Fn-coated islands (Vinculin, green). On the 1C-3,3 pattern, cells moved randomly while on the $1 \mathrm{C}-1.5,3$ pattern, cells elongated and moved preferentially along $x$ axis where island spacing was reduced. (Bottom) Rac-FRET analysis showed that Rac1 activation, which generates lamellipodial protrusions, was colocalized with peripheral membrane protrusions contacting the fibronectin-coated adhesive islands. Images adapted and reprinted with permission from Xia et al. ${ }^{[81]}$ (e) Cell polarization on micropatterns. (i) Short-term polarization of highly motile cancer cells (here, B16F1 mouse melanoma) 
constrained to micropatterned circular islands $(D=40 \mu \mathrm{m})$. Micropatterned substrates are used to obtain population averages of F-actin distribution (top row, F-actin distribution in one cell; bottom row, heat map representing population distribution averaged over 25 cells) and to follow the reorganization of F-actin in time (2-8 hr), for details see. ${ }^{[46]}$ (ii) Cell polarization on cross-bow micropatterns. Fibronectin shows an adhesive pattern; Phase contrast shows cell boundaries. Cell spreads across adhesive and nonadhesive regions into a tear-drop shape. The organization of internal cellular components mimics polarized cell on unpatterned substrates with Cortactin ( $r e d$ ) marking leading edge lamellipodia, F-actin (green) distributed along the straight edges and centrosome (white) located between nucleus (blue) and leading edge. Population averages for each component shown. Image reprinted with permission from ${ }^{[45]}$. 


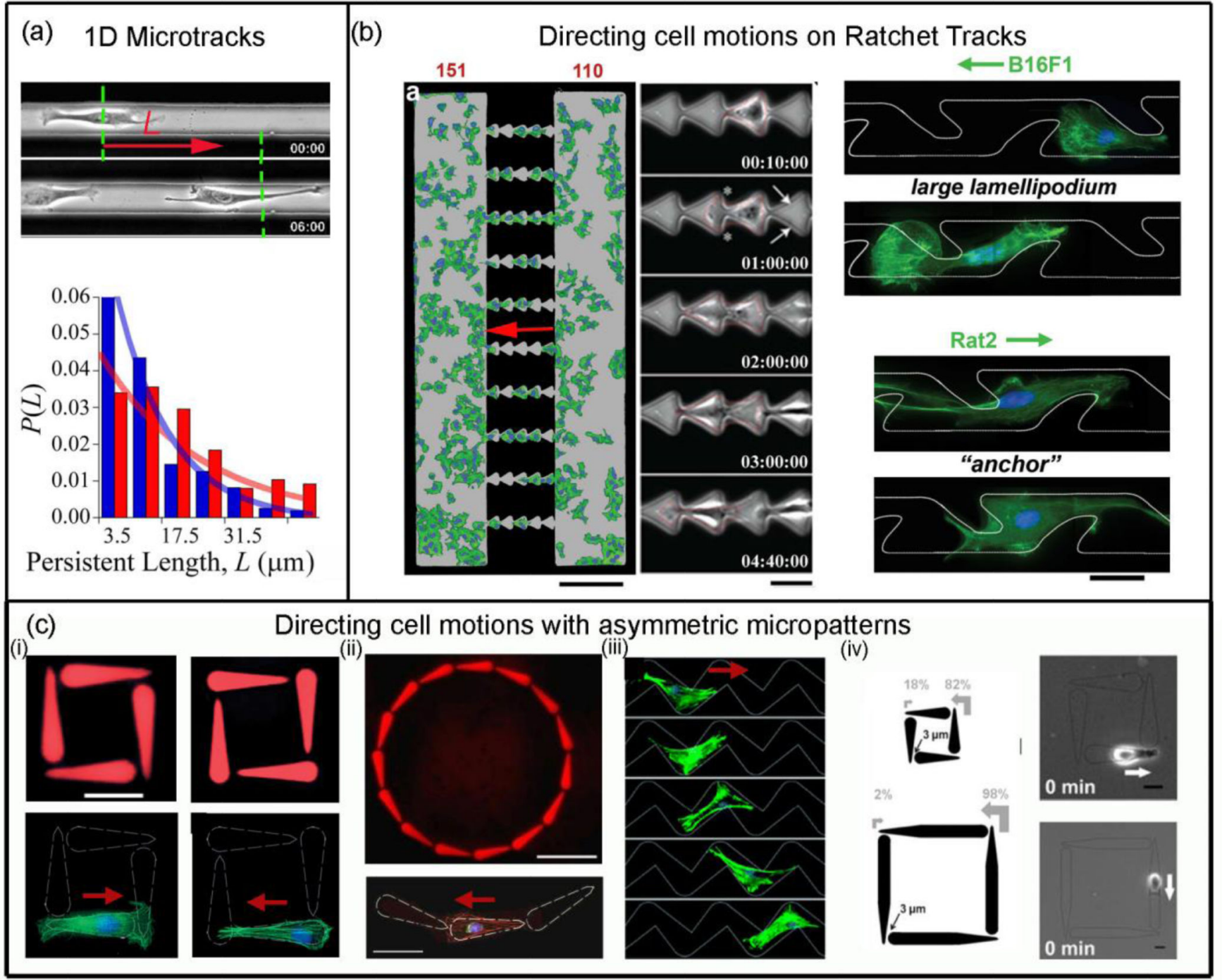

Figure 14. Quantifying and directing cell motions on 1D linear and ratchet microtracks (a, top) Optical micrograph showing cell (here, B16F1 mouse melanoma) migrating on a 20$\mu \mathrm{m}$ wide micropatterned line (optically transparent regions = cell adhesive lines; dark regions $=$ non-adhesive regions that do not promote cell adhesion/migration), $L=$ persistence length or distance that cell travels before reverting its direction of motion; arrow indicates direction of cell's motion during this particular "step". Image adapted with permission from $^{[130]}$. (a, bottom) Histogram quantifying persistence lengths, $L$, for PC-3 (blue) non-metastatic prostate cancer and PC-3M (red) metastatic prostate cancer cells on microtracks coated with Laminin-5. Note that the metastatic cells are more likely to take longer steps. (b) Directing cell motions with ratchet tracks. In contrast to linear tracks, ratchet tracks ${ }^{[82]}$ composed of connected triangles bias cell motions in the direction (red arrow) of triangles' open vertices. (Left) Phase-contrast microscopy image showing two reservoirs connected by multiple triangle-ratchet tracks (cells adhere to grey, but not black areas; green, cells from actin staining; blue, cell nuclei). Cells initially are plated without bias ( $50 \%$ of cells in each reservoir), after 48 hours cell motions result in $~ 55-68 \%$ bias 
depending on cell type/ECM substrate, here $57.8 \%$ bias). Scale bar $250 \mu \mathrm{m}$. (Middle) Phasecontrast time lapse series of B16F1 cells moving on ratchet tracks. Time - hr:min:sec. Scale bar $50 \mu \mathrm{m}$. (Right) Two-directional ratchets. A differently designed ratchet - in which asymmetric 'spikes' alternate on the opposite sides of the linear track - differentially directs cancerous (B16F1 mouse melanoma, or MDA-MB-231 breast cancer to the left side, green arrow) and non-cancerous (Rat2 fibroblast; to the right) cells resulting in partial separation of cell populations. Green, F-actin from fluorescent phalloidin staining; Blue, nuclei from Hoechst staining; white lines delineate ratchet pattern; scale bar $30 \mu \mathrm{m}$. Images reprinted with permission from Mahmud et al. ${ }^{[82]}$ (c) (i) Two variants of rectangular tracks, each consisting of 4 tear-drop shapes, guide motions of NIH 3T3 cells in opposite directions. (Top) pattern; (Bottom) images of cells moving on the pattern (direction of motion indicated with red arrows). Scale bar is $50 \mu \mathrm{m}$. Images adapted and reprinted with permission from Kumar et al. ${ }^{[196]}$. (ii) Circular tracks consisting of tear-drop shapes guide cell motions clockwise (towards the wide end of tear-drops). Scale bar is $100 \mu \mathrm{m}$ for top and $50 \mu \mathrm{m}$ for bottom image. Images reprinted with permission from Kumar et al. ${ }^{[198]}$. (iii) Zig-zag tracks consisting of joined tear-drop shapes guide cell motions towards the wide-ends of teardrops. Red arrow indicates direction of motion. Image reprinted with permission from Ko et al. ${ }^{[199]}$ (iv) Epithelial MCF-10A cells on rectangular tear-drop track move in opposite direction (MCF-10A move to the narrow end of the tear drop, iv top, vs. NIH 3T3 shown move towards the wide end of the tear drop, $i$ ). The bias is improved by modifying tear-drop shapes into spear-shapes (bottom). Scale bars are $20 \mu \mathrm{m}$. Images are reprinted from Kushiro et al. ${ }^{[200]}$. 


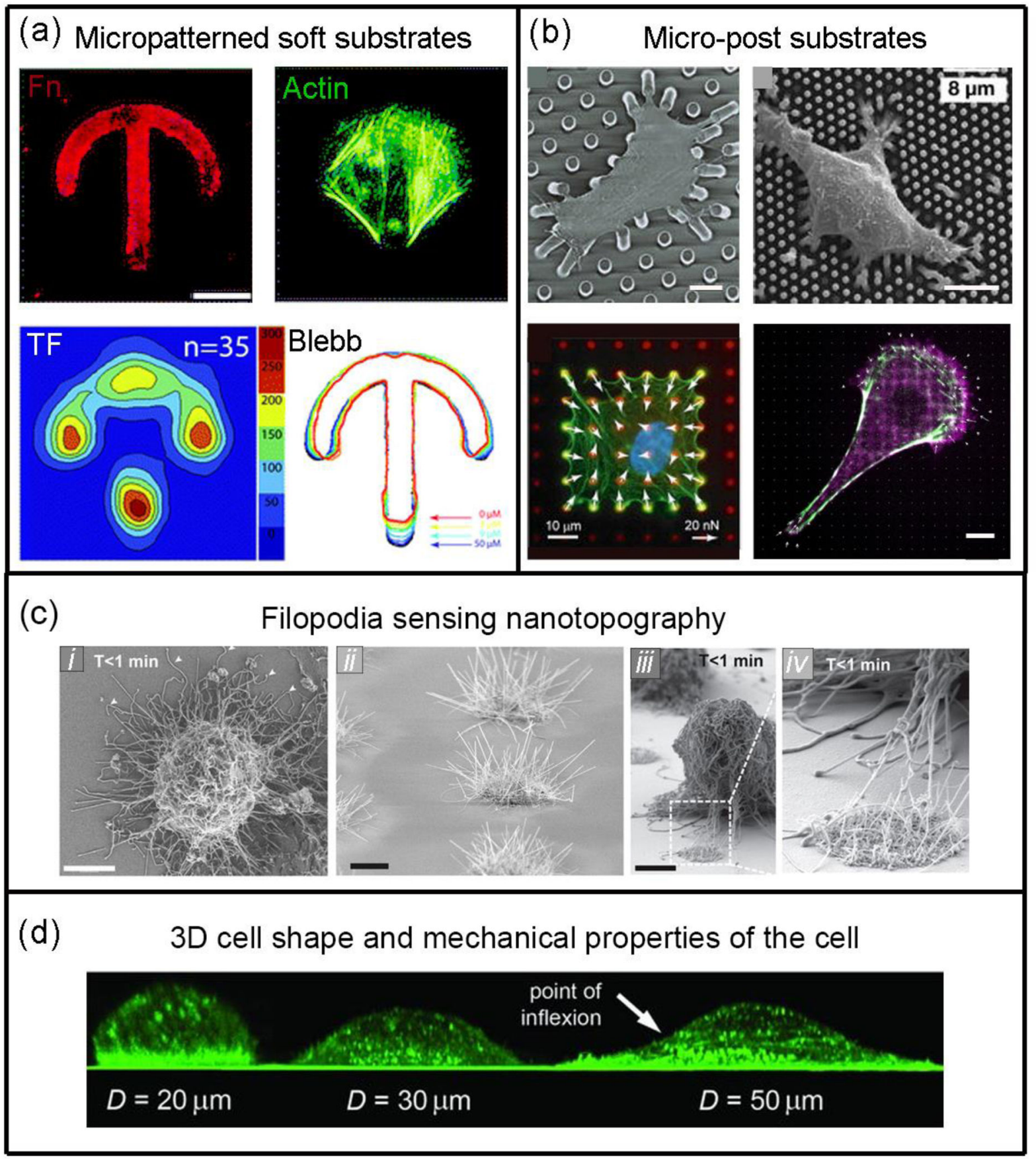

Figure 15. Microfabricated substrates for studying cell mechanics

(a) Micropatterned soft substrates for simultaneous control over cell geometry and cell substrate stiffness. Fn, fibronectin image shows crossbow pattern; Actin, visualization of actin filaments shows that cells spread over crossbow patterns to assume tear-drop shapes; TF, map of average traction forces (TFs in Pascals) in cells $(n=35)$ attached to cross-bow patterns. Because highest forces are localized to the sharp tip of the cell (pointing downward in the picture), a cell spreading contracts and ultimately shortens the micropattern. Blebb panel shows the relaxation of the shortened micropattern (red) upon application of Myosin II 
inhibitor blebbistatin ( $50 \mu \mathrm{M}$, blue) back to the original length. Scale bar $=10 \mu \mathrm{m}$. Images reprinted with permission from Tseng et al. ${ }^{[213]}$ (b) Microfabricated post or micropillar substrates for traction force measurements in stationary and migrating cells. Cells were cultured on a microfabricated substrate presenting and array of force-sensitive posts whose deflection quantified local traction forces. (top, left: image reprinted with permission from Tanet al. ${ }^{[217]}$, scale bar is $10 \mu \mathrm{m}$; top, right: image reprinted with permission from du Roure et al. ${ }^{[218]}$, scale bar is $8 \mu \mathrm{m}$ ). Bottom, left: controlling the geometry of the cells on microposts by microcontact printing of substrate protein onto the tips of the posts in a patterned manner. Red, fibronectin; green, actin delineating the boundaries of a rectangularly-shaped cell; blue, nucleus; arrows, directions and magnitudes of traction forces. Image reprinted with permission from Han et al. ${ }^{[222]}$ Bottom, right: MDCK epithelial cell migrating over a micropost substrate (the tips of the posts shown as a grid of white dots on black background). Note the naturally occurring (here, not due to micropatterning) teardrop shape characteristic of motile cells. Magenta; Myosin IIA; green, Myosin IIB; arrows, traction forces. Scale bar is $10 \mu \mathrm{m}$. The strongest TFs and Myosin IIA were co-localized to the leading edge (wide end, top right), while Myosin IIB and smaller TFs were localized to the tail (pointed end of the cell, bottom left). Image reprinted with permission from Jorrisch et al. ${ }^{[219]}$ (c) Studying of the role of filopodia in sensing nanotopography. (i) Filopodia mediate cell interactions with a substrate at initial stages of spreading; (ii) micropatterned islands displaying silicon nanowires (NW); (iii) cellular filopodia interacting with NWs; (iv) enlarged inset from iii showing filopodia and nanowire interactions. Scale bars are $5 \mu \mathrm{m}$. Image reprinted with permission from Albuschies and Vogel, 2013.[105] (d) Cell tomography for reconstructing 3D cell shape and studying cell's mechanical properties. Circular micropatterned islands (Diameter, $D=20-60 \mu \mathrm{m}$ ) were used to quantify the minimal-energy shapes of cells (shown here are side-views of full, 3D shapes reconstructed by confocal imaging of cortical actin) and to infer their micromechanical properties which are similar for benign and cancerous cells. Images reprinted with permission from Soh et al. ${ }^{[168]}$ 

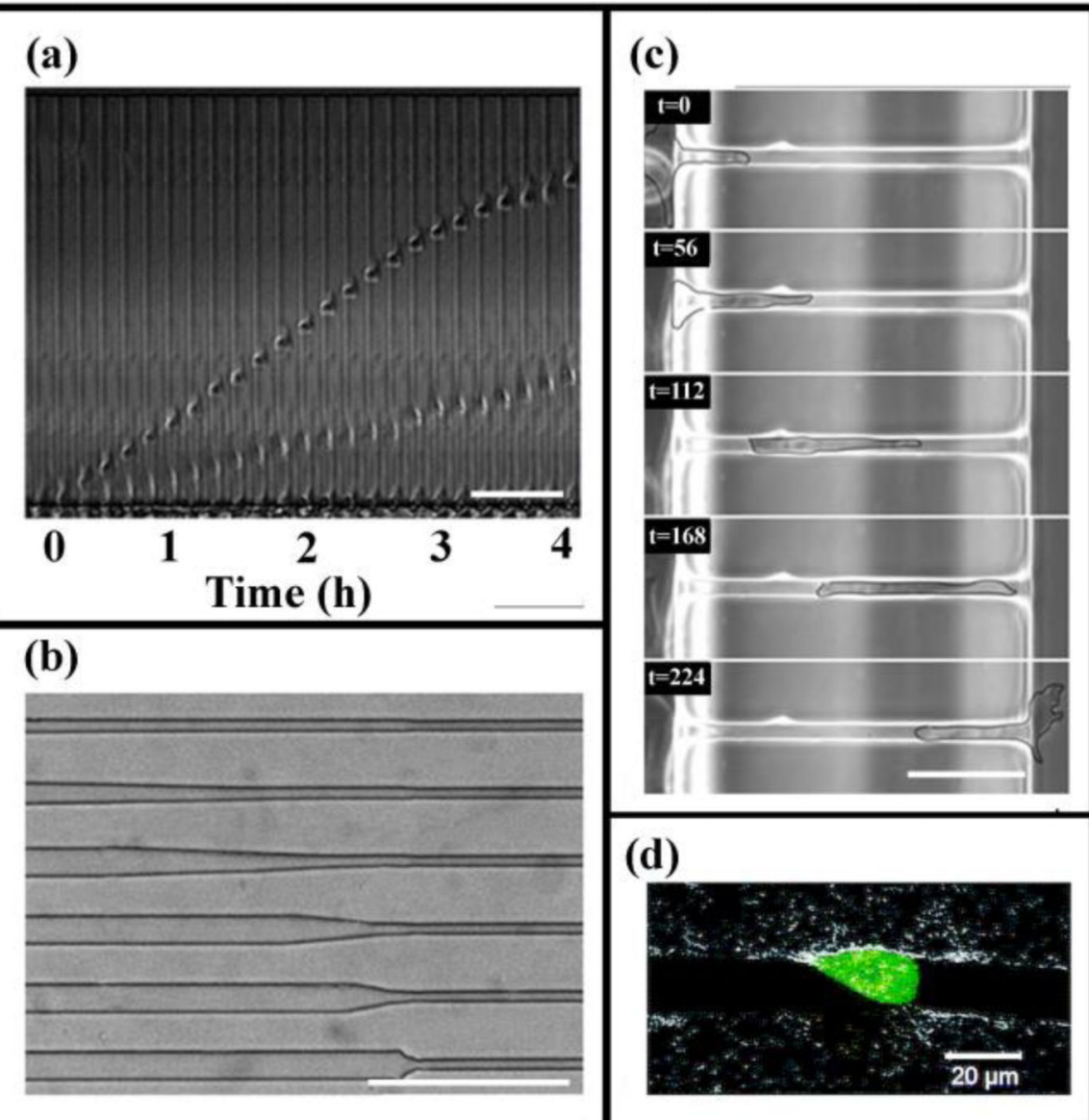

(e)

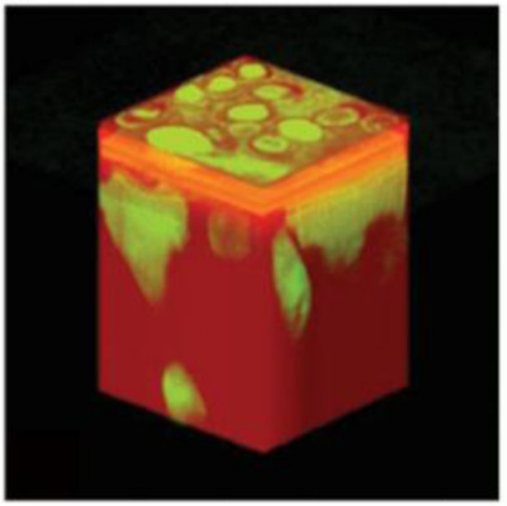

(b)
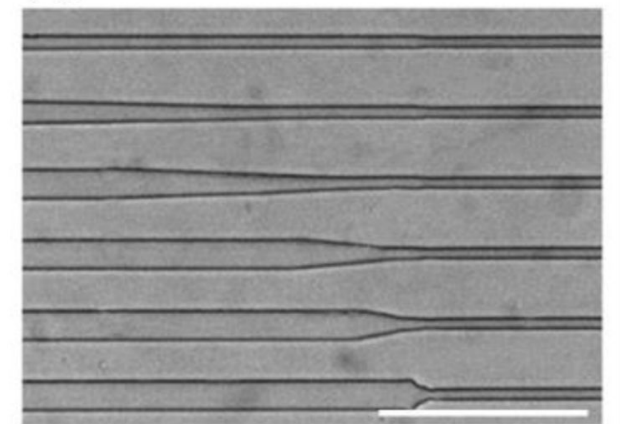

Figure 16.

Cancer cell motility within spatially challenging 3D environments. (a) Time-lapse series (taken over 4 hours) of two metastatic MDA-MB-231 cells moving within a 3D channel microfabricated from PDMS. Scale bar $=100 \mu \mathrm{m}$. The image adapted and reprinted with permission from Irimia and Toner. ${ }^{[231]}$ (b) Microfabricated PDMS channels with different line widths and tapering regions. Image reprinted with permission from Mak et al. ${ }^{[232]}$ Metastatic cells are more likely to squeeze into narrow channels than non-metastatic ones. Scale bar $=100 \mu \mathrm{m}$. (c) Increasing the deformability of cell membrane by the treatment with sphingosylphosphocholine (SPC) enables pancreatic cell cancer (Panc-1) to traverse narrow (7 $\mu \mathrm{m}$ wide) microfabricated channels. Image reprinted with permission from Rolli et al. ${ }^{\text {[233] }}$ Scale bar $=50 \mu \mathrm{m}$. (d) MDA-MB-231 cancer cell moving through a 3D channel/track microfabricated in a collagen matrix (white, collagen; green, cell labeled with a cell tracker dye). Image reprinted with permission from Kraning-Rush et al. ${ }^{[235]}$. (e) Metastatic potential can be screened by monitoring if cells can climb onto topological 'highlands'. Red, 3D highland of cubical shape; green, cells marked with green fluorescent protein. Highly metastatic PC3 prostate cancer cells (top) quickly occupy the tops of the highlands, while only few noninvasive LNCaP prostate cancer (bottom) reach the tops of the highlands. Image reprinted with permission from Liu et al. ${ }^{[203]}$. 


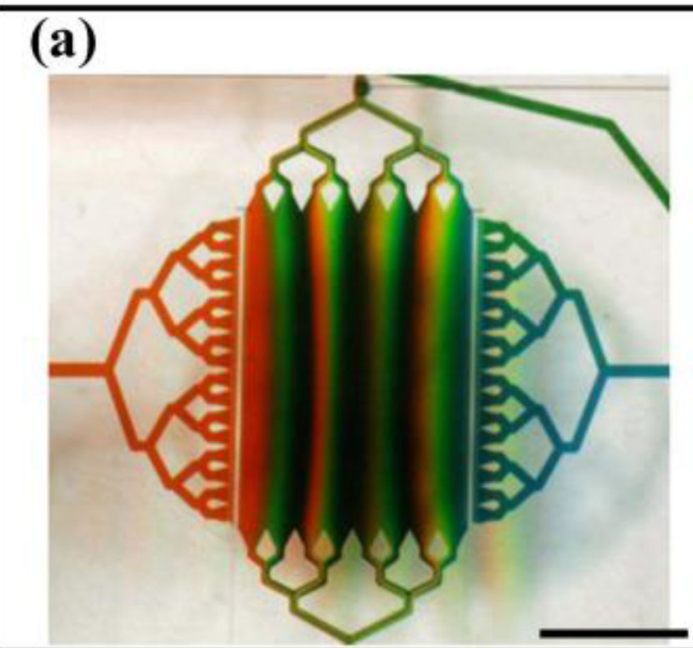

\section{(b)}
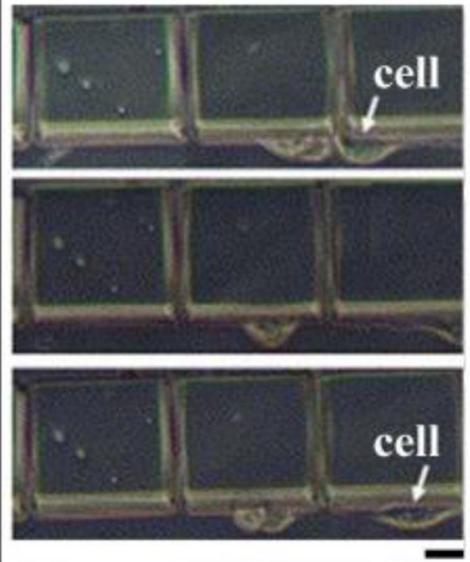

(c)

MDA-MB-231 vs. MCF-7

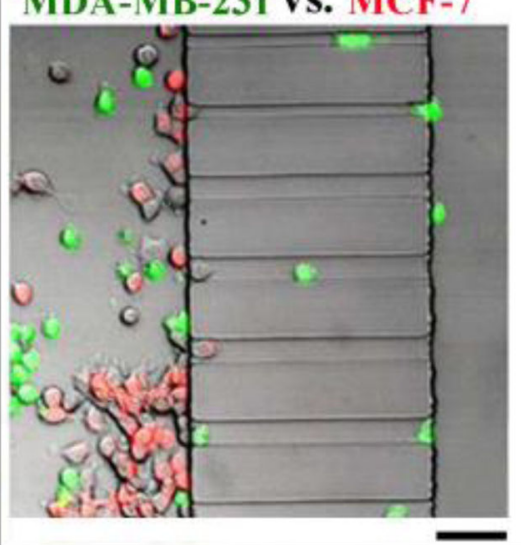

(d)

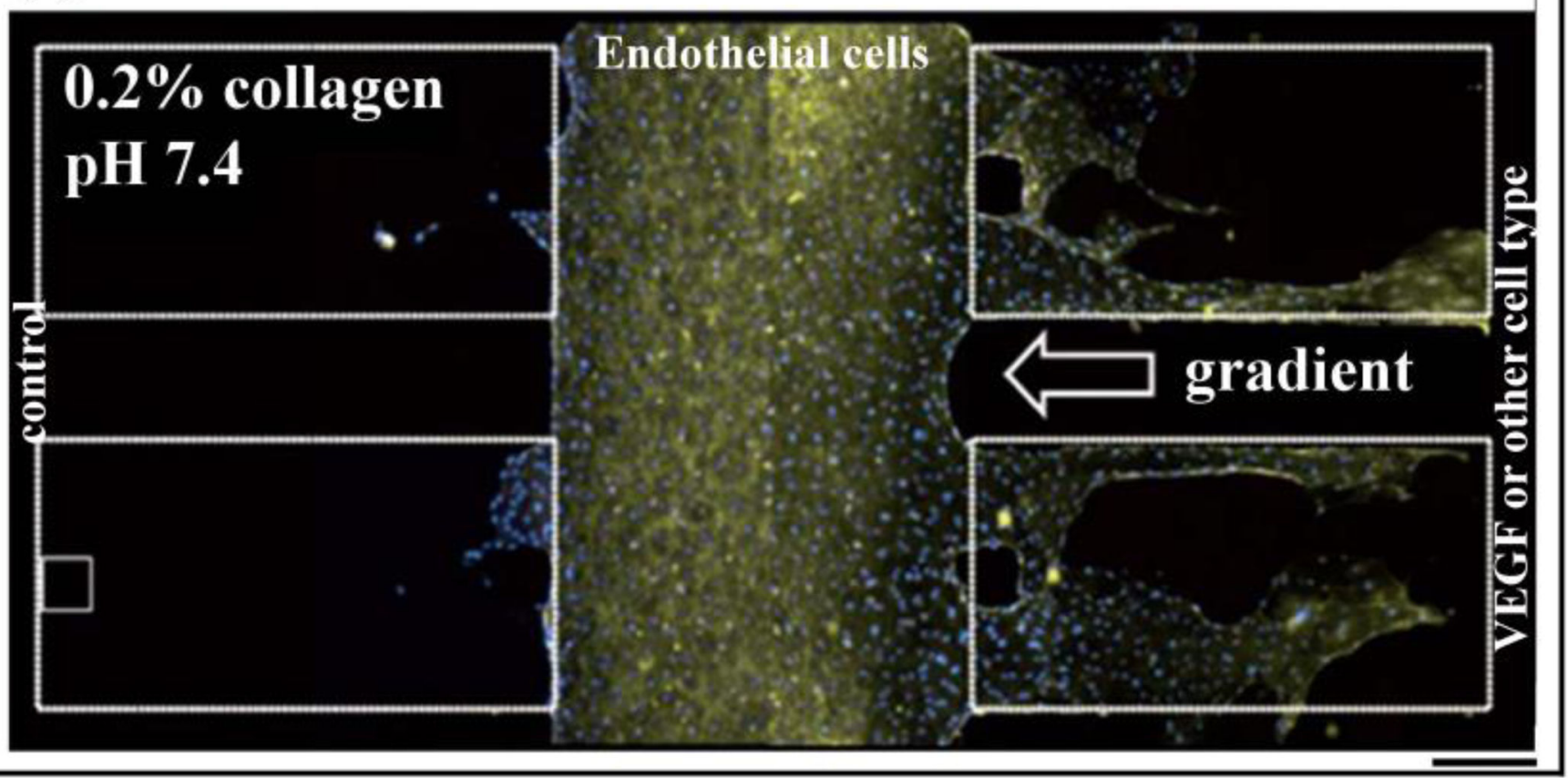

Figure 17.

Microfluidic devices for studying chemotaxis. (a) Microfluidic devices allow for the design of precise chemical gradients. The image shows a pressure-driven microfluidic cell culture device capable of creating heterogeneous laminar flows, a variety of gradient profiles, and flow patterns. In this image, multiple colored dyes were used to visualize the effect of different flow combinations/gradients. Scale bar corresponds to $3 \mathrm{~mm}$. Image reprinted with permission from Cooksey et al. ${ }^{[254]}$ (b) Cell migration through micro-gaps - fabricated using replica molding -can be used as a means to quantify migration capacity. The device shown here consists of patterned PDMS mold bonded to a glass surface. The composition of the cell culture media and the creation of gradients within the device are controlled by microfluidic pumps. Scale bar corresponds to $30 \mu \mathrm{m}$. Image reprinted with permission from 
Chaw et al. ${ }^{[255]}$ (c) Metastatic cells can be screened by forcing cells to migrate through microchannels (here, 10 and $20 \mu \mathrm{m}$ wide). This device was also fabricated using replica molding whereby a negative PDMS mold was created from a patterned photoresist. The PDMS mold containing the gap architecture was then bonded to a glass coverslip and microfluic pumps were used to control the media inlet/outlet and to create gradient of hEGF (with high concentration of hEGF in the right side chamber). Cells are only seeded in the left side chamber-non-metastatic MCF-7 cells (red) do not migrate through the channels whereas metastatic MDA-MB-231 cells (green) are more likely to migrate through channels up hEGF gradient. Scale bar represents $50 \mu \mathrm{m}$. Image reprinted with permission from Tong et al. ${ }^{[254]}$ (d) Microfabrication can be used to simultaneously control the biochemical (via gradient) and biomechanical (via modifying matrix stiffness) forces placed on a cell and to study cell motility characteristics at single cell level. The image shows human dermal microvascular endothelial cells (HMVEC, seeded in central compartment) which have been migrating through a collagen gel scaffold along the gradient of vascular endothelial growth factor (VEGF; right side) vs. few migrating cells towards control side without VEGF (left side). The cells were stained using Rhodamine-phalloidin (yellow) and the nuclei were stained with DAPI (blue). The large rectangles show the boundaries of the gel matrix scaffolds. In co-culture experiments instead of VEGF, the cells of second type were seeded in the compartment to the right. The scale bar corresponds to $300 \mu \mathrm{m}$. Image adapted and reprinted with permission from Chung et al. ${ }^{[258]}$ 


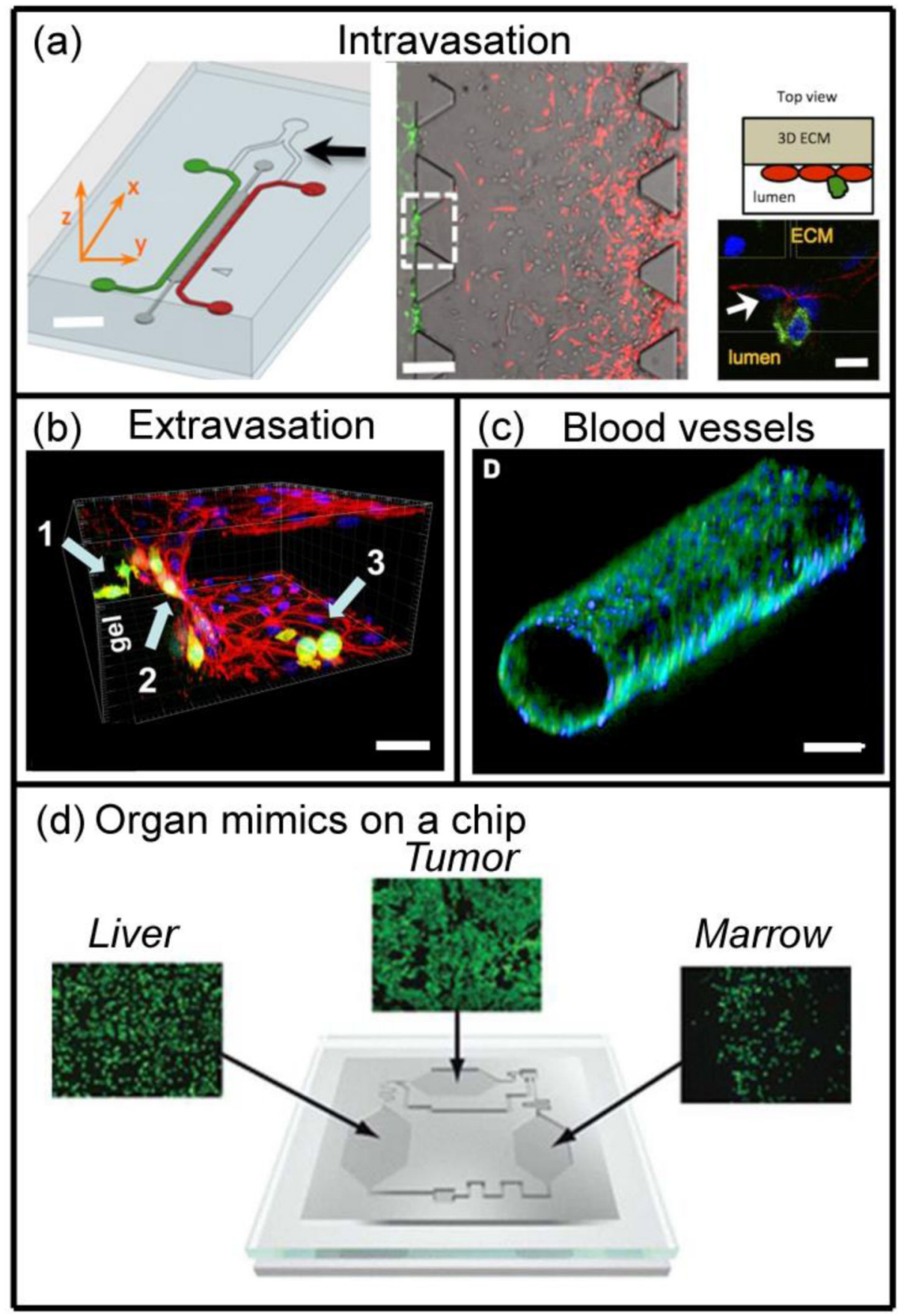

Figure 18.

Microfluidic model microenvironments relevant to cancer metastasis. (a, left) A crosssectional channel view of an in vitro microfluidic device with which to study intravasation under dynamic control of barrier permeability. The device is made out of PDMS containing two chambers for cells which are separated by a collagen hydrogel mimicking 3D extracellular matrix. (middle) For this study, HT1080 fibrosarcoma cells were seeded in the right channel (red) and microvascular endothelial cells (MVEC) were plated on the left channel (green) and were separated by a gel layer. (right) The specific confocal microscopy 
image shows the cancerous cells (green) invading into the 3D matrix and adhering to the in vitro endothelium (red). This system provides a means to study how cancer cells interact with the endothelium prior to and during intravasation. Scale bar $=30 \mu \mathrm{m}$. Images reprinted with permission from Zervantonakis et al. ${ }^{[263]}$ (b) The image illustrates a microfluidic model for tumor cell extravasation. The device has a channel for seeding cells which is lined on one side by a collagen gel. First, human microvascular endothelial cells (HMVEC) were seeded into the channel and cultured for two days before the highly metastatic MDAMB-231 human mammary carcinoma cells were seeded into the same channel.

Subsequently, the cells were imaged to study the interaction of the cells with each other and with the collagen matrix. Shown here is a confocal image where a cancer cell (green) has migrated though the endothelium (red cells) and into the gel (dark/black area). This microfabricated in vitro model recapitulates several of the in vivo aspects of cancer extravasation. Scale bar $=50 \mu \mathrm{m}$. Image is reprinted with permission from Jeon et al. ${ }^{[262]}$ (c) Microfluidic devices allow the creation of in vitro lumens for the study and quantification of angiogenesis. In this study, the Beebe lab created microfluidic PDMS channels which were lined with endothelial cells (cells stained green; nuclei blue) to create a 3D cellular structure which bears architectural resemblance to the in vivo structure of the endothelium. Scale bar $=100 \mu \mathrm{m}$. Image reprinted with permission from Bischel et al. ${ }^{[254]}$ (d) A microfluidic in vitro "organ system" in which mimics blood flow from one chamber to another, each chamber representing an organ. This system was developed in the Shuler lab to test the cytotoxicity of anti-cancer drugs on several cell types in parallel. Image reprinted with permission from Sung et al. ${ }^{[266]}$ 